San Jose State University

SJSU ScholarWorks

Master's Theses

Master's Theses and Graduate Research

Summer 2016

\title{
Women Business Leaders in Biotech and Hi-Tech, and Related Industry Cluster Factors
}

Jessica White

San Jose State University

Follow this and additional works at: https://scholarworks.sjsu.edu/etd_theses

\section{Recommended Citation}

White, Jessica, "Women Business Leaders in Biotech and Hi-Tech, and Related Industry Cluster Factors" (2016). Master's Theses. 4744.

DOI: https://doi.org/10.31979/etd.r839-csfx

https://scholarworks.sjsu.edu/etd_theses/4744

This Thesis is brought to you for free and open access by the Master's Theses and Graduate Research at SJSU ScholarWorks. It has been accepted for inclusion in Master's Theses by an authorized administrator of SJSU ScholarWorks. For more information, please contact scholarworks@sjsu.edu. 


\title{
WOMEN BUSINESS LEADERS IN BIOTECH AND HI-TECH,
} AND RELATED INDUSTRY CLUSTER FACTORS

\author{
A Thesis \\ Presented to \\ The Faculty of the Department of Geography \\ San José State University \\ In Partial Fulfillment \\ of the Requirements for the Degree \\ Master of Arts \\ by \\ Jessica White \\ August 2016
}


(C) 2016

Jessica White

ALL RIGHTS RESERVED 
The Designated Thesis Committee Approves the Thesis Titled

WOMEN BUSINESS LEADERS IN BIOTECH AND HI-TECH, AND RELATED INDUSTRY CLUSTER FACTORS

\author{
by \\ Jessica White \\ APPROVED FOR THE DEPARTMENT OF GEOGRAPHY \\ SAN JOSE STATE UNIVERSITY
}

August 2016

Dr. Kathrine Richardson

Department of Geography and Global Studies, San Jose State University

Department of Statistics and Applied

Dr. Wendy Meiring

Probability, University of California Santa

Barbara

Dr. Mike Pogodzinski

Department of Economics, San Jose State University 


\title{
ABSTRACT \\ WOMEN BUSINESS LEADERS IN BIOTECH AND HI-TECH, AND INDUSTRY CLUSTER FACTORS
}

\author{
by Jessica White
}

Women entrepreneurs are on the rise and their numbers have grown at one and a half times the rate of small enterprises generally over the last 15 years. In spite of this, women are underrepresented in the fields of science, technology, engineering, and mathematics (STEM). Women face additional barriers when forging careers within these fields and obtaining startup capital. This study examines female business ownership within the fields of hi-tech and biotech, and the factors that support startups by women throughout the state of California. As both of these industry sectors are known to cluster geographically around sources of venture capital, university research and development (R\&D) investment, and skilled labor, the study explored how these factors influence women entrepreneurs through two methods of analysis, specifically, a quantitative GIS analysis using exploratory geo-statistical tools, and a qualitative analysis using semistructured interviews of twenty women business leaders. Results from the study demonstrated that factors that encourage hub formation are prone to cluster geographically, that women receive less venture capital than their male counterparts, biotech as a sector is more open than hi-tech to women's participation, high numbers of women starting businesses alongside their alma mater, and a high participation of women in business accelerators and incubators. 


\section{ACKNOWLEDGMENTS}

This thesis would not have been possible without the support of many people other than myself. Would like to first thank my thesis committee, Dr. Mike Pogodzinski, Dr. Wendy Meiring, and most of all Dr. Kathrine Richardson, whose guidance, encouragement, and wonderful presence made this study an even more rewarding and enjoyable experience. A most sincere thank you to the women business leaders who participated in being interviewed for this study, for providing their perspectives and for their belief in the project. Would also like to thank these women entrepreneurs and business leaders for pursuing their ambitions, encouraging others to do so, and paving the way for other women to pursue their professional dreams. Thank you to my family and friends, without whose support, belief, and encouragement I might have given into the voices of self-doubt before completing this project. You all mean the world to me and I am so lucky to have such a wonderful support team! Finally, thank you to those individuals that saw talent in myself even before I did, and encouraged me to be true to myself and pursue my dreams. 


\section{TABLE OF CONTENTS}

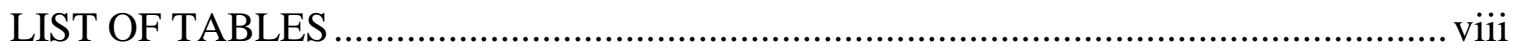

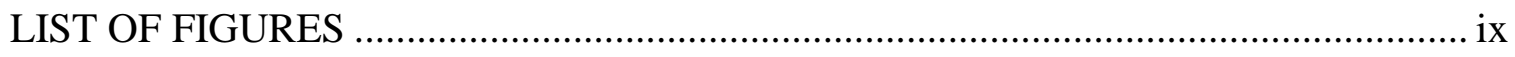

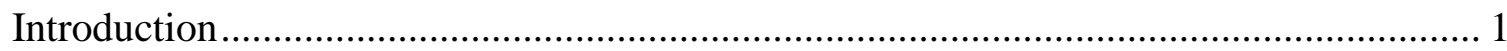

Women Business Owners .................................................................................... 1

Underrepresented in STEM .............................................................................. 2

Women: An Untapped Talent Source ………………………………………... 5

Gender Disparity in Entrepreneurial Pursuits ...................................................... 5

Business Industry Clusters and Contributing Factors ............................................. 11

Venture Capital ................................................................................................. 13

Women business owners and venture capital. ........................................ 16

Funding gap: supply side. .................................................................. 17

Funding gap: entrepreneur side........................................................... 17

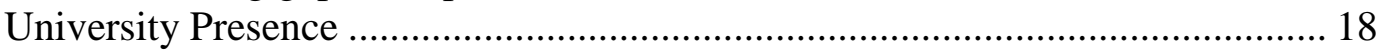

Geography of knowledge spillovers. ...................................................... 19

Talent and Women Business Owners ............................................................... 20

Section Summary and Goals, Scope, and Anticipated Outcomes of Research

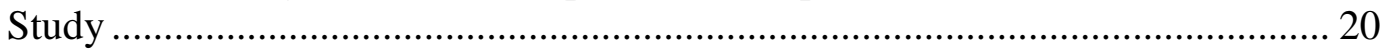

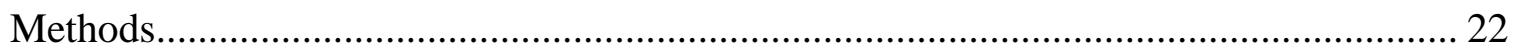

Qualitative Methods: Semi-structured Interviews ............................................. 22

Quantitative Methods: Data Components .......................................................... 26

Hi-tech and biotech business data......................................................... 27

University R\&D expenditure data. ...................................................... 28

Venture capital expenditure data. ............................................................ 29

Quantitative Methods: Data Analysis .................................................................. 30

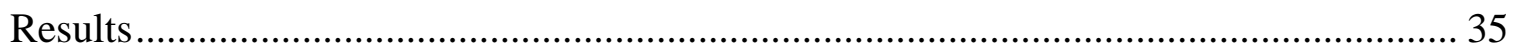

Qualitative Portion: Semi-structured Interviews ............................................... 35

Leadership history and aspirations to leadership..................................... 36

Factors that encouraged career ambitions and success in business ventures.

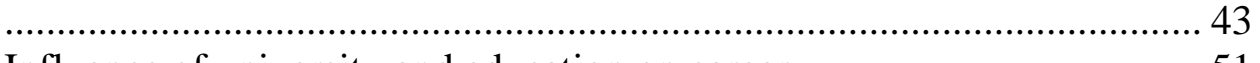

Influence of university and education on career........................................ 51

Venture capital funding experience. ...................................................... 59

Potential setbacks and perseverance. ………………………………....... 73

Benefits and refocusing the conversation. ………………………............ 80

Possible causes of low women representation and possible solutions...... 85

The importance of a company's geographic location. ………………....... 92

Quantitative Portion: Data Analysis .................................................................. 97

Hi-Tech and Biotech Data. .................................................................. 99

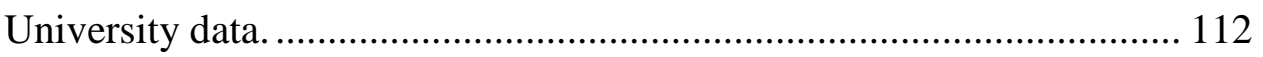




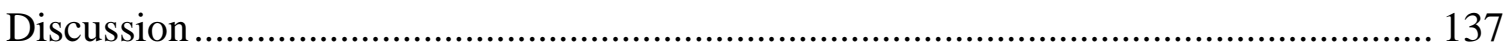

Business Participation in an Accelerator or Incubator..................................... 137

Reasons for Low Percentages of Women Business Leaders in Hi-Tech and

Biotech

Businesses Spun Out of University........................................................... 142

Biotech Sector More Open to Women than Hi-Tech........................................ 144

Low Percentages of Women Receiving Venture Capital .................................. 146

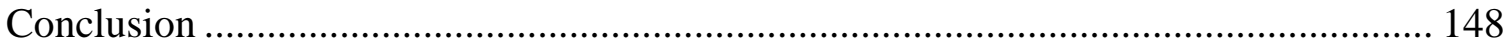

Chapter Introduction ....................................................................... 148

Summary of Findings.............................................................................. 149

Quantitative Study Components ................................................................ 150

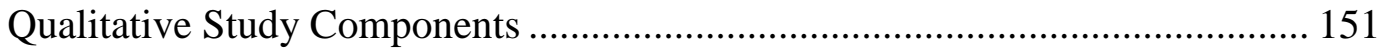

Future Research ................................................................................ 154

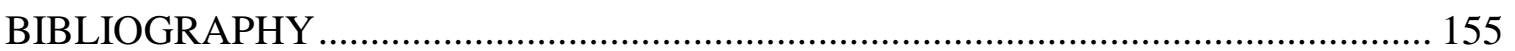

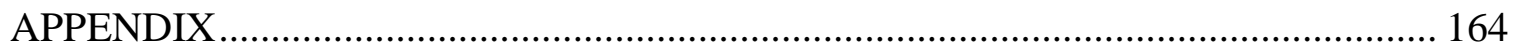

University R\&D Expenditures, Data Definitions ............................................ 167

Venture Capital Business Data Definitions .................................................... 167

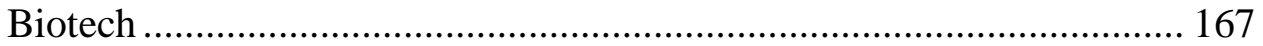

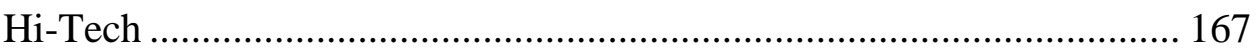




\section{LIST OF TABLES}

Table 1. Company and Interviewee Profile ....................................................... 24

Table 2. List of Variables Thematically Mapped and Analyzed for Clustering

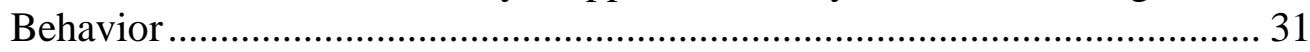




\section{LIST OF FIGURES}

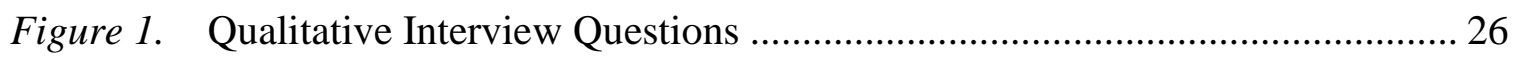

Figure 2. Neighborhood Weights, Corresponding to i=1 (Alameda County) (Source: ArcMap 10.2, California County Base Layer, 2015)..................................... 33

Figure 3. Settings for the Hot Spot Analysis Getis-Ord $\mathrm{G}_{\mathrm{i}}^{*}$ Tool in ArcMap 10.2 (Source: ArcMap 10.2, 2015) ...................................................................... 34

Figure 4. San Francisco Bay Area (Bay Area) Counties (Map Base Source: ArcMap 10.2.1, 2016)

Figure 5. Southern California Region Counties (Map Base Source: ArcMap 10.2.1, 2016)

Figure 6. Number of Hi-Tech Businesses per California County (Source: Reference USA, 2016) (Map Base Source: ArcMap 10.2.1, 2016) 101

Figure 7. Cluster Behavior of Number of Hi-Tech Businesses per California County (Source: Reference USA, 2016) (Map Base Source: ArcMap 10.2.1, 2016)

Figure 8. Original Data Histogram for Numbers of Hi-Tech Businesses per County 103

Figure 9. Data Histogram for Numbers of Hi-Tech Businesses per County to the 2.103

Figure 10. Data Histogram for Numbers of Hi-Tech Businesses per County to the 4 . 104

Figure 11. Number of Hi-Tech Businesses after $4^{\text {th }}$ root transformation per California County (Source: Reference USA, 2016) (Map Base Source: ArcMap 10.2.1, 2016) 105

Figure 12. Cluster Behavior of Number of Hi-Tech Businesses after $4^{\text {th }}$ root transformation per California County (Source: Reference USA, 2016) (Map Base Source: ArcMap 10.2.1, 2016) 106

Figure 13. Percent of Women Business Leaders in Hi-Tech Businesses per California County (Source: Reference USA, 2016) (Map Base Source: ArcMap 10.2.1, 2016) 107

Figure 14. Cluster Behavior of Percent of Hi-Tech Women Business Leaders of Hi-Tech Businesses per California County (Source: Reference USA, 2016) (Map Base Source: ArcMap 10.2.1, 2016) 107 
Figure 15. Number of Biotech Businesses per California County (Source: Reference USA, 2016) (Map Base Source: ArcMap 10.2.1, 2016).

Figure 16. Cluster Behavior of Number of Biotech Businesses per California County (Source: Reference USA, 2016) (Map Base Source: ArcMap 10.2.1, 2016)

Figure 17. Percent of Women Business Leaders of Biotech Businesses per California County (Source: Reference USA, 2016) (Map Base Source: ArcMap 10.2.1, 2016)

Figure 18. Cluster Behavior of Percent of Women Business Leaders of Biotech Businesses per California County (Source: Reference USA, 2016) (Map Base Source: ArcMap 10.2.1, 2016).....

Figure 19. Number of Universities with Biotech Majors per California County (Source: National Center for Science and Engineering Statistics, Integrated Sciences and Engineering Resources Data System, 2016) (Map Base Source: ArcMap 10.2.1, 2016)

Figure 20. Clustering Behavior of Number of Biotech Majors per California County (Source: National Center for Science and Engineering Statistics, Integrated Sciences and Engineering Resources Data System, 2016) (Map Base Source: ArcMap 10.2.1, 2016)

Figure 21. University R\&D Expenditures in Biotech per California County (Source: National Center for Science and Engineering Statistics, Integrated Sciences and Engineering Resources Data System, 2016) (Map Base Source: ArcMap 10.2.1, 2016)

Figure 22. Clustering Behavior of University R\&D Expenditures in Biotech per California County (Source: National Center for Science and Engineering Statistics, Integrated Sciences and Engineering Resources Data System, 2016) (Map Base Source: ArcMap 10.2.1, 2016)

Figure 23. Number of Universities with Hi-Tech Majors per California County (Source: National Center for Science and Engineering Statistics, Integrated Sciences and Engineering Resources Data System, 2016) (Map Base Source: ArcMap 10.2.1, 2016)

Figure 24. Clustering Behavior of Number of Hi-Tech Majors per California County (Source: National Center for Science and Engineering Statistics, Integrated Sciences and Engineering Resources Data System, 2016) (Map Base Source: ArcMap 10.2.1, 2016) 
Figure 25. University R\&D Expenditures in Hi-Tech per California County (Source: National Center for Science and Engineering Statistics, Integrated Sciences and Engineering Resources Data System, 2016) (Map Base Source: ArcMap 10.2.1, 2016)

Figure 26. Clustering Behavior of University R\&D Expenditures in Hi-Tech per California County (Source: National Center for Science and Engineering Statistics, Integrated Sciences and Engineering Resources Data System, 2016) (Map Base Source: ArcMap 10.2.1, 2016)

Figure 27. Number of Biotech Businesses Venture Funded in 2014 per California County (Source: PricewaterhouseCoopers/National Venture Capital Association, 2015)

Figure 28. Cluster Behavior of Number of Biotech Businesses Venture Funded in 2014 per California County (Source: PricewaterhouseCoopers/National Venture Capital Association, 2015) 122

Figure 29. Percent of Women-Led Biotech Businesses Venture Funded in 2014 by California County (Source: PricewaterhouseCoopers/National Venture Capital Association, 2015)

Figure 30. Cluster Behavior of Percent of Women-Led Biotech Businesses Venture Funded in 2014 per California County (Source:

PricewaterhouseCoopers/National Venture Capital Association, 2015) ..... 124

Figure 31. Number of Hi-Tech Businesses Venture Funded in 2014 per California County (Source: PricewaterhouseCoopers/National Venture Capital Association, 2015)

Figure 32. Cluster Behavior of Number of Hi-Tech Businesses Venture Funded in 2014 per California County (Source: PricewaterhouseCoopers/National Venture Capital Association, 2015)

Figure 33. Percent of Women-Led Hi-Tech Businesses Venture Funded in 2014 by California County (Source: PricewaterhouseCoopers/National Venture Capital Association, 2015)

Figure 34. Cluster Behavior of Percent of Women-Led Hi-Tech Businesses Venture Funded in 2014 per California County (Source:

PricewaterhouseCoopers/National Venture Capital Association, 2015) ..... 128

Figure 35. Venture Capital Expenditures in Biotech Businesses in 2014 by California County (Source: PricewaterhouseCoopers/National Venture Capital Association, 2015) 
Figure 36. Cluster Behavior of Venture Capital Expenditures in Biotech Businesses in 2014 by California County (Source: PricewaterhouseCoopers/National Venture Capital Association, 2015)

Figure 37. Percentage of Venture Capital Expenditures of Women-Led Biotech Businesses in Biotech in 2014 by California County (Source:

PricewaterhouseCoopers/National Venture Capital Association, 2015) ..... 132

Figure 38. Cluster Behavior of Venture Capital Expenditures to Women-Led Biotech Businesses in Biotech in 2014 by California County (Source:

PricewaterhouseCoopers/National Venture Capital Association, 2015) ..... 132

Figure 39. Venture Capital Expenditures in Hi-Tech Businesses in 2014 by California County (Source: PricewaterhouseCoopers/National Venture Capital Association, 2015)

Figure 40. Cluster Behavior of Venture Capital Expenditures in Hi-Tech Businesses in 2014 by California County (Source: PricewaterhouseCoopers/National Venture Capital Association, 2015)

Figure 41. Percentage of Venture Capital Expenditures of Women-Led Hi-Tech Businesses in Biotech in 2014 by California County (Source: PricewaterhouseCoopers/National Venture Capital Association, 2015) ..... 136

Figure 42. Cluster Behavior of Venture Capital Expenditures to Women-Led Hi-Tech Businesses in Biotech in 2014 by California County (Source: PricewaterhouseCoopers/National Venture Capital Association, 2015) ..... 136 


\section{Introduction}

\section{Women Business Owners}

The numbers of women starting, owning, and running businesses have increased dramatically in recent decades. Women have been starting small businesses at a rate never seen before, and women are the fastest growing population of entrepreneurs, both in the U.S. and abroad. As of 2013, women-founded businesses make up nearly $30 \%$ of all U.S. firms, $30 \%$ of privately-held U.S. firms, and up to $46 \%$ of all U.S. businesses when equally owned businesses are included. During that same year, it was estimated that there were 8.6 million women-founded businesses in the U.S., generating $\$ 1.3$ trillion in revenues and employing close to 7.8 million (American Express OPEN, 2014).

Additionally, one in five firms with a revenue of $\$ 1$ million or more is women founded (United States Chamber of Commerce, 2014).

Women are increasingly gaining intellectual property, as well, in numbers of both patents and trademarks received. In 2012, women were listed as inventors on $18 \%$ of all patents issued in the U.S., double the percentage of women-issued patents in 1990 (National Women's Business Council, 2012). Women entrepreneurs and women founded firms have become an important economic force of the U.S. economy, whether measured by the number of businesses founded, by revenues generated, or by the number of people employed. It has been projected that women-founded businesses could create 5 million to 5.5 million new jobs across the U.S. by 2018 and that women business owners account for almost half of all new businesses, generating one-third of the new jobs projected by the Bureau of Labor Statistics (American Express OPEN, 2014). 


\section{Underrepresented in STEM}

In spite of these upward trends in business ownership by women, a gender gap still exists with women being underrepresented in certain industry sectors, such as the science, technology, engineering, and mathematics (STEM) fields. This study examines the sectors of hi-tech and biotech specifically, where, as in all STEM fields, women have unequal access to business development resources and encounter additional barriers in building a career in management and entrepreneurship. The gender disparity of lower rates of women in STEM fields has been a longstanding issue in the U.S. that has undergone much research. It is estimated that if women participated in the labor market at the same level that men do, the U.S. GDP would be $8 \%$ higher (Goldman Sachs, 2013).

In 2013, women held 48\% of all professional occupations in the U.S. workforce, yet in professional computing occupations that number is $26 \%$ (Catalyst, 2013). Not only is the gender disparity in the number of jobs held within STEM of concern, but the rate of attrition within these fields is an issue, as well. Over $52 \%$ of women with hi-tech jobs quit their occupations in 2007, double the turnover rate for men (Hewlet et al., 2008; National Science Foundation, 2004, 2010; Wadhwa and Chideya, 2014). Women in biotech fare better than those in hi-tech, as women hold $46 \%$ of all positions in the biological and life sciences (Priluck, 2010). Biotech is believed to be the most open technology field to women and there are more women in the field, likely due to their educational backgrounds in biology (Priluck, 2010).

The gender difference in hi-tech has not always existed, and until the 1960s many people perceived computer programming as a natural career choice for savvy young 
women. In a 1967 article titled "The Computer Girls," Cosmopolitan Magazine described computer programming as a field offering better job opportunities for women than many other professional careers and urged their fashionable female readers to consider a career in the field (Ensmenger, 2012). It was around this time that computerrelated professions became more masculinized, through hiring practices that favored math and personality tests slanted towards male applicants (Ensmenger, 2012). Since the masculinization of hi-tech, the number of women in the industry has remained low, a fact that has become most pronounced since the 1980s (Wadhwa and Chideya, 2014). According to the Bureau of Labor Statistics, from 2000 to 2011, the percent but perhaps not the number of women working in professional computing jobs decreased by $8 \%$ to $25 \%$ of the total, while the number of men climbed 16\% (Miller, 2012). Regarding the gender diversity in technology, Bright Labs released data about the percentage of men in each of the following jobs and found that in 2012:

$92.7 \%$ of network engineers are men; $92.6 \%$ of desktop support technicians; $91.6 \%$ of desktop administrators; $91.5 \%$ of PC technicians; $90.8 \%$ computer technicians; $90.4 \%$ of IT support; $89.7 \%$ of system administrators; $89.5 \%$ of senior software administrators; $88.6 \%$ of application engineers; $79.8 \%$ of database administrators; $78.3 \%$ of software engineers; $78.1 \%$ of software developers; $77.8 \%$ of technical support specialists; $77.1 \%$ of programmers; $77.1 \%$ of web developers; $77.1 \%$ of senior software engineers; $76.7 \%$ of developers; $75 \%$ of senior programming analysts; $72.3 \%$ of systems analysts; $68.4 \%$ of help desk analysts; $67.8 \%$ of programming analysts; $66 \%$ of web designers; $66 \%$ of software test designers; $65 \%$ of IT project managers; $63.7 \%$ of application developers; $53.8 \%$ of data analysts. (Bollinger, 2013)

The gender disparity of women in STEM fields has been the focus of much academic study, with often conflicting theories on its causality. Potential factors that may contribute to women's lower participation in STEM are industry-type stereotypes, 
women's minority status, lack of female role models, discrimination, gender differences in cognitive development and scientific performance, and low enrollment in corresponding college majors. Potential cognitive differences between boys and girls have been contested, with some researchers finding that boys have innate advanced math skills (Ceci and Williams, 2010; Harpen et al., 2007), and other research showing that differences in math and science abilities do not display until the $8^{\text {th }}$ grade, suggesting interest in the subjects is a major factor (Post-Kammer and Smith, 1985; National Science Foundation, 2009).

Additionally, women are frequently discouraged from entering STEM fields. In 2010, Bayer Corporation conducted a survey and found that $40 \%$ of women and minority chemists and chemical engineers had been discouraged from pursuing their field, mostly by college professors. Survey respondents identified three top factors that helped keep women and minorities from majoring in STEM: lack of quality math and science education in poorer school districts (75\%), persistent stereotypes that STEM isn't for girls or minorities (66\%), and financial issues related to the cost of education (53\%) (Bayer Corporation, 2010).

The low percentage of women enrolled in computer science programs in the U.S. has been designated by some researchers as the "incredible shrinking pipeline" (Randall, 2003). In the U.S., women constitute $55 \%$ of those in baccalaureate and master's degree programs, but only $21 \%$ of those pursuing degrees in computer sciences are female (Robb, 2003). This trend becomes more pronounced in advanced academic programs. In 
the 1999-2000 academic year, women received $28 \%$ of BA/BS degrees in computing, but less than $17 \%$ of PhDs awarded in computer science (Robb, 2003).

\section{Women: An Untapped Talent Source}

Women are an untapped talent resource in the industries of hi-tech and biotech, both of which are expected to grow exponentially. The number of IT vacancies is increasing by $25 \%$ a year, compared with $10 \%$ for all other occupations. It is estimated that by 2020, the U.S. tech industry will have need for 1.4 million computer scientists (Randall, 2003). At the current graduation rate of students enrolled in related majors, an American skilled labor force will fill only $39 \%$ of those jobs, leaving approximately 700,000 jobs unfilled by U.S. educated workers (Wadhwa and Chideya, 2014). Not only are women under-represented within the abundant job opportunities provided in the STEM fields, but they do not benefit adequately from the economic earning potential that is found within those fields, as well. The gender wage gap is smaller in STEM fields (14\%) than in non-STEM fields (21\%) (United States Department of Commerce, 2011). Looking at the gender discrepancy of males obtaining $80 \%$ of hi-tech-related degrees at university, it can be observed that getting additional women to enroll in hi-tech and STEM majors to the point of equal gender representation would help to create a larger qualified talent base, which, in turn, could meet the growing needs of STEM industries, especially hi-tech and biotech.

\section{Gender Disparity in Entrepreneurial Pursuits}

Just as women's numbers are lower in the STEM fields, so, too, are their numbers in entrepreneurship and leadership of companies, throughout all industries and 
particularly in STEM fields. Entrepreneurship remains a male-dominated activity in the twenty first century. In 2014, women founded firms (50\% or higher ownership) in the U.S. represented roughly $29 \%$ of all enterprises, employed about $6 \%$ of the country's workforce and contributed approximately $4 \%$ of business revenues (National Women's Business Council, 2014). When large, publically traded firms comprising more than 10 employees are excluded, women founded firms comprised $30 \%$ of all privately held firms, contributed $14 \%$ of employment, and $11 \%$ of revenues (National Women's Business Council, 2014). Women make up 14\% of Fortune 500 executive committees and $11 \%$ of CEO/founder positions in U.S. firms backed by venture capital (Wadhwa and Chideya, 2014). Women-founded businesses tend to be smaller in size and less profitable than their male-led counterparts (American Express OPEN, 2014). Also, women tend to own businesses in female-typed service sectors (primarily in healthcare, social assistance, education and retail-trade sectors). In 2007, the Survey of Business Owners (United States Census Bureau, 2010) demonstrated that in sectors such as information, manufacturing, and professional, scientific, and technical services, males hold a much larger share of entrepreneurial activity, with women only owning $25.5,18.4$, and $28.9 \%$ of the respective firms. Biotech fares the best out of all technology fields, as $12 \%$ of all biotech founders are female, compared to $1 \%$ of hi-tech firms (McQuaid, Smith-Doerr, and Monti, 2010).

Women's entrepreneurship has been a long-studied subject, with the first published article on the topic, Eleanor Schwartz's “Entrepreneurship: A New Female Frontier," appearing in 1976 (Greene, Hart, Gatewood, Brush, and Carter, 2003). 
Existing research on women entrepreneurs considers several different facets of analysis, including the entrepreneurs themselves at an individual level, the operational descriptions of how they create their businesses, and the business owners' industry choices. Research investigating women entrepreneurs focuses on demographics, previous work experience, educational attainment and qualifications, aspirations, goals, motivators for their ventures, and their reasons for selecting business ownership over wage and salary work (Aldrich, 1989; Brush, 1992). Research investigating operational processes used for creation of their businesses reviews women's social networks, industries that women open businesses within, and access to capital. Business owners tend to open businesses in areas in which they have previous work experience, and women tend to have more work experience in female-typed fields such as service sectors, teaching, retail, or social assistance. The link between work experience and business ownership may account for the lower rates of business ownership in male-typed occupations related to management, scientific, or technical positions (Mayer, 2008; Loscoccoo and Robinson, 1991), and may help to explain women's lower numbers in ownership of businesses within the hi-tech and biotech sectors.

Another important factor in business ownership, in all sectors and specifically hitech and biotech, is spatial location and integration. Firms in these sectors are particularly likely to exhibit geographic clustering due to their reliance on a skilled and talented labor pool, the availability of venture capital, and knowledge spillovers. Business owners of firms within industry clusters find advantages in being geographically adjacent to specialized labor and other business inputs. With these 
benefits, however, comes the challenge of higher costs, which affects women business owners in particular as their firms are usually smaller and less profitable than male-led firms (Mayer, 2008).

The challenges that women face while working within companies and trying to ascend the ranks to more senior or executive positions have been described by the metaphor "the glass ceiling." This is in reference to an invisible barrier that prohibits women from moving up the corporate ladder beyond a certain point (Morrison, White, and Van Velsor, 1987). However unperceived it is by others, the glass ceiling is very tangible to those that experience it, frequently leading to a homogeneous workplace in upper echelon positions. The Glass Ceiling Commission revealed in 1995 that among the top 1,000 industrial firms and the 500 largest corporations of all types ranked by Fortune magazine, $97 \%$ of senior managers are white, and an estimated $95-97 \%$ of senior managers are male (Rosenblatt, 1995). Many mid-level women have alluded to a family penalty in the work place, and studies have shown that mid-level men were almost four times as likely as women to have a partner who assumed primary responsibility for the household and children (Simard, Davies Henderson, Gilmartin, Schiebinger, and Whitney, 2008). Just as there are fewer women business owners and fewer women in senior positions in companies, there are fewer women holding seats on corporate boards. In the U.S., women held 14.8\% of Fortune 500 board seats in 2007 (Catalyst, 2007). Furthermore, the majority of companies with a woman on the board only have one woman in the position, a fact that is often taken as evidence of tokenism (Branson, 2006; Corporate Women Directors International, 2007). Studies have shown that having one 
position on the board filled by a woman is not enough, and that productivity increases the most when there are three or more women on the board (Wadhwa and Chideya, 2014).

In spite of all these challenges, women are founding companies at an unprecedented pace, and much to the benefit of women that work for women-led businesses. Women business owners are supporting a new kind of enterprise, that of the solo entrepreneur. Ninety percent of women founded firms have no employees other than the business owner, compared to $82 \%$ of all firms (United States Chamber of Commerce, 2014). Only $2 \%$ of women-founded businesses have 10 or more employees, lagging behind the $4 \%$ rate for all firms, a fact which points to the greater challenges women face when scaling up their businesses (American Express OPEN, 2014). In a recent survey, $85 \%$ percent of women entrepreneurs feel their work environment favors men, and $41 \%$ blame social and cultural issues for preventing their female colleagues from launching their own startups (Wadhwa and Chideya, 2014).

Women-founded businesses that succeed in scaling up and attaining growth are more apt to perpetuate further benefits to women employees that work for their companies. There is substantial evidence that women are more likely to be promoted to higher job levels and to be paid more in their jobs when there is a higher proportion of women already in the workplace and particularly in a women-led company (Bell, 2005). Literature suggests that women leaders are instrumental in promoting women within the organization, and that women executives support other women not just in better pay but in representation and positions, as well (Bell, 2005). It has also been shown that there are more women executives in women led firms, and that there is a positive correlation 
between women executives pay and the share of female board directors (Bell, 2005). These findings suggest that women business owners and leaders could help facilitate women's participation in the fields of hi-tech and biotech by providing a more diverse workplace culture.

Research has shown that a diverse workforce is a key driver of innovation and a critical component of being successful on a global scale (Forbes, 2011; Dosi, 1982; Quintana-Garca and Benavides-Velasco, 2008). Companies that have a more diverse workforce have increased interactions between different types of competency and knowledge within a firm. Teams made up of men and women are more open to experimentation and knowledge sharing, perform tasks more effectively, and often outperform less diverse teams (Ostergaard et al., 2011). Companies with the highest representation of women on their top management teams experienced better financial performance than companies with the lowest representation. This finding held for two financial measures: return on equity (ROE), which is $35 \%$ higher, and total return to shareholder (TRS), which is $34 \%$ higher (Catalyst, 2004).

In a study done by Dow Jones Venture Source of more than 20,000 venturebacked companies in the U.S., it was determined that successful startups which went public or got acquired had a more gender-balanced workforce, with more women in senior positions. In the study, the median share of female executives was $7.1 \%$ in successful companies, compared to $3.1 \%$ in unsuccessful companies (Canning, Haque, and Wang, 2012). Additionally, having a more diverse team at the top echelons of a company allows the business to cater to the interests of all of its customers and 
shareholders. A board and top management team that reflects the potential consumer base is more likely to have a better pulse on the market, as a result of a better understanding of market needs and by developing better marketing strategies. With women's smaller representation in the upper echelons of companies in the hi-tech and biotech sectors, there is additional effort needed by companies to achieve a genderbalanced, diverse workforce, and a huge potential payout for those that put in the effort to embrace it.

\section{Business Industry Clusters and Contributing Factors}

For a long time, businesses within the same industry have tended to locate closely together and this clustering behavior serves as a catalyst for business growth within the industry. It is possible to create an economic map of industry clusters, or agglomerations. In fact, the U.S. Department of Commerce, along with the U.S. Economic Development Administration and Harvard Business School's Institute for Strategy and Competitiveness, has created the U.S. Cluster Mapping Project, an interactive website that provides over 50 million data records on industry clusters. The project does this with the aim of creating a tool that promotes economic growth, national competitiveness of the various clusters, and competitiveness of the whole nation. That tool can be found online at www.clustermapping.us.

Industry clusters, also known as agglomerations or hubs, can be found throughout the world, and some notable examples in the U.S. are the hi-tech hub of Silicon Valley, the entertainment hub of Hollywood, the financial hub of Wall Street, and the automanufacturing hub of Detroit. Hi-tech and biotech clusters can be found in several 
locations throughout the U.S., and provide huge economic benefits through revenue and job creation to the areas they occupy. As a result, policy makers are eager to create such business clusters for their regions to encourage economic growth and establish centers for innovation and technology. Hi-tech and biotech business agglomerations have been encouraged though government subsidies, the creation of science parks, and the creation of new technical programs and certifications at various universities.

While there are several advantages for local economies in having a hi-tech or biotech agglomeration, there are also benefits for the companies themselves that reside within the cluster. Being a part of a business cluster makes it easier for a company to source inputs, access information, and coordinate with related companies. Geographic proximity also makes it much easier for companies to have closer relationships, get better and more timely information, and learn early on about evolving technology, which allows for early adaptation and greater competitiveness. In 1920, Alfred Marshall hypothesized three reasons for clustering of industries: benefits of a pooled labor supply, access to specialized inputs, and information flows between people and firms. These factors generate a positive feedback loop, where firm concentration brings in additional labor and inputs, which encourage additional firm concentration, and pushes the cycle forward (Arthur, 1994).

Much research has been done on factors that contribute to hi-tech and biotech clusters and the specialized inputs that go into successful firm agglomeration. It is widely accepted that venture capital, universities, and a skilled talent base are necessary components of any hi-tech or biotech firm cluster. Venture capital contributes by 
providing the capital investments that are often needed to establish a new firm in these sectors. Just as important as the investment capital they provide are the business contacts, the business plan screening, and the management advice they give to the firms they fund. Universities provide knowledge spillovers that nearby firms can use and they draw talented individuals to a region. Finally, an elite, skilled talent base provides knowledge and social capital to further drive innovation in an area. Knowing that these factors contribute to successful hi-tech hubs, policy makers have used an almost recipelike approach in their attempts to create their own hi-tech clusters, by adding aspects of university, venture capital, and entrepreneurial culture. These efforts have not always been successful, and it some have determined that it is better for government to support clusters that are already in existence than to write policy to create a specific new cluster from scratch (Porter, 1998).

\section{Venture Capital}

Venture capital provides a key component to both successful agglomeration economies and business ownership. Venture capitalists provide capital and act as a catalyst to business formation by providing networks, contacts, and guidance. The correlation of venture capital and successful business clusters can be seen in both the hitech and biotech sectors, as they are both capital-intensive sectors where available funding is a necessity for business survival and growth. The availability of both the venture capital and the networks attracts entrepreneurs and a talented labor pool to an area, kicking off a self-reinforcing cycle of innovation, business formation, and economic development. Studies have shown that women receive less venture capital funding than 
their male counterparts, depriving them of a leading factor in new enterprise formation that both helps to establish and scale up small businesses. The discrepancy in women business funding has been attributed to a funding gap on both sides of the venture capital equation, with less women applying for venture funding and less women venture capitalists.

Funding for a new venture can be obtained through many sources, such as personal savings, debt financing, loans, and grants, and by equity funding through venture capital firms or angel investors. Self-financing is a time-intensive endeavor that can stagnate business growth, making venture capital an attractive option, as most companies are too small in the initial stages to qualify for debt financing. A venture capital firm will invest funds in new business endeavors that have potential for high growth, in return for equity in, and some control in the direction of the company. Venture capitalists collect their gains by selling their equity in the company when it is adequately matured and goes public with an initial public offering (IPO), or gets acquired by another company.

In addition to the capital they provide, venture capitalists also act as catalysts in the formation of new businesses, by taking an active, ambassador-like role in the development of the companies they fund. In the early stages of a company's growth, venture capitalists provide extensive coaching and can serve as a company advisor, a board member, or a part of the top management team. In these positions, venture capitalists leverage their networks of contacts, financial expertise, industry insight, recruitment expertise, and contacts in all aspects of deal flow. Business coaching and 
monitoring provides an additional benefit to the companies being invested in, as it provides information, and reduces time and opportunity costs for the businesses the venture capitalists are supporting.

Considering the in-depth knowledge that venture capitalists have of their particular industries, as well as how closely they monitor and support their funded companies, it follows that venture capitalists would want to maintain geographic proximity to the growing companies they have invested in (Wallsten, 2001). Investing in young companies that do not have long-term performance track records is a high-risk endeavor, and a great deal of emphasis is placed on obtaining information on the company both before and after investing and on things such as market conditions, competitors, and performance within the industry. Brush, Carter, et al (2004) state that:

By intensively scrutinizing firms before providing capital and then monitoring them afterwards, venture capitalists can alleviate some of the information gaps and reduce capital constraint. Thus, it is the nonmonetary aspects of venture capital that are critical to its success.

The authors also note that the need for this information and oversight has led venture capitalists to focus on local firms in an effort to minimize the cost of their involvement.

Previous studies have analyzed the effect and availability of venture capital in terms of the propinquity of the venture capital firms to the companies they invest in. These studies have found the firms to be highly geographically concentrated, with most of them investing in companies within their region. In an interview cited by Zook (2002), a venture capitalist stated, “if I can't drive to the company in an hour, I'm not investing in it." This concentration of venture capital highlights the increasing returns of location in terms of access and information. Returns for venture capital firms investing 
within a localized area are found in the resulting networks, both personal and professional, as well as the interpersonal trust and reputation, all of which increase over time.

\section{Women business owners and venture capital.}

Recently, as research focus has increased on issues of women as entrepreneurs and business owners, there have been additional studies on the role of gender in obtaining financing (Ahl, 2006; Alsos Isaksen, and Ljunggren, 2006; Becker-Blease and Sohl, 2007; Brush, Carter, Gatewood, Greene, and Hart, 2001, 2004; Brush, Carter, Gatewood, Greene, and Hart, 2009; Harrison and Mason, 2007; Gatewood, Brush, Carter, Greene, and Hart, 2009; Robb and Coleman, 2010). Within the past 40 years, women have received less than $10 \%$ of the venture-capital investments made in the U.S., demonstrating a funding gap between men and women business owners. Additionally, it was observed that women-led firms received only $4.1 \%$ of equity funding during the 1990s (Brush, Carter et al., 2004). Undercapitalization is both a deterrent to starting a business and an inhibitor of success in a capital-intensive field like hi-tech or biotech. This is particularly true of women founded or women-led businesses: the lack of venturecapital funding options for women has been cited as a major source of lower growth and poorer performance in the companies they start (Alsos et al., 2006), and not only because of the lack of funding. When they are unable to access venture capital, these businesses also miss out on the networks and insights into guidance and current market conditions that the venture capitalists provide. Women are almost twice as likely to discontinue their businesses due to an inability to secure funding. Difficulty in financing is the most often 
cited reason women in the U.S. discontinue their businesses $(25 \%$ of women cite this reason, compared to $14 \%$ of men) (Kelley, Singer and Herrington, 2012).

\section{Funding gap: supply side.}

Studies have found women business owners receive roughly $5 \%$ of venture capital deals in technology-based ventures in the U.S. (Bruder, 2010; Brush, Carter et. al., 2009; Robb and Coleman, 2010). Authors Gatewood, Carter, Brush, Green and Hart (2003) devised a model to explain the venture funding discrepancy that highlights lower representations of women on both the supply side (venture capitalists), and the demand side (entrepreneurs seeking funding). On the supply side, the model points to the venture capital industry being overwhelmingly male, with women making up about $12 \%$ of the external equity industry in 2011, and only $22 \%$ of U.S. startups having one or more women on their funding teams (Harrison and Mason, 2007.) Considering that women are more likely to be involved in networks of other women, and that venture capitalists depend on referral networks for deals, fewer females in the venture capital industry results in a smaller chance for women entrepreneurs to get to the negotiating table (Brush, Carter et al., 2001; Gatewood et al., 2009; Robb and Coleman 2010). BeckerBlease and Sohl (2007) acknowledge this genetic homophily in venture capital and show that women professionals in the venture capital industry have attracted more female-led ventures to their firms, even though they claim to not be actively seeking them out.

\section{Funding gap: entrepreneur side.}

Just as there are fewer female venture capitalists, there are fewer women entrepreneurs seeking financing. Women entrepreneurs account for only $8.9 \%$ of 
proposals brought forward for potential equity funding (Becker-Blease and Sohl, 2007). Women use a significantly higher level of external debt and a significantly lower level of external equity funding. Several reasons for the lower level of women utilizing equity capital have been postulated, with the three main reasons being (1) women avoid venture capital so as to maintain ownership and control of their companies (strategic choice), (2) women experience structural barriers when trying to acquire equity capital, and (3) women do not possess the necessary knowledge and capabilities to acquire equity capital (human capital) (Alsos et al. 2006; Brush, Carter et al., 2001; Robb and Coleman 2010).

\section{University Presence}

Universities and higher education institutions are an important component in successful industry cluster formation as they provide knowledge spillovers to nearby geographic regions through research and development (R\&D). Industry can gain access to knowledge and resources from nearby universities by forming linkages with these higher-education institutes. Methods of linkages may include the transfer of skilled labor into employment in firms; the transfer of knowledge; access to university facilities; contracted or sponsored research in the university conducted by faculty and students; and contracted development, design, analysis, testing, evaluation, etc. These factors, combined with less formal contact with academics, may lead to the important exchange of information (Monck, Porter, Quintas, Stoery and Wynarczyk , 1988). This exchange of knowledge though a university allows for the growth and development of the local technology industry in three ways: universities develop and attract talent to create a specialized labor pool, they fund research that translates into new products and processes, 
and university administrators promote new business formation to contribute to regional entrepreneurship (Mayer, 2007; Saxenian, 1996). Universities also play an important role in contributions to local economic development, real estate development, and community development (Mayer and Heike, 2007).

\section{Geography of knowledge spillovers.}

Empirical evidence suggests that location and proximity play a key role in knowledge spillovers. The geographic estimation of the knowledge production from spillovers is limited, however, because there is no understanding of the way in which spillovers occur and are realized at the geographic level. In both hi-tech and biotech, the pre-existing pattern of related activities makes it difficult to separate spillovers from the correlation of variables at the geographic level (Audretsch and Feldman, 2004). Looking at university research and development (R\&D) expenditures and a company's decision to locate new plants in a county, authors Woodward, Figueiredo, and Guimaraes (2006) determined that knowledge spillover effects may extend up to 145 miles from universities, without regard to city lines or county boundaries. In order to study the geographic effects of knowledge spillovers, authors Jaffe and Trajtenberg (2000) and Almedia and Kogut (1997) have analyzed patent families in hi-tech — that is, patents that reference or cite each other and in doing so indicate the flow of knowledge from one invention to another. All studies found citations to be more localized than in control groups, indicating that location and proximity clearly matter in benefiting from knowledge spillovers. 


\section{Talent and Women Business Owners}

While skilled talent is important in all areas of business, it is of utmost importance where there is a skilled labor supply shortage or where clustering or agglomeration economies are present. For agglomeration economies, the ability to draw in world-class talent is paramount. It increases the competitive edge of individual firms within the cluster and brings prestige and growth to the region as a whole (Richardson, 2015). While the causal connections are not known, scholars have noted the degree to which urban knowledge capital is crucial for the continued advancement of hi-tech and biotech clusters, frequently a part of the economy of emerging global cities (Beaverstock, 1996; Beaverstock and Smith, 1996; Findlay, Jowett and Skeldon., 1996; Stalker, 2002). Malecki (1997) was possibly the first to note the importance of a skilled labor force as a knowledge transfer mechanism in technology-based industrial clusters. The key role of human capital in biotech is noted as a mechanism for knowledge appropriation for startup firms (Audretsch and Stephan 1996; Zucker, Darby and Brewer 1998; Prevenzer, 1997). The importance of skilled talent in an area is particularly evident at the pinnacles of organizational hierarchies (such as at the chief executive level), in specialist skilled roles, and in entrepreneurial activity (Faulconbridge, Beaverstock and Hall, 2009).

\section{Section Summary and Goals, Scope, and Anticipated Outcomes of Research Study}

As the literature review has demonstrated, there has been much effort dedicated to looking at women entrepreneurs in relation to the differences between the genders, and the availability of venture creating resources for women. However, far less academic work has focused on how the factors of venture capital and university R\&D expenditures 
geographically may correlate to the numbers of women business owners and other possible critical elements that have enabled women entrepreneurs to succeed, even in Silicon Valley. Thus, two of the driving research questions for this study include, "Do the availability of venture capital and university R\&D expenditures correlate geographically to the number of women business owners within a particular area?"; and, "Are there other possible critical elements that have enabled women entrepreneurs to succeed within a geographic cluster, such as Silicon Valley?"

To address these questions, this study will begin to document and explore how factors that encourage geographic clusters of the hi-tech and biotech industries may influence women business owners within these fields. Using both geostatistical analysis and semi-structured interviews as methodology, the study will work to determine how women company founders in hi-tech and biotech have succeeded over the past 30 years, and how the factors that contribute to successful clustering of these industries, namely venture capital and university $R \& D$, have influenced their ventures. Also explored in the study will be the career aspirations and motivations of women business owners in hi-tech and biotech, their previous employment experiences and how these factors influenced their career path, their observations of possible gender disparity within these fields, and their tenacity to persevere as entrepreneurs.

The specific methodology behind this research study will focus on geographic analysis and semi-structured in-depth interviews of women business owners in the hi-tech and biotech industries primarily within the San Francisco Bay/Silicon Valley area, specifically, and the state of California, generally. Currently there is a lack of 
understanding regarding how the factors that influence successful geographic clustering of hi-tech and biotech industries affect women business owners and business formation by women. Thus, analysis showing the geographic association of these factors will be conducted, in tandem with confidential semi-structured in-depth interviews to gather information on how these factors affect women-led businesses within these fields, as well as to gather anecdotal stories from the women business owners themselves. Quantitative data will be at the County level, to standardize the scale at which all data are measured.

It is the intent of this study to contribute to the knowledge regarding women entrepreneurs and business owners in the fields of hi-tech and biotech in the following ways: 1) The findings will attempt to demonstrate how factors such as venture capital and university R\&D expenditures associate spatially with the abundance of women-led businesses; 2) The findings will attempt to demonstrate women business owners' individual experiences with attaining and securing key elements and factors perceived as critical in achieving business success; and 3) The findings and outcomes from this study may aid in supporting or negating assumptions held to be true on the factors limiting women's business ownership within both the hi-tech and biotech sectors.

\section{Methods}

\section{Qualitative Methods: Semi-structured Interviews}

The qualitative material used for this study was taken from 20 semi-structured, indepth interviews with women business founders and so-called C-Suite executives (the most senior executives of an organization, such as the chief operating officer or the chief financial officer) in hi-tech and biotech companies. Initial information for recruitment of 
individuals was obtained through the PriceWaterHouseCoopers (PwC) MoneyTree Survey database, using a listing of companies that had received venture capital in 2014. In 2014 , the venture capital market was at its highest point nationally since the recession of 2008, with over 800 deals secured, $\$ 9.5$ billion directed towards hi-tech and biotech companies, and an average of $2.2 \%$ of all venture capital expenditures for the year going towards those sectors. This can be compared to the low point of the market in this period, which came in 2009, when only 700 deals were financed, just over $\$ 5$ billion was invested, and only $1.2 \%$ of deals went to the hi-tech and biotech sectors. Additional information on the companies besides what was provided in the interviews came from the web pages of the surveyed companies.

The initial list of firms in 2014 was reduced to 34 woman-led companies in the San Francisco Bay Area, and 10 out of these 34 firms contacted agreed to participate in the research project. From there, the snowball method was use to find additional participants (Biernacki and Waldorf, 1981). The snowball method was selected as an additional purposive sampling technique with the goal of existing study interviewees identifying other women entrepreneurs who they knew, had secured similar levels of firm funding, and may be interested in participating in the study. This additional sampling technique procured ten additional interviewees for the study. The surveyed firms received various amounts of venture capital funding, ranging from $\$ 1$ million to $\$ 33$ million. Firms contacted via the snowball method were similarly reliant upon venture capital as a source of funding. Table 1 shows the year of startup, the location, the contact method, and the interviewee's title for each company. 
Table 1.

\section{Company and Interviewee Profile}

\begin{tabular}{|c|c|c|c|c|}
\hline Firm & $\begin{array}{l}\text { Year of } \\
\text { Startup }\end{array}$ & Location & Contacted Through & Interviewee's Title \\
\hline \multicolumn{5}{|c|}{ Biotech Companies } \\
\hline B1 & 2013 & Bay Area & Venture capital funding list & CEO and Co-founder \\
\hline B2 & 2008 & San Francisco & Venture capital funding list & CEO \\
\hline B3 & 2013 & San Francisco & Venture capital funding list & CEO \\
\hline B4 & 2004 & $\mathrm{MD}$ & Snowball method & President and CSO \\
\hline B5 & 2007 & $A Z$ & Snowball method & President and Co-founder \\
\hline B6 & 2000 & San Carlos & Snowball method & CEO and Board Director \\
\hline B7 & 2014 & San Francisco & Snowball method & CEO and Co-founder \\
\hline B8 & 2013 & NY & Snowball method & Co-founder \\
\hline B9 & 2014 & San Francisco & Snowball method & Founder, CSO \\
\hline B10 & 2010 & San Francisco & Snowball method & Executive in Residence \\
\hline \multicolumn{5}{|c|}{ Hi-Tech Companies } \\
\hline $\mathrm{H} 1$ & 2013 & San Francisco & Venture capital funding list & CEO and Co-founder \\
\hline $\mathrm{H} 2$ & 2010 & San Francisco & Venture capital funding list & CEO and Founder \\
\hline $\mathrm{H} 3$ & 2010 & San Mateo & Venture capital funding list & President and CEO \\
\hline $\mathrm{H} 4$ & 2013 & Redwood City & Venture capital funding list & CEO and Co-founder \\
\hline H5 & 2010 & Boston & Snowball method & CEO and Co-founder \\
\hline $\mathrm{H} 6$ & 2013 & San Francisco & Venture capital funding list & CEO and Founder \\
\hline $\mathrm{H} 7$ & 2014 & Menlo Park & Venture capital funding list & Co-founder \\
\hline $\mathrm{H} 8$ & 2000 & San Mateo & Snowball method & President and CEO \\
\hline H9 & 2010 & Palo Alto & Venture capital funding list & Chief Operating Officer \\
\hline $\mathrm{H} 10$ & 2001 & Palo Alto & Snowball method & President \\
\hline
\end{tabular}

Of the 20 companies interviewed, 16 were found in the San Francisco Bay Area

technology hub. After utilizing the snowball method, described above, other firms were located for interview participation that were located in Arizona, Maryland, Boston, and

New York. While it would have been interesting to include interviews from both the Bay Area and Southern California regions, no interviewees were located in the southern 
California region. The hi-tech firms that were interviewed focused on the following specialties: predictive intelligence, food allergen detection, geospatial business intelligence, business analytics, wearable technology, and mobile points of sale. The biotech firms that were interviewed focused on bone grafting, DNA manufacturing, genomic analysis, diagnostics and therapeutics, blood tests, and protein analysis. Silicon Valley was selected as an area of focus for interviews as it is an internationally recognized hub for both the hi-tech and biotech sectors, has a leading position in venture capital expenditures in the U.S., and has a talent pool that includes skilled workers from around the globe. Its international status and its proximity to San Jose State University made it an ideal area of focus for the qualitative portion of the study.

Interviews took place from April 2015 to June 2015, and the average length of the interviews was 40 minutes. All interviews were recorded and later transcribed. While the interviewees were assured confidentiality, all informants were aware that the results could potentially be published in future research reports. The semi-structured interview method was selected to give a better understanding of the life of a woman business owner or executive in hi-tech and biotech, and to show how the factors that are believed to be important to business sector agglomeration affected them on a personal level. The interview questions, which are presented in Figure 1, focused on such topics as their leadership histories, factors that contributed to their leadership aspirations, challenges they encountered and their perseverance, the influence of university and education, their experiences with funding, and their opinions about the importance of geography to their 
business' success.

\section{Where are the Hi-tech and Biotech Women Business Owners? Mapping out Women Business Owners, Venture Capital Expenditures, and University R\&D Expenditures Sample Interview Questions Jessica White, Graduate Student Department of Geography, San Jose State University}

\section{Introduction:}

1. Can you tell me a little about yourself and your current position?

2. Can you tell me a little about how you came to becoming enter interviewees job title?

II. Career Aspirations and Contributing Factors:

3. Was this something you always envisioned yourself doing?

4. What are the critical opportunities/factors that lead you to being enter interviewee's job title?

5. What about education and professional experiences, how did those attributes contribute to you being enter interviewee's job title?

6. Can you tell me a little about your experience to funding sources that allowed you to launch this firm, such as Venture Capital, Angel Funding, Bank Loans, or family or personal savings?

\section{Potential Setbacks and Perseverance:}

7. Spoken description: "Silicon Valley has been described as a bit of a boys club, with a fraternizing culture with an exclusionary attitude towards women in a male dominated industry.")

a. How did you find this proposed culture of Silicon Valley to support the establishment and growth of the venture you lead?

8. Many ventures have gone through hardship, if not failure before they eventually succeed. Can you say that you have experienced this, whether with this venture or other ventures? If so, what were critical elements / factors that you embraced to succeed?

\section{Conclusion:}

9. Might you have any suggestions for other individuals to be included in this study?

10. Do you have anything else to add?

\section{Figure 1. Qualitative Interview Questions}

\section{Quantitative Methods: Data Components}

This section focuses on the quantitative data analysis methodology, first by reviewing the data and explaining how the data were obtained, and then how the data were explored and analyzed. As previously mentioned, three datasets were collected for use in this study: 1) the number of hi-tech and biotech businesses by California county 
and the gender of the top executive in each business, 2) the amount of university R\&D expenditures in hi-tech and biotech by California county, and 3) the number of venture capital deals in hi-tech and biotech by California county, as well as the funding amount and the gender of the top executive for each company.

\section{Hi-tech and biotech business data.}

Business information data was collected from the Reference USA database. The database was utilized through association with San Jose State University, and can be found at http://www.referenceusa.com/Static/Home. Reference USA is an Internet based service that is used by top libraries throughout the U.S. for business reference and research. Current business data were collected in February 2015, for businesses with NAICS codes associated with the hi-tech and biotech industries (see Business Industry NAICS Codes in the appendix.) Data obtained from the database included company size, length of operation, and revenue. While many detailed attributes found within the dataset looked to be of interest for exploration, several of these factors were considered out of scope for this project, and the business data used were a compilation of the number of businesses of each industry type and the gender of the company leader by California county. Data were collected on an individual company level, which included businesses that are sole proprietorships, and in order to keep all geographic data at the same geographic level, aggregated to the county level in Microsoft Excel, added to ArcMap, and joined to a California county shapefile for further analysis. 


\section{University R\&D expenditure data.}

Data used to determine university R\&D expenditures were obtained through the Computer-Aided Science Policy Analysis and Research (webCASPAR) web portal. This web portal is also known as the Integrated Science and Engineering Resources Data System, and is maintained by the Division of Science Resources Statistics (https://webcaspar.nsf.gov). It contains information about academic science and engineering resources and allows users to select variables from surveys conducted by the National Science Foundation (NSF), and the National Center for Science and Engineering Statistics (NCSES). The survey used for this study was obtained from the NSF's Higher Education R\&D Survey, and included the key variables of academic institutions throughout California, academic discipline, and total $R \& D$ expenditures. Data were collected for the most recent fiscal year available at the time, namely 2012, and included institutions that have a 4-year bachelor's degree or higher degree program and annually perform at least $\$ 150,000$ in science and engineering $R \& D$ (see the university information in the appendix). From there, data were queried to display the number of universities providing majors in hi-tech and biotech industries, and R\&D expenditures to hi-tech and biotech research projects within the university; namely computer science, electrical engineering, and mechanical engineering for hi-tech, and biological sciences and chemical engineering for biotech. University data were then summarized and aggregated to the county level in Microsoft Excel in an effort to keep the geographies consistent across all GIS data layers, added to ArcMap, and joined to a California county shapefile for further analysis. 


\section{Venture capital expenditure data.}

Venture capital data were collected for the most recent fiscal year available, 2014, and were obtained through the PricewaterhouseCoopers $(\mathrm{PwC})$ MoneyTree $^{\mathrm{TM}}$ Report. Data were provided for each company investment made on a quarterly basis and included information on industry, company name, city, and deal amount. The MoneyTree Survey is a quarterly study of venture capital investment activity in the U.S. It is a collaborative effort between PwC and the National Venture Capital Association that is based upon data from Thomson Reuters, and is the only industry-endorsed research of its kind.

Data were obtained for both the biotech and hi-tech sectors and consisted of the predefined PwC MoneyTree Survey database industry classifications (see the venture capital data definitions in the appendix). Biotech data had its own classification in the database, and the hi-tech industry included the following industry classifications from PwC: computers and peripherals, electronics/instrumentation, IT services and software, networking and equipment, semiconductors, and telecommunications. After venture capital funding information was obtained from the database, information on each company's CEO was collected through company websites. Data was compiled at the city level and included industry classifications, investment amounts (per quarter and total amount invested throughout the year), and company leader gender. It should be noted that the company leader was reported by the individual companies themselves, and as such, did not have standard titles such as only "CEO" or "Company Founder." Data were then aggregated to the county level for consistency across all datasets, and a new attribute table was created showing the total number of companies in each county to receive 
venture capital funding, the total amounts of funding received in each county (per quarter and total amount invested throughout the year), the number and gender of company CEOs, and the percentage of each gender type of company CEOs per county. Attribute tables for both the biotech and hi-tech industries were created, added to ArcMap, and joined to a California county shapefile for further analysis.

\section{Quantitative Methods: Data Analysis}

Once the GIS data were compiled for hi-tech and biotech business information, venture capital expenditures, and university R\&D expenditures using the methods described above, the data were prepared for analysis in GIS. GIS data were mapped and analyzed using ArcMap 10.2, using a shapefile of California counties with the aforementioned aggregated data as attributes. The shapefile consisted of California's 58 counties and was projected to NAD 1983 UTM Zone 10. Data were initially thematically mapped to review geographic patterns, then analyzed using the hot spot analysis GetisOrd Gi* tool in ArcMap as an exploratory analysis approach to assess patterns in spatial clustering. Mapping and analysis were done individually for variables such as number of businesses (including percentage women-led), university R\&D expenditures, and venture capital expenditures (including percentage going toward women-led businesses) in the fields of hi-tech and biotech (see Table 2). 
Table 2.

List of Variables Thematically Mapped and Analyzed for Clustering Behavior

\begin{tabular}{l|l|}
\multicolumn{1}{c}{ University Data Hi-Tech } & \multicolumn{1}{c|}{ University Data Biotech } \\
\hline Number of Universities with Hi-Tech majors & Number of Universities with Biotech majors \\
\hline Amount of University R\&D expenditures in Hi-Tech & Amount of University R\&D expenditures in Biotech \\
\hline \multicolumn{1}{c|}{ Venture Capital - Hi-Tech } & \multicolumn{1}{c|}{ Venture Capital - Biotech } \\
\hline $\begin{array}{l}\text { Total dollar amount of VC expenditures to Hi-Tech } \\
\text { companies }\end{array}$ & $\begin{array}{l}\text { Total dollar amount of VC expenditures in Biotech } \\
\text { companies }\end{array}$ \\
\hline Total number of companies invested in Hi-Tech & Total number of companies invested in Biotech \\
\hline $\begin{array}{l}\text { Number of Women led businesses receiving funding } \\
\text { in Hi-Tech }\end{array}$ & $\begin{array}{l}\text { Number of Women led businesses receiving funding } \\
\text { in Biotech }\end{array}$ \\
\hline Amount of funding received by women in Hi-Tech & Amount of funding received by women in Biotech \\
\hline \multicolumn{1}{c|}{ Business Data - Hi-Tech } & \multicolumn{1}{c|}{ Business Data - Biotech } \\
\hline Number of businesses in Hi-Tech & Number of businesses in Biotech \\
\hline Number of Women led Businesses in Hi-Tech & Number of Women led Businesses in Biotech \\
\hline
\end{tabular}

Data were thematically classified and mapped using the natural breaks (Jenks) method in ArcMap, which partitions data into classes based on natural groups in the data distribution (Environmental Systems Research Institute, 2016, Data Classification Methods). After the measurements for each quantity listed in table 2 were thematically mapped across California counties, they were analyzed for spatial clustering behavior using the hot spot analysis Getis-Ord $G_{\mathrm{i}}{ }^{*}$ tool in ArcMap. The hot spot analysis tool, found in the Spatial Statistics toolbox, aims to find counties that exhibit geographic clustering behavior, with either a cluster of high/low values surrounded by other features with high/low values (Environmental Systems Research Institute, 2016, How Hot Spot Analysis (Getis-Ord $\left.G_{i}{ }^{*}\right)$ works).

The hot spot Getis-Ord $G_{i}{ }^{*}$ tool was selected for this study instead of the Anselin Local Moran's I tool since ArcMap indicated Getis-Ord $G_{i}{ }^{*}$ is better suited for hot spot 
analysis, as the Moran's I tool shows the similarity of nearby features, but does not indicate if the clustering is for high or low values (Environmental Systems Research Institute, 2016, Hot Spot Analysis (Getis-Ord Gi*)). Additionally, the Moran's I tool is often used to determine geographic outliers in data, (Anselin Local Moran's I, Environmental Research Institute) whereas this study was interested to determine if high values exhibited clustering patterns, or hot spots. The hot spot analysis Getis-Ord $G_{i}{ }^{*}$ tool uses the following equation to investigate spatial clustering patterns, citing Ord and Getis (2010). Counties are ordered alphabetically, and given the numbers $i=1,2, \ldots, 58$ respectively, for simplicity in notation. For example, $i=1$ would correspond to Alameda county. For each variable of interest, here a single variable is denoted " $x$ " (for example $x_{i}$ would represent the number of hi-tech businesses in $i^{\text {th }}$ county when number of hi-tech businesses is the variable of interest) the value of $G_{i}{ }^{*}$ is calculated for each of the $\mathrm{n}=58$ counties. Within the equation for $\mathrm{G}_{i}{ }^{*}$ for the $i^{\text {th }}$ county, the summations are over all $\mathrm{n}=58$ counties, where $\square_{\square}^{*}=\frac{\sum_{j=1}^{\mathrm{n}} \square_{\square \square} \square_{\square}-\square \sum_{\square=1}^{\square} \square_{\square \square}}{\mathrm{s} \sqrt{\frac{\sum_{\square=1}^{\square} \square_{\square \square}^{2}-\left(\sum_{=1}^{\square} \square \square\right)^{2}}{\square-1}}}$ where $x_{\mathrm{j}}$ is the measured value of the variable under consideration for the $j^{\text {th }}$ County, for each of the $\mathrm{n}=58$ counties. For each combination of counties $i$ and $j, \mathrm{w}_{i j}$ represents a weight indicating whether or not county $i$ is a neighbor of county $j$. Figure 2 illustrates an example of these neighborhood weights used in my study for the example of $i=1$ corresponding to Alameda County, where Alameda county is purple and receives a weight of zero $\left(\mathrm{w}_{i j}=0\right)$ along with the grey nonneighboring counties ( $\mathrm{w}_{i j}=0$ for all counties $j$ shaded in grey) and the neighboring counties are green, receiving a value of $1\left(\mathrm{w}_{i j}=1\right.$ for all counties $j$ shaded in green). 


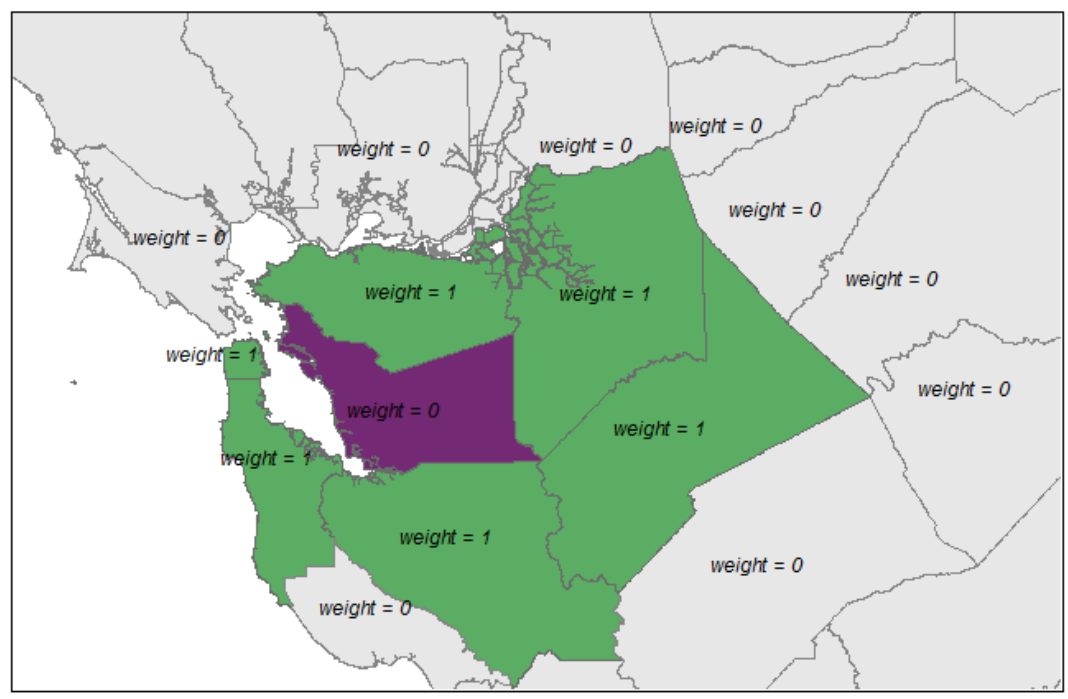

Figure 2. Neighborhood Weights, Corresponding to $\mathrm{i}=1$ (Alameda County) (Source: ArcMap 10.2, California County Base Layer, 2015)

The contiguity edges corner option of ArcMap defined neighbors as sharing a corner or a boundary. For each value of $i, \mathrm{w}_{i i}=0$, meaning, a county is not a neighbor of itself.

$$
\begin{gathered}
\bar{\square}=\frac{\sum_{\square=1}^{\square} \square}{\square} \\
\square=\sqrt{\frac{\sum_{\square=1}^{\square} \square}{\square}-(\bar{\square})^{2}}
\end{gathered}
$$

In order to calculate the $\mathrm{G}_{\mathrm{i}}{ }^{*}$ value of the number of hi-tech businesses found in Alameda county, using the above example, the equation considers all of the counties in the state, using weighted values for the neighboring counties by allowing only the values for the counties that are geographically neighboring Alameda to have values as not multiplied by zero. The standard deviation on the denominator of the equation measures the square root of the variance of the values. If that value of $G_{i}^{*}$ is higher than expected, 
a hot spot is displayed. Similarly, if the value of $G_{i}{ }^{*}$ is much lower than expected, a cold spot is indicated.

Hot spot analysis was performed on each of the variables tested to investigate whether there was sufficient evidence against the null hypothesis of no spatial clustering in favor of the alternative hypothesis that there was geographic clustering in the county level of the measured variables. Within the tool, Euclidean distance was used to measure the straight-line distance between features, and as mentioned previously, polygon contiguity, or conceptualization of spatial relationships, was measured by contiguity edges corners. The False Discovery Rate was applied within the tool to control for the proportion of incorrect rejections of the null hypothesis (Caldas de Castro and Singer, 2006).

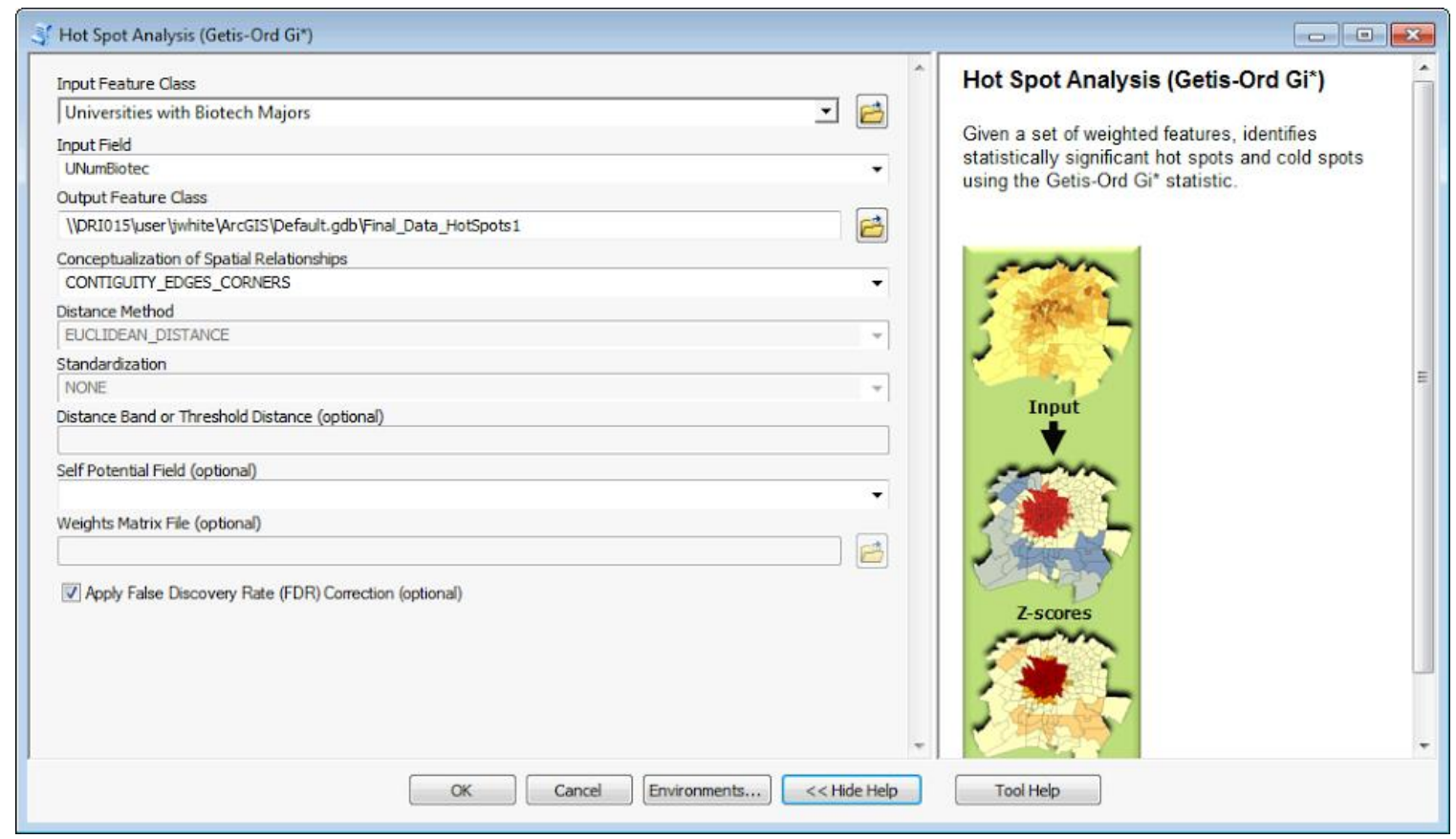

Figure 3. Settings for the Hot Spot Analysis Getis-Ord $\mathrm{G}_{\mathrm{i}}{ }^{*}$ Tool in ArcMap 10.2 (Source: ArcMap 10.2, 2015) 


\section{Results}

This chapter focuses on the results of the empirical data analysis, both from the qualitative semi-structured interviews and from the quantitative data. The chapter will first review the results from the qualitative interviews and then go on to discuss results and visualizations from the quantitative data analysis.

\section{Qualitative Portion: Semi-structured Interviews}

This section focuses on the qualitative portion of the study and the results of the empirical data. Specifically, the chapter reviews and assesses data collected from semistructured, open-ended interviews conducted from April 2015 to June 2015. A total of twenty interviews were conducted with women business leaders in the hi-tech and biotech industries, with 10 in the hi-tech industry and 10 in the biotech industry. The group of women business leaders interviewed consisted of company founders and C-level executives, including Chief Executive Officers (CEOs), Chief Science Officers (CSOs), and Chief Operational Officers (COOs). Interviews focused on the factors expected to contribute to the success of industry hubs, namely access to venture capital, presence and proximity of higher education universities, and a skilled labor pool. Interview questions also asked about factors believed to contribute to the success of the women entrepreneurs themselves, including topics such as career ambitions, leadership aspirations, factors contributing to career success, and potential setbacks and perseverance. This chapter reviews characteristics of the businesses surveyed, the questionnaire used for the interview, the entrepreneurs interviewed, and interview findings. 
The women interviewed had a wide range of experiences, backgrounds, and reasons for going into leadership. The ages of the women entrepreneurs interviewed ranged from early 20 s to late 60 s. Some women were still settling into the role of CEO as their first professional position, while other women interviewees had run multiple companies and been in the position of CEO for over half their lives. While the histories and stories of how the interviewees had found their positions were different, there were many similarities, for instance in personality characteristics and professional experiences. The rest of this chapter will review interview responses for both the hi-tech and biotech sectors.

\section{Leadership history and aspirations to leadership.}

Question 1 and question 3 from the survey (Figure 1) helped to reveal the women interviewees' leadership histories and leadership aspirations. Specifically, the questions were "Can you tell me a little about yourself and your current position?" and "Was this something you always envisioned yourself doing?" These questions were aimed at understanding how the respondents had attained their current position, what their motivating factors were, and if the respondents had held a longstanding vision of leadership for themselves. For all of the firms surveyed, $60 \%$ of all interviewees were first-time business leaders, and $40 \%$ had a history of running a company prior to their current position (see Table 2 in the appendix). This number held steady across both the biotech and hi-tech sectors. Interviewees typically had not envisioned leadership for themselves: $70 \%$ of respondents claimed they had not predicted a leadership role for themselves, $20 \%$ said they had known that they would eventually go on to lead but not 
necessarily in that particular role, and $10 \%$ of respondents claimed that they had long envisioned a leadership role. A total of $80 \%$ of interview respondents founded their own companies, and $20 \%$ of the respondents got to their position of company leader by moving up the corporate ladder. It should be noted that business founders made up the bulk of the interviewees. That number shifts slightly by sector, with the same numbers holding steady for both hi-tech and biotech. For those women that founded their own company, $80 \%$ percent were first-time entrepreneurs, and $20 \%$ had held previous positions of leadership.

Women business founders had varying levels of aspirations to lead, with the majority not specifically aiming to hold a position of leadership at their current level. A total of $70 \%$ of founders interviewed had not foreseen leadership in their future, $10 \%$ had envisioned themselves in their current role for some time, and $20 \%$ had known they would lead but had not known how. Women in hi-tech seemed more certain of the fact that they would eventually go on to lead, with $40 \%$ of these respondents knowing they would lead as the head of a company or in a similar position, compared to only $20 \%$ of women in biotech who knew they would go on to lead in some capacity. Variation in long-term visions of leadership could be seen in the differences in responses to the question of whether they had always envisioned themselves in their current role. The majority of respondents stated that they had not anticipated themselves going on to lead, as can be seen in the following comments.

I once took an entrepreneur class at (a prestigious East Coast University), and the professor asked a class of about $30 \%$ women and $70 \%$ men who wanted to be a CEO, and hardly any women raised their hands. I certainly wasn't one of them either. I remember thinking, why me, I'm not 
qualified. You always think about all the reasons you're not qualified. But when we started this venture, I was just like, well, why not? I shifted my frame of thinking into why not. You need that in order to start something. (Founder and CEO, Firm H1)

Definitely not (being a CEO.) I didn't think I would be a bench scientist; I always really loved neuroscience and loved thinking about the intricacies of disease and potential therapeutics. Thinking about the puzzle pieces. I knew I didn't quite have the personality to be at a bench for the rest of my life but I also never envisioned being a CEO. (CEO, Firm B2)

I would say that even when we started this company I wasn't really envisioning myself having this role. I always wanted to be in healthcare, always wanted to help people and make a difference through health. Knew I wanted to do that. I wouldn't say I am inherently an entrepreneur, it was just that this idea was too good to pass up, so we started a company around it. (Co-Founder and CEO, Firm B7)

While the above comments about not envisioning leadership were typical, some of the respondents indicated that they had known they would be a leader, though they had not foreseen that role being fulfilled as the founder or head of a company. Business founders who had felt a pull towards leadership had the following to say about whether they had ever held leadership aspirations:

No absolutely not (on being CSO.) I think it makes a lot of sense for me. I'm very stubborn and like to have a lot of control. I like the learning curve (in my present position), and I get bored really easily. I think I thrive when I'm at capacity, when I'm just about overwhelmed. In those ways I think it has been a good fit for me. (Founder and CSO, Firm B9)

Yes and no [on being CEO and Founder]. I didn't even know what the Valley was and what VC funding was. Of course I had heard of it and peripherally knew what it was, but even though I'd lived in SF for a very long time I wasn't in the startup culture of things and in college I never aspired to "be a CEO." I did always know my whole life that I would never work for somebody. So I kind of always knew I would be my own boss in some way, shape or form. (Founder and CEO, Firm H6) 
While not envisioning leadership or having the sense that they might be suited to leadership in some form was typical, some respondents seemed to know they were more suited to leadership, even from a young age:

Growing up and working on my education and then my early career, I always knew I had very strong leadership skills and gifting in that area. As I continued to progress, I knew at some point I'd probably end up either leading a very large division of a public company, and that the potential to become a CEO in a private company existed. It was through a series of opportunities that ended up presenting itself. The original founder stepped down, which created a hole that I was able to step up and fill. (CEO and Board Director, Firm B6)

I always figured that I'd end up running the show in some way, shape or form. Since I was little, I tended to rise to the pinnacle of leadership positions in whatever I was doing in a lot of ridiculous and ironic ways. Terrible example, but lots of student leadership stuff, running and managing clubs, different organizations that I was a part of, I would just end being at the very top of them. So I thought that I would ultimately be an executive director of a non-profit organization. But once I realized that was not the case then I figured I'd end up being $\mathrm{CEO}$ or $\mathrm{COO}$, but CEO most likely. (Co-Founder and CEO, Firm H5)

It's hard to describe it, I've always been entrepreneurial. Whenever someone says no it can't be done I just always want to make it done. I heard this quote once, which I love, and it says an entrepreneur is someone who gets motivated by the word no. That totally defines me. You can see a pattern throughout my life of things that needed to change and I like to make change happen. (President, Firm H10)

While all of the women interviewed enjoyed their work and discussed having a motivation and a desire to start something, there was a difference in the motivating factors to start a company. The women typically fell into one of two categories related to the reasons they founded their company: they were either "mission driven" or had "the bug" to found a company. Women that had "the bug" to found companies were in their element while running a company, had potentially done it a number of times, and would 
likely find themselves running another company should their current business endeavor not work, or it came time to move on. The other category of business owner had gotten into her position through a cause that was personal and that she was very passionate about. While the women in the latter camp also enjoyed their work and seemed in their element, they were not running a company due to a longstanding desire to be in that position. Of the 20 women interviewed, $56 \%$ founded their companies with a sense of a mission, and $44 \%$ founded their companies because of an affinity for running a company. There is a significant difference in the ratio between the two sectors, however: $75 \%$ of biotech business founders reported being mission driven compared to $37.5 \%$ of hi-tech business founders.

Of the women interviewed, that had founded their own company and had "the bug" (35\% of total interviewees) were more likely to have envisioned leadership for themselves while growing up (30\% of them envisioned leadership compared to $10 \%$ of mission-driven founders), described themselves as being in their element in their current position, and expressed a desire to continue running companies going forward. Many of the women discussed how they found an unmet need in the marketplace that needed to be filled, felt passion for their work, and described how they would likely be running additional companies going forward:

I believe that I am so lucky to have this experience and if I don't give it my all then I will always regret it. This is my one shot. That said, I have a couple of other business ideas already for my next company. (Founder and CEO, Firm H6)

I'm an entrepreneur, I've had successful companies in the past. I'm currently in a position where I'm doing some consulting and also looking for my next thing that I would like to put a lot of my energy into. 
Until I find that, I split my time up between a lot of different startups in an advisory role. (Executive in Residence, Firm B10)

I (founded) a company in 1996, took it public in 2001, sold it in 2002, worked for the company that acquired it for about 18 months, and then retired. After a year of retirement I figured out that I wasn't very good at that. I was looking for a company to go work for and (found this one through) a friend of mine that had funded the company originally when it (needed a new CEO). (President and CEO, Firm H8)

Many women interviewed discussed starting their company because they had

found a market-based need or discovered a solution to an issue that they believed would only come to fruition if they took it forward. These women had a personal mission that drove them to start their businesses. Women that fell into this category in biotech were working on problems and issues such as blindness, Alzheimer's, strokes, brain diagnostics, and the growing of artificial tissues. Hi-tech business founders that were likewise categorized had business focuses on food allergies and environmental improvement. Women stated the following reasons for founding their companies.

I fell into it (being a CEO) because I got so excited about this back when I was in graduate school, to start the company, I was so excited about the technology. It's something I think a lot of founders fall into, because there's no one else to do the job, no one else as passionate as you. I just did it because there was no one else to do it. (CEO, Firm B2)

What we saw was an opportunity to take an expertise in a field that we've been working on and developing instrumentation for, and combined it with a biological application, to go after building a whole new world of therapeutics. It was just such a cool idea and we could see it was starting to bubble up. We were like, "Someone's going to do this company, we should do it!" That was how it got started. (Co-Founder and CEO, Firm B7)

I never thought I would do this, wasn't like I really want to look for a company to start. It was that I was working and am passionate about the science and the technology and if I didn't do it, nobody was going to. It was hard to envision it happening otherwise. That was the point that we 
were, like, this is really cool, this could have a huge impact on the world. (Learned that we can work to combat the leading cause of blindness in developing countries), and it was kind of this chilling thing, like, if I don't take it forward there's a possibility that nothing would ever happen here, and it's too cool to let just sit on the shelf. (Founder and CSO, Firm B9)

An interesting and unexpected finding in the interview responses was that some women who had founded companies and who were more mission driven had a lesser opinion of their counterparts who ran companies without having a personal mission. While this sentiment was not universal, it was repeatedly mentioned. Women who expressed this sentiment stated that they did not identify with the idea of running a company for the love of running a company, and that their personal mission helped inspire them to further succeed in their business venture. As stated by interviewees:

One of the things that I have found, some of the hype of Silicon Valley has attracts people that are real entrepreneurs that have visions and want to do great things. It also attracts a bunch of people that want to make a lot of money, and in some ways those people are looking for the opportunity that will allow them to make a lot of money versus having a vision. I think it is harder to stay through the challenges when you're just looking for an economic outcome. I believe its much easier when you have an idea of what you want to achieve and how you think you are going to change the world with your technology. My guess is if you could evaluate whether the founders were vision driven versus money driven, first and foremost, you would find that people who are ultimately really passionate about what they are building run the best companies. Of course they like economic outcomes but that is not the absolute first driver. (President, Firm H10)

I have friends who, on their Facebook profile or LinkedIn profile, say they're serial entrepreneurs [but] who really have never had any companies, or have had small ones and tried and done their thing. That's not who I am, or have sought out to be. (Founder and CEO, Firm H6)

The entrepreneur sort of glamour tends to attract people. You see people that go to startup events and are looking for an idea to help start, and that has never made sense to me. I think coming at it from the other direction where you have the data and you have the concept and it's the 
only way to get it done does tend to be a different motivator. It's hard to run a company. Nothing comes easy. I think that motivation is what helps to carry me. (Founder and CSO, B9)

Of the interviewee respondents that had not founded their company but had instead gotten to their position by moving up the corporate ladder, $100 \%$ had previous experience running other companies prior to their current position. As stated previously, $25 \%$ of all interviewees had gotten to their positions by ascending the ranks and moving up the corporate ladder. That number changes slightly by sector, with $30 \%$ moving up the corporate ladder amongst those in biotech and $20 \%$ moving up the corporate ladder amongst those in hi-tech. Of the woman that climbed up the career ladder, $70 \%$ had not had visions of themselves as leaders, and $30 \%$ had known they would lead, but not necessarily as a $\mathrm{C}$-suite executive.

\section{Factors that encouraged career ambitions and success in business ventures.}

Questions 2 and 4 aimed at finding the factors that helped inspire interviewees to leadership and to found their own company, if they had done so. The questions asked specifically, "Can you tell me a little about how you came to become [enter interviewee's job title]?" and "What are the critical opportunities/factors that lead you to being [enter interviewee's job title]?" The goal in asking these questions was to determine what the woman attributed her success to. Interviewee responses for these questions fell into one of two different categories, either experiential or innate factors. Experiential factors were events in the interviewee's life that encouraged her to strive for a professional career as a leader in either biotech or hi-tech, and typically involved role models, mentors, and the presence of a social network. Innate factors were qualities that had always motivated the 
interviewee and had been a part of her personality, such as ambition, tenacity, persistence, and a drive to make a meaningful contribution.

While a deep exploration of what truly makes a leader falls outside the scope of this thesis, some factors were mentioned repeatedly in the interviews. In looking at what the women business leaders attributed their success to, several reoccurring themes, both experiential and innate, became apparent. Many women expressed experiential influences, such as mentors (65\% of interviewees), a network (60\% of interviewees), and confidence that another person helped develop in them (20\% of interviewees). Many women also cited innate characteristics, such as a work ethic (100\% of interviewees), a desire to make a positive change (45\% of interviewees), and $100 \%$ felt they had personality characteristics that pushed them towards success, such as tenacity, resilience, focus, determination, self-knowledge, and awareness.

As stated, experiential factors were related to mentors, role models, and the availability of a beneficial network. Central to all of the experiential factors was a strong sense of self-knowledge and self-confidence. While self-confidence was not necessarily mentioned by name, it was often displayed and there were several occasions when the respondents cited a specific memory of how or when an individual had inspired them and instilled the belief that they could succeed in whatever they put their mind to.

There was an angel VC guy who believed in me for the first time. He told me that whatever I put my mind to, I could do. Something shifted in my brain when he said that. From then on I was like, maybe I could do this, and started dreaming about it, and thinking about it, and what it would take to do this. For me the challenge was definitely to dream bigger, not how to get it done. Once I started dreaming bigger, I found a way to get it done. (Co-Founder, Firm H7) 
Another (influencing factor) was having grown up with my dad being a serial entrepreneur himself. We grew up below the poverty line with my mom, but we would see my dad every other weekend but he was always doing some kind of software company. He had multiple companies, successful in his own right, but a different scale and a different way. He always gave me the vision and passion to believe in myself. He was always saying how great we were. Both of my parents gave us an unbelievable amount of love, and self-worth, and knowledge that we are awesome, and I guess my two brothers and I grew up to believe it as they are entrepreneurs, as well. (Founder and CEO, Firm H6)

Many interviewees also stressed the importance of mentors to provide guidance in

their current role. They always talked about their mentors positively, highlighting the

contributions made by these individuals in areas such as providing expertise and guidance, making important introductions, and developing long-term relationships that helped to inspire and guide the interviewee.

I think that one thing that has been very helpful has been surrounding myself with other female mentors. I have a lot of mentors, but the females are few and far between. But it's the females that have had the CEO positions, the leadership positions, that have helped a lot of reframing how I think about things. I've self-managed as a leader, and a lot of that inspiration has come from those women. They have lived it. (Co-Founder and CEO, Firm H1)

(One factor was) having really good managers that encourage you and provide guidance. I had a lot of that between the ages of 25-35. Those people had a big influence on my life. I still call them up and have relationships with all of them, all of my managers from those periods. One of them is even on my board now. So having good managers and the relationships you might have with those people, those relationships are huge as they share their experiences, provide coaching. You don't necessarily have to do exactly what they say, but its good info to have as you can make the best decisions you possibly can. (CEO and President, Firm H3)

I would say that identifying mentors and people that will help guide you (as a contributing factor), I think that is really important. It kind of goes back to this safe-house concept where it is someone that you can feel comfortable being vulnerable with, and telling them what you want 
and they are really going to be there to help you get those things. A lot of times your mentor is not your direct boss, as they have too much invested or they are too tied in with corporate goals or things like that. It is just so important to have mentors. I don't think it has to be a man or a woman, it just has to be somebody that you trust and who is doing something that you want to see yourself doing and is going to help you get there. I think mentorship is a huge part of being successful. I have mentors now and I mentor people. It's sort of this ongoing chain as you move forward. I think that's a big part of it. (Co-Founder and CEO, Firm B7)

The presence of both mentors and a beneficial network were mentioned several times throughout the interviews. While the terms are similar there is an important distinction between the two. Within the context of this study, a mentor refers to an individual that is familiar with the interviewee. They know her background and the goals that she is working towards and it is expected that the mentor will assist the mentee in reaching these goals. A networking contact is an individual with whom the interviewee has a connection — whether through a mutual friend, a group affiliation, or an alma mater - that allows for the exchanging of information without the expectation of future support going forward. Network contacts could be beneficial to the interviewee as a means of sharing knowledge and information about opportunities, such as open positions in companies or opportunities in the market; for introductions to other people within the social network that can be of assistance; or for support, in the form of money or advice. The interviewees mentioned the benefits of having a strong social and professional network on several occasions throughout the course of the interviews.

Having a really strong support network, which has got a lot more to do with luck than trying to build that. If you feel that you have people that are supporting you and that are behind you, and that your value isn't drawn from a single success or failure, but rather you have all of these people that love you and care about you and you place your own value on that 
than on single events, that will help you to take risks that you wouldn't otherwise take. (Co-Founder and CEO, Firm B7)

Started fiddling around with the idea of a startup. Luckily I knew someone that gave me some seed money. Had no idea what I was doing, was all alone. It was horrible. Made tons of mistakes. Eventually got some smart people to work on it with me, and things have been better and better since. (Founder and CEO, Firm H2)

That's how I got involved and our other cofounder, our CTO, he was one of my advisors' colleagues and was in the industry for about 10 years, and his site was getting shut down, so he was looking for a job, too. (Co-Founder and CEO, Firm B1)

(The company's) general approach for everything that we do is we automatically admit that we know nothing and we are building from the ground up. We will be learning and moving really quickly and having advisors and mentors that can help us through the process. The brunt of what we are doing is execution. (Co-Founder and CEO, Firm H5)

I would say that I had a very strong set of teachers who were open and great mentors, and a great strong community. I'm still tied in with those alumni networks pretty strongly, so it played a pretty big role. (CoFounder and CEO, Firm B7)

In addition to experiential factors, all of the women referred to innate factors that motivated them to push themselves professionally. As previously mentioned, this study does not intend to understand how leaders come into being or how the innate factors mentioned here come about; rather, it intends to report on their existence. The innate factors discussed varied among interviewees but there was reoccurring mention of qualities such as a desire to make a positive change in the world, personal drive, tenacity, a strong work ethic, adaptability, a long-term vision, and self-awareness. All of the women interviewed exhibited similar personality characteristics, and all appeared to have a strong work ethic, with many directly discussing topics such as tenacity, the importance of adaptability, self-awareness, and determination. 
Of all of the innate factors, the one that came up most often was tenacity. The women often used the word "tenacity" to describe themselves, and when the respondent didn't explicitly use the term, it was more often than not seen in her response, as were determination and drive.

If I were to say what the critical success factors are, one of the things that has helped me in all of my jobs is tenacity. Unrelenting. It can also be a negative. I think in all of my launches, it has won out for me. Very goal focused, but in a way that creates a wake. It isn't about talking about how hard we work, everybody gets tired, and it's about quietly delivering results and being unrelenting. I think that is one of the things that have served me well. (Co-Founder and President, Firm B5)

(To succeed) you just have to be unbelievably persistent and tenacious. Unbelievably. To win you have to just fail, fail, fail, fail. To get to yes, it has to be no, no, no, no. You have to have the confidence that you're on the right path, do it, and just be persistent. (Executive in Residence, Firm B10)

There are going to be so many obstacles and there are going to be a million things you can think of why not to start something and why you can't, but you have to focus on the success path and how you can. (CoFounder and CEO, Firm H1)

(Success) requires flexibility, tenacity, and the ability to sense shifts in the market, and to view your market, or those shifts in the market, as your real competition, versus looking at competitors as your competition. Because if you're really looking at those market transitions as your competition, you're really staying ahead of where you need to be in the competition from an actual competitor takes care of itself, so to speak. I think it's those things that you've got to be really good at to succeed. Especially when you're the smaller player and you've got larger players in the market that you're competing against. (CEO and Board Director, B6)

(Getting venture capital funding) is really hard. Think the first round I did, I got about 50 nos, fifty people told me no, they weren't going to give me any money. You have to have a strong sense of self to be able to take care of that much rejection. You need to have stamina and a little bit of stubbornness to not give up. It would have been easy to give up after the 10 th no, the 20 th no, the 30 th no, the 40 th no, or even the 49 th no, it 
would have been easy. I'm not a quitter and more than that, I am more stubborn than you would believe. That part was really hard. It was harder being a woman. (CEO, Firm B3)

The women interviewed all displayed a work ethic, drive, self-awareness of their personal strengths, dedication to their cause, enthusiasm about their work, and an ability to focus and accomplish tasks. Many of the women interviewed exhibited the ability to adapt, to learn from mistakes quickly and pivot to a different direction when necessary. Having a long-term vision, along with the ability to focus on it and take the steps necessary to realize it, were also often cited as factors essential for success. The following are some excerpts of what interviewees had to say on the topics of adaptability, self-awareness, and having a long-term vision for success. With regard to adaptability, one woman said:

Every day, you're going to have a series of successes; every day, you're going to have a series of failures. Some are going to be big, and some are going to be small. It's not so much the count of those as much as what it is you do when you succeed and what is it that you do when you fail, big and small. How quickly you can extract the value from a fail, which is higher than a value from a success, how to extract the value and move forward. I sort of focus on that. How quick can I take the vitamin context here and absorb that and get stronger and move forward. (Co-Founder and CEO, Firm H4)

With regard to self-awareness, one interviewee said:

I'm always of the mindset that, while this organization grows through all of these different growth stages, you always have to be really critical, not just of all of the members of your team but for yourself as well, to know, like, when should you, should step up and when should you step out of the way. (Co-Founder and CEO, Firm H1)

Regarding a long-term vision, two respondents said:

To me, there are things that you need to keep in mind. One is you have sort of an end goal in sight. That's your vision, and your company vision. You get up, you get out of bed every day and you put one foot in front of 
the other and focus on the issues that are right in front of you. There is a combination of being able to zoom out and see this thing that's motivating you, of where you want to get and what you are going to do now, in this moment, and for the next week, and for the next quarter. (President, Firm H10)

The other would believe a vision, way out ahead, and communicating that vision. If you don't make it visual for people, they don't get it. Constantly creating that and making it feel real long before its real is very important. Visualize things. That's a skill set. Entrepreneurial efforts take a long time. Visualizing things is not necessary if you can deliver a product in 90 days, but if it takes you years to deliver a product, keeping sustained interest is an important thing. Communication, tenacity, and having a vision are key elements to success. (Co-Founder and President, Firm B5)

Another factor that came up often was the respondent's desire to make a meaningful contribution to the world. Several of the women interviewed had previously worked with nonprofits, volunteered time to causes they found important, lived and volunteered abroad, and founded companies to make a positive impact on society. A drive to make a positive change can be seen in $65 \%$ of interview responses. A philanthropic drive and desire to make a contribution to the greater good can be seen in the following comments:

Before this company I wrote a business plan to start a charter. Thought I was going to do that, and I spent about 7-8 months thinking that that was where I was going. I've always been a big believer in bringing together atrisk kids with more affluent children; I think it's good for both parties. Then I started working with an nonprofit organization that educates girls in developing countries. When I met the executive producer I was just floored by the impact and what they could do and so I thought, instead of giving my time to my school, I'll give it to this nonprofit right now, and learn how to create a charity, create an NGO, and do that by helping someone else's organization, rather than starting my own. (Founder and CEO, Firm H6)

If you want to do something to impact the world, wealth creation is more powerful, job creation is more powerful, than any of the things that I 
saw the volunteer or NGO-type organizations doing. (President, Firm H10)

I've always been driven for unmet medical need, and a passion for making a difference and making an impact. Also, there's this very practical side of me that wants to make a difference. Then, within a period of several years after finishing my $\mathrm{PhD}$, both of my parents passed away close together. Sort of tragic the way it played out, relatively young. So it made a big impression on me. Kind of like, hey, wait a minute. It was one of those moments in your life, where you're like, wait, what am I doing? Maybe I should be using this expertise I've developed to do something directly to help patients. (Executive in Residence, B10)

The comments above suggest the interviewees thought beyond just themselves and had larger goals of making a positive impact on the world. In fact, many of the companies were founded with the goal of helping people, by helping to cure blindness or Alzheimer's, for example, or enabling people with food allergies to eat without fear of their food, improving medical testing, or making life easier through technology.

\section{Influence of university and education on career.}

The study looked at the influence of education on the interviewees' careers, and it did so by asking interview question 5: "What about education and professional experiences, how did those attributes contribute to you being [enter interviewee's job title]?" The interviewees were an educated group of women. All had at least a bachelor's degree, and many had master's degrees, MBAs, and PhDs and had worked in postdoctoral research positions. The respondents credited their education for their success in many different ways and to different extents. Several said their firms were a product of a class project or a university program and that they had advisory members on their company boards who were still tied to the university and provided ongoing access to 
university resources. Many interviewees also reported that their firms had participated in business accelerators or incubators, many of which were connected to a university.

The education analysis revealed an interesting disparity: the women in biotech held more advanced degrees than the women in hi-tech. All of the women had earned at least a bachelor's degree and 65\% had obtained an advanced degree (a master's degree or higher), but the breakdown by sector was interesting. Ninety percent of 10 women interviewed in biotech held advanced degrees and they had collectively earned two MBAs, three master's degrees (in disciplines other than business administration), five PhDs, and two postdoctoral fellowships; what's more, some respondents held more than one advanced degree. On the hi-tech side, however, only $40 \%$ of women held advanced degrees and they had collectively earned only three MBAs. In addition, three respondents had dropped out of college during the pursuit of an advanced degree (see Table 3 in the appendix). A degree and its corresponding scientific knowledge seem more important in biotech than hi-tech. The leaders of three biotech startups stated the following:

I got a lot of advice that I needed to go back and get a PHD to get a technical job. In our field, in life sciences, a lot of people told me that you need the title to be taken seriously in a meeting, and I think especially as a woman. I'm very glad I did a PhD now. Looking back, the advice I was given was correct. To be somebody, to be in the types of roles I want to be in, in my career, having a $\mathrm{PhD}$ is critical. (Co-Founder and CEO, Firm B1)

I am running a biotech company, so having that bio background is really important. Half of my job is making sure that the direction of what's happening in the science makes sense. I couldn't do that without that background and education. (Co-Founder and CEO, Firm B7)

I think there are a lot of people in the biotech field that started out on the business side, thinking that it's really going to be straightforward to find some technology and push it forward and make a lot of money. There is so much more to it. Not really understanding the technology is a big 
problem. I have a $\mathrm{PhD}$ in biochemistry and have used that at numerous companies and been able to use biochemistry in biotech. It was critical. While I don't have an MBA, that type of information or experiences that you get in an MBA, you can actually get that from other people. I hired a $\mathrm{CFO}$ that had that experience. The real technical background that you get from the $\mathrm{PhD}$, that really is the critical element. (CSO and President, Firm B4)

While all interviewees were very well educated, they had varying opinions on how and how much their education had benefited their careers. Over all, $85 \%$ of respondents credited their education with having a positive impact on their career, but whereas $100 \%$ of interviewees in biotech connected their success to their education, only $70 \%$ in hi-tech made the same connection. Interestingly, this difference in how much the women in the two sectors attributed their career success to their education seems to positively correspond roughly to the difference in the levels of education among the women in the two sectors: the women in biotech had a greater number of advanced degrees than the women in hi-tech and they gave more credit for their success to those degrees. Some respondents claimed their education had directly benefited them, for example, through what they had been taught or through connections they had made with university faculty and others, or because their company had spun off directly from the university; other respondents cited more indirect factors, such as learning to think critically or to look at the bigger picture; a third set of respondents did not see how their education had benefited their career at all. Women who thought their education had been beneficial to their career made the following observations:

Without question (my education was helpful). I had an excellent education abroad at an all-girls boarding school. I was brainwashed, as I was very heavily educated. I think it made a huge difference. The most useful thing 
I learned was public speaking and I write very well. (CEO and President, Firm H8)

I came back and went to (a prestigious private East Coast University) for my MBA. A professor there talked to me. I told him that I was really interested in trying to build a company, but had zero ideas. Knew I could build something, though, and get a lot of stuff done. Interestingly, there were these two guys that he was the advisor for that were phenomenally smart and could invent and build anything but they can't operationalize. He suggested we meet, so we did and hit it off and then a couple months later they told me I had to drop out of school. I finished my first year of business school and I've been on indefinite leave ever since. (Co-Founder and CEO, Firm H5)

They helped tremendously. I think the network that I got and the number of inspirational people I met. (Co-Founder, Firm H7)

When I got to CA, (a major IT company) was growing really fast, doubling year over year in size, and there were about 2,000 people when I joined the company. They were interviewing a lot of people, and had criteria for getting a job there. One of the criteria that made it easier to get a job there was having gone to one of 15 universities. I happened to go to one of these universities and that allowed me to get a job there. (CEO and President, Firm H3)

Found my education as a good foundation for how to go about learning, how to think about critical factors, how to be curious, but I am not a strong believer that education necessarily is indicative of success in a field. This might be counter view. It's really about broadening your mind and opening yourself up to experiences. I have an undergraduate degree in chemistry, which I think taught me a lot about critical thinking. It set a nice foundation for my ability to make decisions. That has been extremely helpful. I also think that my education opened my eyes to bigger opportunities in the world. (CEO and Board Director, Firm B6)

I always went to small schools, and small programs. Makes you feel like you have a support network and are a part of a community that is supporting you. I would say I had a very strong set of teachers who were open and great mentors, and a great strong community. I'm still tied in with those alumni networks pretty strongly, so it played a pretty big role. (Co-Founder and CEO, Firm B7) 
While the majority of the women interviewed believed that their education had had a positive influence on their careers, some women did not attribute any of their professional success to their education, as can be seen in the following comments:

My major had absolutely nothing to do with what I do now. (Founder and CEO, Firm H6)

I wouldn't say any academic training prepared me to be a CEO. It's all been on-the-job training and stepping up to what needs to be done. (CEO, Firm B2)

I don't know that it did, honestly. In a way there was no direct relationship between what I went to school for and anything that happened afterward in my life. I don't know how it helped me. I liked school for the studying and it is the process of growing up, process of figuring out whether you do or don't want to work hard and whether you do or don't want the benefits of hard work. (Co-Founder and CEO, Firm H4)

With respect to the role of university and the opportunities that it gave the interviewees, $50 \%$ of the firms interviewed were created and spun out of the respondent's alma mater. That number varied by sector, with $60 \%$ of firms in biotech being spun out of university and $40 \%$ in hi-tech. In most cases, the company was spun off through a faculty member that the respondent was studying under. The faculty member recognized a viable business idea and laid the groundwork for the creation of a company, which the faculty member then typically advised from a seat on the board of directors. Having the faculty member on board could benefit the newly founded company by giving the company access to university resources, such as grant funding, a knowledge base, and a talented labor pool. Many companies were started as a result of the faculty advisor pulling together a group of students from their network to create the company.

Sometimes the best way to transfer technology (out of the university) is to transfer people, usually some of the more senior people that stay in the 
university, like the professors that come up with the ideas to start companies. (Executive in Residence, Firm B10)

I founded the company with my graduate school advisor with some research I was doing in grad school. So I've been working on the scientific basis of this company for seven years now, and the company for the last year and a half. When we incorporated, it was just my co-founder and I. He's still a professor at my alma mater. (Founder and CSO, Firm B9)

When you think of biotech efforts launching companies from academia, I would say it's really important what going on inside that academia. It's a really entrepreneurially focused academia in that it's one that really understands licensing of technology to the inventors. And not every school is the same. Stanford and MIT are pretty much the only schools to get it right and everyone else it trying to catch up. I think that's very, very, very, very important. (Co-Founder, B8)

Some of the companies were founded through a university offering, such as a course or program aimed at entrepreneurship. There are several courses at universities that provide mentors and a network to entrepreneurially minded students, and help the students take their ideas from concept to funded startup. Respondents that participated in these programs cited positive outcomes, such as the formation of a business, being able to secure funding for their ventures, and being able to recruit a team from the talent resources available to them.

Been working together with my cofounders for about two and a half years, and this is our fourth idea. We worked on a bunch of different things together. We started in a class in an entrepreneurial program at (a prestigious private West Coast University). Most of the company was built because we lived off of student loans. We built our company while we were in business school. That was fun. We raised 50k from these angels (tied into the program) that liked our app and wanted to have fun with it. When we were about to graduate, they gave us 250k because they believed in us. It was easy to raise money. Our first round took us less than a week from us thinking we should raise money to having a term sheet for us to sign. The second time it was our current investors [who] came to us and said, we want to fund you, and we said, ok, great! We spent very little time fundraising. (Co-Founder, Firm H7) 
We decided to submit an application to a translational research initiative program through a West Coast State University, where they set you up with a number of advisors and consultants and there's an opportunity to get a small amount of grant funding to work on translational stuff. We used that program as an opportunity to pressure-test the idea, going out to venture capitalists, going out to experienced business people, showing them our data, pitch deck and asking if it looked like a startup to them, and had this overwhelmingly positive response. There are a number of these (programs) that are meant to do exactly this. You take an idea from an academic lab and intellectual property from the university and see if you can make that jump into becoming a company. That was really great. I went through that program, and pitched at the end of the program to an audience of all investors and advisors that were involved in the program. From the program, we actually met two people who were not involved in advising us in the process but were just sitting in the audience when I gave the pitch. One has come on as a chair of the board of directors and been a mentor to me and gotten super-involved. That started it all I guess. (CSO and Founder, Firm B9)

We've pulled together an early team as it was a project out of the (university), their entrepreneurial program, and we took it as a sign, and all agreed as a team that coming out of, that if it was commercially feasible, I would take it and go ahead and launch. All of the rest of these people on my team were younger and needed to go off and get jobs that paid. (Co-Founder and President, Firm B5)

Another surprising result that came out of the interviews was the number of companies that were a part of a business accelerator or incubator. A total of 35\% of the companies interviewed were a part of, or had participated in, either an accelerator or an incubator. The number of firms with a link to an incubator or accelerator varied between the sectors, with $50 \%$ of biotech companies interviewed and $20 \%$ of hi-tech companies interviewed being connected to an incubator or accelerator at some point. The disparity of participation in accelerator and incubator programs between the sectors was interesting, as biotech had a much higher participation rate in accelerator and incubator programs. Also of interest were the rates of participation in the two types of programs: 
hi-tech participated only in accelerators, whereas $75 \%$ of relevant biotech companies participating in incubators.

While the terms "accelerator" and "incubator" can be a bit vague and are at time used interchangeably, there are distinctions that separate the two. Both accelerators and incubators can be independent or sponsored by a university, major corporation, government entity, venture capital firm, or other funding source. Accelerators tend to focus on businesses that are already more developed by entering them into a structured program that "accelerates" the business to the next level. They often attempt to get a business to two years of growth within only two months, with an office space, access to startup guidance through a network of mentors and beneficial contacts, and the first round of seed funding. In exchange for these services, the accelerator often takes equity in the company, typically 7-15\% ownership. As the CEO and co-founder of a Bay Area biotech startup in an accelerator states:

(Going through an Accelerator tied to a prestigious West Coast University) if you're in it, (the University) will invest in your company, like an index of affiliated founders, which is a fantastic investment on their behalf! Because you think about all of the startups tied to this University, some of them won't work out but the ones that do, it's a great idea. It's basically young companies that they give office space, a lot of mentorship, access to their network of advisors, and its general idea sharing and help and support for young companies. (Co-Founder and CEO, Firm B1)

Incubators focus on companies that are at an earlier stage in the business formation process and tend to be less formal. Companies that are accepted into the incubator typically move into a large co-working space and pay rent for access to utilities. As stated by the founder of a company located in a Bay Area biotech incubator: 
In our case, this is what's called a no-strings-attached model or openinnovation model. So there's no equity stake, the incubators are our landlord. That's it. We have a clear lease relationship. We're renting space and access to equipment from them. They have no right to invest in the company; we've given no equity in the company. It's important to maintain your independence; you don't want to be tied to a group as an early-stage company. So it's a good thing for us, in that we have exposure. They know of us. They get a first look at our technology, so if we want to reach out to them, we already have a relationship with them. But we're not seen as contaminated. So when it comes time to actually do partnerships or think about selling the company, we don't already have an existing relationship (Founder and CSO, Firm B9)

\section{Venture capital funding experience.}

Question 6 looked at the interviewees' experience with funding their ventures.

Interviewees were asked how they had secured financing to run their businesses, with the question, "Can you tell me a little about your experience to funding sources that allowed you to launch this firm, such as venture capital, angel funding, bank loans, or family or personal savings?" In the discussions about funding sources, the interviewees mentioned self-financing, bootstrapping, taking out loans from family and friends, and obtaining venture capital. When discussing venture capital, they talked about the positive aspects of venture capitalists, the challenges they faced securing venture capital, and changing attitudes among investors.

All of the women interviewed had gone through the process of obtaining venture funding and had secured venture capital at some point during their careers. Many of the women interviewed-30\% of the 10 hi-tech interviewees and $40 \%$ of the 10 biotech interviewees, for an average of $35 \%$ of respondents — had made multiple attempts at securing venture capital. Many women discussed using the bootstrapping method, or relying on their personal savings, credit card debt, loans from friends and family, and 
formal sources of private equity (Freear, Sohl, and Wetzel, 1995.) A total of 30\% of interviewees (10\% in biotech and 50\% in hi-tech) discussed bootstrapping in the initial phases of their company, and a total of $20 \%$ described using loans from friends and family as a financing mechanism (20\% in both hi-tech and biotech.) A recurring theme throughout interviews was the difficulty of being limited in funding and making decisions with funds as a limited resource. The answers below describe the challenges of starting a company with limiting funds:

If you looked in the dictionary, under bootstrapped, you'd see my picture. I've bootstrapped this company for about 10 years now. All friends and family funded, grants from the state as well as government funds. Only in the last couple months was the last real venture funding that I've risen. It took about 10 years before I actually got some venture funding. (President and CSO, B4)

We have no money. One of our cofounders still lives in my garage as it was a way to save money. (To be successful in starting a company,) you need to be able to say, I want to build a successful company and that is the most important thing in my life for the next few years. That means it is your priority. (Co-Founder, Firm H7)

The real hardship is you have to constantly make decisions on what you are going to spend your limited resources on, and you can't make a mistake, unfortunately, because that could put you out of business, and very quickly. The hardship is living on a minimum amount of money and still trying to move forward. (CSO and President, Firm B4)

(To start our company,) we sold a house and had some money. We bootstrapped initially because when we were starting, we were focused. We were a small technology startup; we didn't have anything, just had an idea, frankly. (President, Firm H10)

Perspectives regarding the ease of attaining venture capital differed between interviewees that were located within and outside the Silicon Valley or Boston area industry hubs. Geography was often cited as a factor in the types of venture capital that 
were available and how easy it was to secure the capital. Women who had companies in Silicon Valley describe the process of meeting with investors until finding a good fit and securing funding. As previously mentioned in responses on the importance of education, two interviewees discussed the benefits of attending a university program within the Silicon Valley or Boston hub and how that helped in accessing funding. As stated by a co-founder of a hi-tech company in the Bay Area:

We raised 50k from these angels (tied to university) that liked our app and wanted to have fun with it. When we were about to graduate, they gave us $250 \mathrm{k}$ because they believed in us. Then it was really easy to raise money. The second time (raising funds) it was literally on a Friday, I had emailed this guy about an event. He said, oh, I work for this VC, do you want to meet with my partner? Went the next day and the guy said I want to give you a million in the meeting. We went to dinner (a couple days later), and at the end of that dinner, they had an analyst come and give us a term sheet, which we signed the next morning. It was a Friday-to-Thursday thing. (Co-Founder, H7)

While the above is an extreme example of the ease of raising venture capital from within a hi-tech or biotech hub, companies outside a hub often cited geography as a major challenge to obtaining financing. Both of the interviewed companies that were located outside of a hi-tech or biotech hub mentioned the challenges of their geography:

There was a reporter that wants to do an interview on the number of Maryland biotech companies, as I'm still in Maryland at the moment. I'm trying to move and expand the company to California. The reporter called me - the founder and CEO — a survivor. It wasn't in a good light; it's not the way you should do it. It's too slow and arduous a process. You're constantly looking for money just to do the next step, the next study. I wouldn't suggest anyone run a company it this way. Maryland was a great place, and the environment for biotech has just kind of gone away. You need the funds and you need the investors. There really are very few biotech investors here, and almost no VC funding at all. I have to move to CA. The choice is either Boston or CA. (President and CSO, Firm B4) 
(Obtaining venture capital) is a real challenge; there was the challenge that the whole country faced, the 2008 recession. There are also challenges related to the geography that we're in. Life science hubs are in Silicon Valley, in San Diego, and in Boston. Everybody else is flyover state. Being in those hubs has its own set of challenges. But our challenge has been launching a life sciences company when you're not in a hub. That one is extreme difficulty. You have good angels here that are good for one round of funding. We don't have a lot of the same high net worth people that are good for multiple rounds. We have people that like investing in life science and like investing in early stage as it's more of an affinity investment. When you're a flyover state, you have to move beyond and into the hub. With this round, I've spent a lot of time outside of Arizona. Very difficult to get in as it's kind of a good ol' boys network, and everybody sticks together for the right reasons. When you're out of it, and on the outside looking in, it makes it a bit more difficult. We always need money; you never have enough money. (Co-Founder and President, Firm B5)

Interviewees that obtained venture capital mentioned several benefits of the venture-capital relationship besides funding, such as market insights and guidance. The investors can also make important additions to an entrepreneur's business network and act as an ambassador on behalf of the company founder. A total of $35 \%$ of interviewees ( $20 \%$ of hi-tech and $50 \%$ of biotech) mentioned positive, company-advancing interactions with venture capitalists, and $30 \%$ of interviewees ( $40 \%$ of biotech respondents, $20 \%$ of hi-tech respondents) gave specific examples of how venture capitalists had benefited the company.

I knew angel investors, people who had started companies. So, I said, I'm going to write a business plan, could somebody give me feedback? So I sent out my business plan, and people said, not only is it a business plan, it looks really good! Let me get you some introductions. (CEO, Firm B2)

We met the chair of the board, who put the first seed money in through this catalyst program. Met through a pitch event at a West Coast University. He's very involved in the UC system, ex-venture capitalist, exbiotech management person, veteran in the biotech industry; he's been around since the early days in biotech. Knows a lot of people. Really 
smart strategist when it comes to building companies. Got him informally involved as an advisor to this company, helping me out in the early days. And when we incorporated, brought him on formally. He's the chair of the board of directors. He put the first money in. (Founder and CSO, Firm B9)

I have had a pretty positive [experience] with my investors around the fact that one of the venture firms I have in has done a lot of investing backing women CEOs. That's been very positive. (CEO and Board Director, Firm B6)

While having access to venture capitalists and the opportunities they provide is beneficial, the majority of interviewees stressed the difficulty of securing venture capital funding. Obtaining funding is challenging, particularly for women, and it was the most often cited challenge for an entrepreneur trying to grow a business. Possible reasons why it is harder for women to obtain funding were discussed, along with the specific challenges faced by women when pitching for funding. A change in attitude in the investor community was also discussed.

All of the women interviewed discussed the challenges of signing a deal for venture capital, many stating that obtaining venture capital is the most difficult part of their job. Several women acknowledged the overall difficulty of getting venture capital regardless of gender. Women typically cited having roughly 50-60 meetings with venture capitalists before coming to an agreement with one firm. They also mentioned the need they often felt to get a concrete answer from an investor so as not to waste time pursuing an unlikely deal. Another concept that was mentioned repeatedly throughout the interviews was the idea of a power play when it came to signing on with a venture capital firm: the more reputable the firm that the entrepreneur signs her deal with, the more legitimacy the entrepreneur and her venture gets on the market. 
At the end of the day I was able to get funding, and not a lot of people are able to do that. It was bloody and I don't relish doing that again. It's the world we are in and we did it and I'm really proud of that. (Co-Founder and CEO, Firm B7)

Raising the other financing has been the worst thing I have ever gone through, ever. We raised a series $\mathrm{A}$, and then a series A extension. I pitched probably $150 \mathrm{VCs}$. It's horrible. It is so time consuming, they drag you along, they ask you a million questions, they say no, they say no rudely, they just stop responding to you-it's is just a miserable way to spend your time. (Co-Founder and CEO, Firm H2)

While it is true that obtaining venture capital funding is difficult regardless of gender, the fact remains that a disproportionately larger number of men get funding than women. In discussions about the potential causes of the disparity, two common themes emerged. Many interviews mentioned "pattern recognition" and a "tribal" way of investing on the part of the venture capitalists. They also mentioned the pipeline problem of not as many women applying for or being employed within venture capital, the inability of women to have both a family and a career as an entrepreneur, and male venture capitalists not wanting to invest in a woman for fear of legal retaliation if things don't work out.

Thirty percent of women interviewed cited pattern recognition as one of the main reasons that women are not getting equal amounts of venture capital funding (30\% of respondents in both hi-tech and biotech). In this context, pattern recognition refers to a venture capitalist seeking commonalities between past high-performing entrepreneurs and current entrepreneurs seeking funding. As the majority of high-performing entrepreneurs are men, women do not fit the desired pattern. This adherence to a pattern was a source of frustration for interview participants, who saw it as unfair and unfounded. 
Being a woman (leader) is actually very hard. If you ask a venture capitalist to draw a CEO and give them a paper and pen, they would never ever draw a woman. That's the way it works. They will tell you that they work by pattern recognition, that they see a pattern that they have seen work in the past, and that they are trying to find the same pattern again. You can ask all of them, it's not a secret, and they are open about it. It is kind of ironic because they are supposed to fund innovative companies. The process that they use is not innovative at all. As far as the pattern in funding a woman CEO and being successful, they've never done it. That's why for them it's a huge step to have a woman CEO because they've never seen it successfully. (CEO, Firm B3)

It is a very strange situation where if you don't look the part, if you don't look like what they expect you to look like, it can be really tough. I assume it's the same if you are an African American male. You just have to have very thick skin and say I'm going to do what I'm going to do; I'm going to build my company and serve my customers. (CEO and President, Firm H8)

Venture capitalists in Silicon Valley take less risk with women leaders than male leaders. I have seen male leaders in our space be able to get a lot more money in greater-risk businesses than the women. That's not true in all cases; I'm making a general statement. (CEO and Board Director, Firm B6)

You go into those meetings, and right there, the very first impression is, "Oh, I've never seen this work." It's a much harder mountain to climb. I have had VCs tell it to me to my face, [that] they would fund the company if I step out to do a different role and put in a male CEO. Being a woman is a lot harder to raise money just because they have never seen it before. But if you're stubborn, and you push, you can do it. (CEO, Firm B3)

Another reason the interviewees gave for the lower numbers of women getting venture capital funding was the tendency among investors of like investing in like, which amounts to a tribal mentality. According to the interviewees, venture capitalists are more likely to invest alongside individuals that they can relate to and possibly network with through similar activities. Since most venture capitalists are white males, a tribal mentality will direct more funding to white male entrepreneurs. This explanation, or a 
variation of it, was cited by $35 \%$ of the interviewees (50\% of biotech and $20 \%$ of hi-tech respondents). Though it had been experienced by many respondents, the tendency toward tribal investing did not result in as much disapproval or angst as pattern-recognitionbased funding, as women seemed to understand the reasoning behind like investing in like, but it was also noted that what makes the tribal investing mentality so harmful to women is the fact that there are few women working within venture capital investing, making the "tribe" of women almost nonexistent.

You have a lot of money, who would you invest in? You would invest in people like you. That think like you, talk like you, maybe belong to the same sports club. I think women get left out there. We (women) are not in the same places that men are. It really is a difficult sale, unfortunately. (CSO and President, Firm B4)

My opinion is its all tribal. The guys are in one tribe, the ladies are in another, and the tribes don't cross over. People like to hire people like themselves, and that's natural. Especially venture investors. When they invest in a company, they are not just giving the money and walking away. They are investing in a relationship with that CEO. They have to talk to them, take their phone calls, hear all of their problems; it's a 5-10 year relationship. Not a short-term thing, it's a long-term thing. Especially the early-stage investors. So, that's, in my point of view, that's why these investors are not investing as much in women. So, if we don't have more women in venture, we won't have any change. We need more women in venture to get more women entrepreneurs funded and more women considered for these higher-level jobs and more things will change. (CEO and President, Firm H3)

I was raising money last year, trying to do a small add-on round, and I was talking to a VC, who led a later stage fund. They invited me to their networking event. It was at the Rosewood Hotel, downstairs, for Monday-night football. There are probably 150 people in the room mingling around with their cocktails, and there were no women. No women. None. There wasn't even a waitress in the room. The only woman I saw was the young twenty-something on the front desk giving out badges. I walked through, and thought, this is insane. I don't know if it is because of the kind of fund that it was, or because the networking event was Monday-night football, but I walked through and spent five minutes 
and I walked out and thought, "I don't need this, I just don't need this." I have a thousand stories like that. (CEO and President, Firm H8)

Other potential reasons why women get funded at different rates than men were discussed. One explanation was that women pitch differently than men, and that male investors typically do not know how to interpret the differences in pitching style and, therefore, are less likely to invest in women. Another explanation was the fear among male investors of legal retaliation from women if an investment deal didn't work out.

When I pitch, I only pitch what I know I can do. I realize that when males pitch, they embellish five times, ten times, to the venture capitalists. The venture capitalists then discount, they take the number and divide it by five because they know of this embellishment. They know that people do that. As a woman, if you just promise what you know you can do, and you don't embellish - these are cultural differences that make it harder to change. You have to embellish or acknowledge that you are not embellishing. There is an extra layer of education that you have to do in your pitch. The male CEO is more aggressive than women are used to doing. I think that discourages a lot of women from even trying to get in. If they get in, it makes it harder to be successful. It's a tough point. It's how you are trained to behave, either by nature or by nurture. (CEO, Firm B3)

When it comes to funding, I think the other thing is (venture capitalists) are not as accustomed to the way women lead and the way we compete. Leading and competing looks different between genders. (CoFounder and President, Firm B5)

I think kids are a big reason. You see a drop off of women in the workforce, and then women aren't in the position to make it to the top, and then if you look at the investors, a lot of them are successful operators who have sold their company and then switched to the operating or investing side. That's a very typical VC, and there just hasn't been that many women who have done that. So, then, its male dominated. It is what it is. (Founder and CEO, Firm H6)

I had a male VC tell me he would never hire a women CEO, that his firm would never fund or hire a female CEO. The reason was that you do fire CEO's quite a lot, and he said, "If we hired a woman and had to fire her, she'd file for sexual harassment and we'd have to give her stock 
and that would dilute us so we just don't hire women." True story. Three years ago. I responded and said, "I would never sue! My career would be over! I might get angry, but I wouldn't sue." But they had a policy. An unwritten, unspoken policy. (President and CEO, Firm H8)

In addition to sharing their thoughts on potential causes for the lower number of women entrepreneurs obtaining funding, the women interviewees also shared experiences of sexism and gender discrimination when applying for venture capital. Specifically, $75 \%$ of women interviewed shared stories of encounters with these issues, or $80 \%$ in biotech and $70 \%$ of hi-tech. Not all women cited experiences of sexism, but several stated that while they were lucky they had not come into direct contact with it, they knew of several women that had. The most commonly mentioned example of gender discrimination while obtaining venture capital was the women entrepreneur being told that she needed to have a man in the room in order to successfully pitch and get a venture capital deal. Also discussed were changing attitudes among venture capitalists regarding sexism and gender discrimination.

As stated above, $75 \%$ of women respondents mentioned directly experiencing gender discrimination as a women entrepreneur looking for funding. Some of the women who had not directly experienced discrimination said the following:

In terms of the old boys club, I have been really lucky. I haven't really encountered that. Certainly I've encountered sexist individuals. I've also encountered racist individuals, and people who are ignorant and stupid. In terms of feeling like there is a barrier or a wall that's been created that I can't tap into, I haven't really experienced that. I've been lucky. I also think that in California we have less of that, but I don't know. Certainly women have gone up against it and it is out there, I just don't have any personal stories about it. I'm lucky. (Co-Founder and CEO, Firm B7) 
Generally I've had a really positive experience with fundraising, I cannot say that has been consistent among a lot of other female CEOs and founders that I've chatted with. (Co-Founder and CEO, Firm H1)

I haven't (had issues with venture capital and gender-based discrimination). That being said, it doesn't mean it's not a reality. I think it's a mixture of, I've been lucky, and I tend to be very impervious. I don't know if that is what people want to hear but I know there are people who don't necessarily agree with me and don't want to believe that. I think it's different if you are a sole female founder and think I might have had a different experience with that. (Co-Founder, Firm H7)

The above comments show that though not all of the women interviewed had directly experienced gender-based discrimination, they admit that it is an issue that women entrepreneurs face. Of the women that did share their experiences, stories ranged from getting asked out on dates to being asked about future family plans, to not being recognized as the $\mathrm{CEO}$, and to being asked to step down and let a man fill the CEO role in order to secure a funding deal.

I was recently married (when I went into venture capital funding meetings). In the time between unmarried to engaged, having an engagement ring was a game changer in how people treated me and then having a wedding ring. It opens up a whole other ballpark of questions that people ask you. They don't want to invest in someone who is recently married and is going to have kids. They don't want a CEO who is going to get pregnant. I definitely had conversations about that with investors; they wanted to know my family plans. They didn't ask my male cofounder, of course. (Co-Founder and CEO, Firm B1)

As a CEO, I'm sitting down with some investment bankers, interviewing them to take my company public; 50 million in revenue, profitable, growing. One of the investment bankers had not done his homework on the company and while coming into the room, knocked over a coke. I was walking into the room and he said, "Sweetie, could you clean that up for me?" ...I was the CEO. (CEO and President, Firm H8)

My two cofounders are male, I had meetings where they would ask the questions to the guys, who look at me because I am the CEO and I have the answer. I would answer, and then the VC would ask the next 
question to the guys, and, you know, we would have this weird way of asking questions. (CEO, Firm B3)

I was the CEO. I was being interviewed by the editor in chief for a financial paper, I was there with my technical lead, he was an Asian man, and he and I had agreed that I would answer the strategy questions and he would answer the technology questions. The editor in chief asks a question, I answer, he looks a little irritated, he asks a second question, I answer, and he goes, "I don't think you understand, we're here to talk to the executive." I literally have a thousand stories like that. (CEO and President, Firm H8)

Sometimes, some of the VCs can be outright sexist, who will tell our advisor after we've pitched, "We're not going to invest in something that's run by a little girl." That's only happened twice, and it's actually better because then you know. It's better to know why. Like, if they tell you, "Your revenues aren't strong enough," or "We don't [think] your business model is quite there," but really, it's about you, that's very difficult because you don't know if the feedback is something that you should be taking to heart or not. So, I prefer the overtly sexist people to those that are secretly sexist or, worst of all, people who think that they aren't being sexist but really are. (Founder and CEO, Firm H2)

The most often cited example of gender-based discrimination was the woman entrepreneur being told that she needed to have a man present in the room while pitching to venture capitalists to have legitimacy and be taken seriously. Twenty percent of all women interviewed experienced gender-based discrimination in this way. They were advised by friends, company advisors, and even venture capitalists themselves to have a male in the room. Often, this occurred on its own, as many women entrepreneurs had a male co-founder; however, the difficulty, redundancy, and logistic hassles of making sure the male co-founder attended pitches were repeatedly mentioned.

When we were just starting, my team and I would all go to meetings and that was such a drain on emotional and all resources, for time and everything else, and I knew that a lot of CEO's bring everyone else once they got to certain stages. You know, it's the CEO who goes out and raises money and everything else. So I said, "Fine, it's just going to be me, I 
don't want to burn a bunch of product time having my cofounders come." I went to a bunch of meetings in California last year, and met with two female venture people and a male venture person. They asked if they could give me some honest feedback, to which I agreed. They said, "You're not going to want to hear this, but (and they said this independently and not together), you should have your cofounder come with you, it will give you instant credibility. They won't say anything, but you have to have a guy in the room with you, else, you're not going to raise money as a solo female trying to do venture stuff." My response was pretty much, are you fucking kidding me, this is the dumbest thing I have ever heard. (Co-Founder and CEO, Firm H5)

It used to be all three of us going to fundraising meetings and now it's just me. Over the last six months, however, I've gotten feedback that as a female founder and CEO it's actually beneficial for me to bring a male cofounder with me to investor pitches, so now we are back to me oscillating between the two of them when we go to raise money. We sort of work on a really high level of trust and most of the decisions come back to me, but I definitely lead the forefront on sales, marketing, cash, money, all that stuff. (Co-Founder and CEO, Firm H5)

I had two very close friends advise me that it would be very challenging to raise without having my cofounder in the room while having those discussions. I'd planned to have him in there anyways, but they told me if you're trying to sell these investors on this pretty hi-tech startup as someone who has no technical background and someone who is, I hate to say it, a woman, it's all pattern recognition for these guys and there aren't a lot of women they've built patterns on. (President, Firm H1)

My cofounder would go to most of the meetings. But let's say there was another company and they were both guys, like, it's not always typical to bring your cofounder and CTO to the pitch meetings. Eventually they will meet, for diligence, or whatever, but it's not necessary (to bring him initially) I would say. Coming right out of academia, it was definitely a slap in the face that this is how the real world works. I think it is very challenging for a woman to walk in and get venture funded unassisted. (Co-Founder and CEO, B1)

Finally, a change in the landscape of venture capital was discussed, in particular by women entrepreneurs who had been successful more than once in securing venture capital. According to respondents, older venture capitalist much more readily recognize 
what it takes to run a business, whereas their younger counterparts are less respectful of the entrepreneur and the effort that goes into leading a firm. Of the women interviewed, $45 \%$ had raised multiple rounds of venture capital and of those, $22 \%$ cited a change in the attitudes of venture capitalists. Also discussed was the increase in the number of women venture capitalists and executives.

My experience is that the old school VCs, the guys who have been around since the early to mid-1980s, are a lot more respectful. They are kinder, more respectful, a lot less attitude, a lot less of the sense of selfentitlement, self-worth that I see in a lot of the new VCs. Of course that's a blanket statement and it's not true across the board. There's a class of VCs, the older ones, they've been doing it a long time and they know how hard building companies is as they've seen it for a long time. They are really, really helpful to the entrepreneur. There is a class of newer VCs who have gotten rich quick, they might have gotten lucky at Google, or lucky at somewhere, they are much more judgmental of the entrepreneurs. I see it coaching young CEOs too. I see what they are dealing with in some of these VCs. I often look across the room and think, "These VCs have no idea how hard it is to build a company. No idea." So, I'm probably aging myself, but I see a big difference in the VCs and their attitudes. This can be seen in a lack of respect and appreciation for what it takes to build a company. Disrespecting the CEO, telling the CEO what to do, micromanaging the CEO. My experience with the older school of VCs is very much sort of elder statesman, more "Tell me what you are trying to achieve, and let me figure out how to help you achieve that." Instead of the "Let me sit and critique you and how you're doing it." I'm very fortunate that I have an old school VC. In my experience in trying to raise money I have met an awful lot of VCs that I would not want in my company. (CEO and President, Firm H8)

So this is the third company that I've run. The first one I raised 41 million, the second one I raised 18 million, and this one I've raised 5 million. This has been over a long time, not a short amount of time. The first one was, like, 19 years ago. What I've found in the financing situation is that women has not improved in two decades, I actually think it's gotten worse, not better. I've raised a lot of money, right- 55 million in the past two decades; this time I've found it more difficult. It's odd, and I think it is dismaying. The investors who funded this company were both investors of my prior company, so getting that initial funding was not difficult from them. In my effort to raise that and add additional investors into the mix, I 
find that the climate has decayed over ten years and not improved over ten years. I find that dismaying actually. It's interesting; the "hoodie" thing was there a decade ago. There's an arrogance with it that wasn't there before. There was always the money and the gender politicking, and there was a gender tone that was more based on innuendo and a come-on. Now it is disdain or being an asshole. It's a little weird. I think there is more arrogance in the Valley now than there has ever been. And there has always been plenty. (Co-Founder and CEO, Firm H4)

I mean, I hope there is momentum (in addressing the issue of the gender gap), but frankly, I have been in the field for 15 years, and I don't see much difference. There may be a small uptick. But I still go to meetings, and its $90 \%$ men in their black suits, and I don't see that big of a shift. (CEO, Firm B2)

So it's a challenging environment as far as being a woman. It is a little bit different as there are more women in venture capital, and in biotech venture capital. I know those numbers are also pretty meager, but at least I'm encountering more of them. (The woman VC I met) decided not to invest but she would just offer me advice and phone calls and I feel like there is a bit more community in that sense that I can tap into, with other women leaders, whether they are VCs or executives. So that's really nice. (CEO, Firm B2)

\section{Potential setbacks and perseverance.}

The goal of this portion of the study was to review challenges faced by the interviewees as woman leaders and how the women overcome them, both as leaders in general and as women leaders in particular. This part of the study looked at challenges of being in a position of leadership, experiences of failure in business and professional endeavors, and how to recover from and move past failure. These issues were the focus of interview questions 7 and 8, but they were explored at other points of the interviews, as well. Question 7, which began with a statement, was as follows: "Silicon Valley has been described as a bit of a boys club, with a fraternizing culture with an exclusionary attitude towards women in a male dominated industry. How did you find this proposed 
culture of Silicon Valley to support the establishment and growth of the venture you lead?" Question 8, which alluded to the same theme, was "Many ventures have gone through hardship, if not failure before they eventually succeed. Can you say that you have experienced this, whether with this venture or other ventures? If so, what were critical elements/factors that you embraced to succeed?" Trouble raising financing was the most cited obstacle, which was discussed at length in the previous study section. Other challenges mentioned were a lack of personal life, feeling alone in the company vision, the desire to be their true authentic selves in a position of leadership, and facing genderbased discrimination in the workplace, from a non-venture capital perspective. The interviewees explained that they had faced and overcome failures by, among other things, learning from failures, focusing and working toward problem solutions, and easily being able to pivot and shift approaches when necessary.

Regardless of gender, being in a position of leadership is challenging. For many of the women interviewed, being a company founder and leader was their first professional position, making the position all the more difficult. Women that had held the position in other companies stated that the position became easier over time. In either event, most interviewees cited that entrepreneurism is not for the faint of heart:

If you are going to start a company and run a company, you are going to have to be prepared for it. It's an extreme sport. It's not a casual, not simple recreation. It's the equivalent of heli-skiing. The chances that you might get hurt or injured or die are real. (Co-Founder and CEO, Firm H4)

Every day (running a company) there is something that you think might potentially derail and the deltas between the highs and the lows are so intense that if you don't manage that piece of it properly, absorbing those shocks, then it's not for you. (Co-Founder and CEO, Firm H1) 
This is the second biotech business. Feel a lot better prepared to do it this time around. Also have fewer questions about my capabilities to do it personally. Internally, I feel more confident. I also have a very good network now, so fundraising, and getting those meetings, the course of those meetings, is a lot more predictable as people can trust that I know what I'm doing. (CEO, Firm B2)

Specific difficulties of being a leader were discussed and interviewees mentioned feelings of loneliness in their leadership position, the struggle to remain authentic when others look to you for guidance, and the challenge of having a vision in the midst of the uncertainty of a new venture. While the interviewees repeatedly stated the need for a vision throughout the interviews, women also cited challenges in finding and holding onto that vision, sometimes seemingly by themselves, and trying to sell that vision to others. Related to these feelings of loneliness was a struggle to bring their authentic selves to work when leading a team, further increasing feelings of isolation.

Being the CEO is lonely, being one of the few women business owners in IT is lonely. So you have to be independent, and you also you have to have an unshakeable confidence so that you can deflect some of the messages of discouragement. (Executive in Residence, Firm B10)

That's a long, hard process, especially in the early stages of a company in entrepreneurship, that's a bit lonely. You're isolated in what you can imagine, the outcomes you want to see, and there's a shortage of evidence that other followers would want to see. I think that is one of the most challenging parts of the journey, is believing alone. It's really easy to believe when a million people believe the same thing as you. It's really hard to believe when three people do, especially to sustain that belief and continue driving [for additional believers]. I think for growing, that's one of the most challenging things for leaders, entrepreneurs, and cofounders need to do. (Co-Founder and CEO, Firm H4)

One of the biggest challenges to starting a company is the vast unknown. When you first start something, you don't know what you're going to do, and it's all there for you to choose. Every choice you make is setting a stone on a path. When you're in a more established company, you know what product you're making, as does everyone else, so your 
choices seem less heavy. I would say that's the biggest challenge. Being comfortable with that unknown, and being able to integrate new information and be comfortable with changing courses frequently is one of the biggest challenges. If you have a personality that doesn't like that, or finds that uncomfortable, that's going to make it a lot harder to move forward. (Co-Founder and CEO, Firm B7)

I sometimes feel as if I'm not myself. That was a hard transition. I really feel as though it's important for everyone to bring his or her authentic self to work. But, now having this bigger team, it is definitely a different way in which I manage myself than when I was at previous jobs. Used to be, when I had a hard day, feeling a little off or a little stressed or whatever, I could have a quiet day on my own in my little cube and recoup and not want to engage and I had control over that. But here, you don't have that control. You have to always be on. I think that is the responsibility of a leader. (Co-Founder and CEO, H1)

Another issue that was often discussed was a lack of work-life balance. Getting a company started and subsequently growing a business places huge demands on those who embark on the path, sometimes at the expense of having a personal life. Difficulty managing the pressures of their professional and personal lives was the second most cited challenge faced by the women interviewees. Though they did not do so negatively, several women described the sacrifices they have made in their personal lives for their companies. They said:

Being a founder is really hard. I don't have a personal life; it is very hard to date. I think there is probably something like-I don't know how many people are willing to make that sacrifice. You need to be able to make a lot of sacrifices for the company. Last night, at $10 \mathrm{pm}$, everyone had gone home, except the four of us cofounders. Many nights are the same; the three or four of us are always there really late. We don't really put that much effort into our personal lives. (Co-Founder, Firm H7)

I am very tired, all the time. I have gotten a lot of grey hairs. I have aged 15 years in one year. I've gained a lot of weight. All of those things are true. But, on the flip side, I've been able to balance. I do work out almost every single day and I try to go to bed early. I will be here for 12 hours. I'll get here early and leave at 7 or 8 , but I go straight to bed. Like, I 
go home and don't do anything but go straight to bed. So I have lacked having a life through the process, which is something I'm trying to work on. I'm working on that, getting out and socializing again. I used to be a very social person. (Co-Founder and CEO, Firm H6)

Many gender-specific challenges were discussed, as well. The main challenge

they mentioned was not being taken seriously as a leader because of pattern recognition and preconceived notions of what a leader looks like. Though pattern recognition as it relates to venture capitalists has already been discussed in detail, it is worth noting that pattern recognition affects women leaders in many, often obscure ways. Women mentioned having their roles confused by people in all professional ranks, and being treated differently than their male counterparts. Many interviewees also reported their sense that the landscape is changing favorably for women in the workplace as a whole.

If you stood outside of Whole Foods in Palo Alto and you held up a picture of me and you held up a picture of some of my male colleagues and you asked who has the $\mathrm{PhD}$ in materials in chemical engineering, who would they choose? Women do it, too. It's unconscious, it's not like people are sitting there saying that I don't want this poor young woman to reach her ultimate potential in the scientific field. It's this sort of expectation, that people look at me and they expect one thing, and they look at a man and expect something else. (Executive in Residence, Firm B10)

Once in a while it is obvious that someone, like I said, is confused by me. I'll hear, 'Well, you're really competent, but I don't know, there's something holding us back." You then think, maybe it's my gender. (CEO, Firm B2)

It's me and the chair of the company that do the strategic work. He is an established venture capitalist who is handling the legal and financial stuff with the company, and I'm running the company and overseeing all of the science. When we go have meetings I'll run them, he is there for backup in a lot of ways, and to mentor me. However, a lot of times, the power dynamic is assumed to be the opposite. I oftentimes get requests for scheduling saying, "please see when he's available." I'll respond with, "Let me forward this to him, he manages his schedule." There's 
oftentimes like that kind of thing, but I don't care. Often times it comes from the female administrator from the other side. It's totally harmless, and it's because of pattern recognition. (Founder and CSO, Firm B9)

Another issue that was often discussed was the difficulty women experience in rising to a leadership position in the STEM fields because of the discouragement that comes from others. As discussed in the literature review, many women feel pushed out of STEM fields at many points in their lives. This often leads them to abandon their STEM pursuits, which in turn contributes to the pipeline issue. It has been reported that women feel pushed and/or talked out of careers in STEM, and that the pressure on them starts as early as junior high and continues up through university and into the workplace. Women interviewed cited experiences of sexism, being discouraged from pursuing a career in STEM because they were women, and their concern for the pressures currently being placed on young women.

I had (discouraging messages from) high school math teachers, messages started then. It was myself and this other student, a young guy, we were constantly competing, and the teacher, a man, would always say, "Oh, soand-so, he's really smart, and she, well she works really hard." I must have been instilled genetically or had conferred some confidence to say, "Well, no, I don't think I work any harder than him, and that's not right." I was more of a number in a large public university. I could take tests and be two standard deviations above the mean. They didn't see what I looked like, and they didn't know if I was male or female. It helped me to stay under the radar. As soon as I started talking about, I want to go on, I want to pursue something more, there was pushback from some of the more conservative professors. I've had a boss tell me once that no women should make more than $75 \%$ of the man. What are we supposed to do with that? This was my boss, but I went to a better school, I had a better background, I worked for it. Someone once wrote on my performance review that only if I have children, maybe I could be a better manager, seriously. (Executive in Residence, Firm B10)

I feel like the issue of women in tech is being much more acknowledged, but I am worried about what's happening in schools. With 
women dropping out of tech. Really concerning as technical skills are so important for the future now. Wealth is going to accumulate to the people who have technical skills. This applies to people of any gender or race. So, if a particular demographic and particular sub group is getting pushed out, they are being pushed out of future wealth. Then it becomes a selfperpetuating thing. I think it is really worrying. The dearth of women and African Americans in tech is just appalling. (CEO and President, Firm H8)

In addition to discussing the challenges they faced, the women interviewed also

discussed failures and how they overcame them. Many women discussed failures that they had gone through in the past and how learning from those experiences enabled them to be where they are today. The ability to focus and work determinedly through problems was repeatedly mentioned as a way to overcome failure, as was the ability to pivot and pursue other options. The women discussed addressing failures head on and recognizing mistakes and changing their course when possible.

I learned a huge amount (from my previous company's demise) and it set me up to do this much more effectively than if I hadn't. (Co-Founder and CEO, Firm B1)

Ran my previous company when I was 28 . The technology was extremely hard to control, we sold it as we failed to control it, and the next people that bought it failed to control it, and my investors really didn't get a win out of it. That was rough, and probably played into me not wanting to jump into anything for a long time, because it's a lot of stress to have other people's money in your hands and not be able to deliver. That's what you have to accept when you start a company. Like, this can fail. The more out of the box, the more rogue way of thinking that you're doing something, the more likely it is to fail. I took ten years to do something a little different where I didn't have to take any investor money. (CEO, Firm B2)

We failed in many things. Our first product line failed. Totally failed, so we expanded our vision to something more important, which is what we do now, which was always the bigger picture. We wanted to raise a series B six months ago, which failed. I feel like my life is a constant series of failures and just enough successes to stay alive, which is sort of what the startup is. (Founder and CEO, Firm H2) 
(In my previous company) the board told inexperienced CEOs, like myself, told them to grow as fast as you can. These types of CEOs didn't know how to read balance sheets. You had a lot of CEOs who were stupid and didn't know how to run a company, with the board saying to run as fast as you can. You ran yourself into the ground basically. That was a really big learning experience for me and I will never do that again. It was very painful to hire and fire 100 people. Really hard. Not doing that ever again. I knew I had made several mistakes but then my mistakes were paled against some other companies' failures. The way I look at it, my 15 million was way less than some other companies, literally billions of dollars. That was how I took comfort in that. Many key learning's in that experience. This company probably would have failed if I hadn't had that experience. This company is now more on track because of that failure. (President and CEO), Firm H3)

The need to pivot is so critical. We started as a life technology and demonstrated why it wasn't going to work to be commercially feasible, but because we suffered for a while, we developed our own technology. The bad news is it cost us time and money; the good news is that it's our own IP. Everybody's got pivots. We had more than one pivot. That was a technology pivot. There are business model pivots. There's so much you don't know. Nothing has been proved. Technology hasn't proven itself; the market hasn't proven itself, the business model hasn't proven itself. Each one offers opportunities for multiple errors, but you have to try them. Everything is new compared to an established business. There is more of an opportunity for failure. (Co-Founder and President, Firm B5)

There's a lot of ways something can't happen and a few ways it can. I wake up every day mitigating risk and thinking how can we shift ourselves on that path of this is happening. And it is happening! (CoFounder, Firm H1)

\section{Benefits and refocusing the conversation.}

In spite of the aforementioned challenges, the interviewees repeatedly stated that

they did not focus on being a minority within a business world of predominately male leaders. In fact, interviewees repeatedly stressed the importance of shifting the conversation from a negative dialogue into a more positive one. Women were adamant about the need to re-appropriate the conversation and change the underlying tone. 
Interviewees also mentioned several benefits of being a woman leader in hi-tech and biotech, in particular the advantage it gives them in recruiting other women to their teams, additional opportunities for presentations and publicity, and greater memorability after presentations and public appearances with no special effort.

All women interviewed acknowledged that they were a part of a minority group as leaders in hi-tech and biotech. Interestingly, while all women knew they were a part of a minority, several women stated that they did not focus on it. Women stated that they did not use being a woman as an excuse not to succeed or as a point to focus on. Two even mentioned how representing an under-represented group was a driver that pushed them forward.

I don't think of myself as a woman as much. I think of myself as a founder and developer, I don't think I'm different as a woman. Maybe that would change if I was married and had a kid or was at a different stage in my life. I know it's hard. I don't think it's hard just for women, I think it's hard for guys too. (Co-Founder, Firm H7)

I do not focus on gender bias or gender differences in my day to day. I really think leadership is about common vision and motivating people and challenging people to be curious. You can do that as male or female. I don't look at it as much as boys vs. girls. At the end of the day, I think it's about vision and curiosity and that is what helps create the level playing field. Women need to get out of their own way on this topic and not make it so much about the gender difference, and make it more about what are they bringing forward and not being shy about letting the world know what they are bringing forward. (Co-Founder and President, Firm B5)

I definitely think about the fact that I am a women but I don't like to overly rotate on it. Yes, I'm the only woman in this room. But I don't want it to be an excuse for anything. I saw Condoleezza Rice speak, she was awesome, she said, "not only was I a woman, I was a black woman, and I had to be twice as good. I just had to, in order to be considered on par with anyone." I like that mentality. You just have to be that good. I'm so motivated to succeed because I want it to succeed and I want people to 
know that women can lead organizations and succeed. I would like the success to speak for itself. (Co-Founder and CEO, Firm H1)

With regard to not focusing on being a minority, women also stressed the importance of reshaping the conversation of women leaders into a more positive dialogue. Instead of a negative discussion about the lack of women in the industry sectors, the gender discrimination women face, or the lack of opportunities, the dialogue needs to have a more positive perspective, reflecting on how far women have come, on the strides they are making, and on the impacts they are making on their industries and elsewhere in the world. Thirty-five percent of women interviewed cited the need to reappropriate the conversation and make it more positive, and questioned the current trend of framing the topic in a negative light. Several women stated that they would continue on their career paths despite discouragement and that negative reports about the experiences of women in leadership roles often discouraged other women from aspiring to similar positions. Women interviewed had the following to say on the how dialogue should be shifted, and how things have changed;

I've read a lot of popular press articles about how Silicon Valley is not friendly towards women and the rates of financing are so much lower for women, and I always get a little frustrated because they are very negative, and it's not good to highlight the bias. That's not encouraging for those of us who are in the game, without giving us action items. It always makes it seem like such a bleak situation. For us, the data is the data. Maybe people have an initial reaction of surprise when I walk in the room, and sometimes I get mistaken for a secretary or whatever, but as soon as you see the data, it doesn't matter. It's frustrating to me to hear everything conflated and the fact that women entrepreneurs don't get funded. Maybe it's harder for me that I'm a woman and not a man? I'll never know. I'm going to do it anyway so it doesn't really matter. When I see all of this press that's so negative, it's just frustrating. It doesn't help me at all. (Founder and CSO, Firm B9) 
I think for women working in these spaces, I just think we should change the dialogue and make it more positive. A lot of it is about pattern recognition, just changing the pattern. It doesn't matter how hard it is, I'm going to do it anyway. It doesn't matter what comes your way you're going to figure it out how to make it happen regardless. (Founder and CEO, Firm H6)

There are definitely a lot of companies who raise money and waste it. Maybe it's easier to raise money as a guy, because VCs are guys. Raising money should never be a goal or an accomplishment. We will never celebrate raising money. Why would you celebrate giving up a piece of your company to someone? You should celebrate building something. We celebrate when we reach 1,000 integrations, or if a customer is really happy with us. Those are the things you should celebrate. Nothing about your gender has any impact on. Even if you build something really well, even if they discount you initially, people light up. It doesn't matter if you're a woman or not. If you build something meaningful that can make a change, people will listen to you. There are tons of examples of women-led companies who did that and that's where people should focus more. Not, oh, it's so much harder to raise money as a woman. Ok, so the guys who end up raising money just because they are guys usually end up not doing anything that great with it. There are women out there that do this, and they are my heroes. (Co-Founder, Firm $\mathrm{H} 7)$

The director of our accelerator recently dropped an interesting factoid to me. He's part of a VC firm that invests in early-stage biotech and health care companies. Twenty percent of the companies they invested in are led by female CEOs. Of those companies last year, apparently $100 \%$ of them had successful exits, either through an acquisition, a merger, an IPO, something that got them their money back. Every single one of them has hit. He was telling me, "If I'm going off of the math, I should only fund female run companies." (Co-Founder and CEO, Firm B7)

I think one of the things that has to change, and I think it's only changed in the last twelve months, is that you can now actually call it and say "that's bullshit." Before, women my age never did, because we knew we'd never work again, but wait, we have to work again, so we will just shut up. There's a huge shift to saying that out loud which is awesome. (Co-Founder and CEO, Firm H4)

It is important to acknowledge the recognition that women work and it is ok for women to work. I think that is really important. When I had my kids, you would've thought I had two heads because I was an 
executive working really hard. That is a generational shift. I still know men over 60 who still carry the prejudices of whether women should work or not. I was in a meeting about a year ago, and general counsel was pregnant, and an older gentleman asked what she was going to do after her baby was born. A 37 year old, or a 39 year old, would never say that now. That is a shift, and as that generation retires out of the work force, that prejudice will change. There are a lot more men who want to stay home and there are a lot more men who don't want to work so hard, or want to work but are ok being the secondary breadwinner not the primary, so that will create more opportunity for women. Now we just need to get the tech side solved. (CEO and President, Firm H8)

In addition to saying that it is necessary to reframe the discussion about women as entrepreneurs and leaders, several women also mentioned benefits of being a woman leader in hi-tech and biotech. They said it was easier for them to recruit additional women and thereby add diversity to their teams. As mentioned in the literature review, women-led companies tend to employ more women, and more often in higher rank positions, than male-led companies. As well, they mentioned that they could take advantage of affirmative action in the form of direct attempts to target the gender gap through funding and conference-presentation opportunities, and that while the affirmative action was not sought out by the women, it was not unbeneficial when it occurred. They also said that it was easier for them to be memorable within their sectors. As stated by the women interviewees:

I think it helped that our team had a woman. We may have gotten a bit more publicity because I am a woman, gotten a few more publications. (Co-Founder, Firm H7)

I would say for anyone who is a female founder it makes recruiting infinitely easier. We really think about a diversified team. We have five women on our team out of 11, which is not what I'd want it to be, because it's not half. (Co-Founder and CEO, Firm H5) 
We just got some new angel funding. It was one of these great meetings where in the meeting the guy says, "I'd like to write you a check for $\$ 350,000 "$ " but at the end says to me, "I like the fact that you're a woman, too." He said he had two daughters and wants them to have role models so I don't think it was affirmative action but there are people out there who, either gender, doesn't matter to them, or they are looking to help reduce the gender gap problem. Last night, I gave a talk at a very high-end dinner and there were three keynote speakers. Two of them were older white men. Then the organizer was actively looking for a woman to be a speaker. He was asking around and I ended up with a speaker spot. So, again, I don't particularly like the affirmative action angle, but I can't say that being a woman is always a disadvantage, because things like this happen. You're very memorable. People I talked to 10 years ago while doing my first company remember me still. (CEO, Firm B2)

The number of conferences where I'm the only woman speaking is very high. I think certain conference boards have been very proactive in trying to get woman speakers. It has a flipside benefit, as I'm more memorable, through no doing of my own. If anyone refers to me, they know exactly whom they're talking about. (Founder and CEO, Firm H2)

\section{Possible causes of low women representation and possible solutions.}

After describing the underrepresentation of women in leadership positions in hitech and biotech, the interviewees explored possible reasons for the disparity between the genders and what could be done to produce more women founders and leaders in the two industries. Many potential causes were discussed and two reoccurring explanations were (1) the inertia that follows the present domination of STEM by men and creates the pipeline problem, and (2) the difficulty of getting established in those industries as a minority gender. Other potential causes of the lower numbers of women business leaders in STEM were the difficulties of being both a mother and business leader; disinterest among women in being entrepreneurs because of their desire for balance in their lives; an overall difference in gender cultures, with men and women competing and seeking recognition differently; and a discomfort among women in competing with men in a 
male-dominated culture. Interestingly, while they acknowledged that there were far fewer women as leaders within their sectors, the women interviewees occasionally mentioned that they did not realize they were different or part of a minority until it was pointed out to them. Potential solutions were also discussed, namely, mentorship of young women, changes in the way women network, and the implementation of the Rooney Rule, or the mandatory interviewing of one minority candidate for vacant upperechelon management positions (Collins, 2007).

The most commonly cited reason for lower numbers of women as business leaders and entrepreneurs was the pipeline problem, which is the idea that there aren't enough qualified women to participate. As discussed in the literature review, the pipeline problem stipulates that the unequal ratio of men to women in STEM starts early, with a lack of girls interested in STEM fields in high school, fewer women interested in and pursuing the topic in university, and even fewer women wanting to go into STEM industries for their careers. Thirty-five percent of interviewees cited the pipeline problem as one of the causes of the lower representation of women in hi-tech and biotechnology. The interviewees also described how the pipeline problem makes it difficult even for women-founded and -run businesses to hire women, because of the low numbers of women applicants for technical positions.

It's a pretty small number (of women in leadership). I noticed it throughout my career. In my graduate program, we were 50/50 women and men. In my first job, there were almost more women than men, and as I've gone forward in my career, in time as well as maybe the track, I've noticed fewer and fewer women. When I started this company and we started talking to VCs, I definitely noticed it. (Co-Founder and CEO, Firm B7) 
It's very hard to change that now that those are the numbers. We need to change the numbers. We need more women to get into it, which will make it more acceptable. Changing the culture now is hard; need to change the perception earlier. I think it is a pipeline problem. (CoFounder, Firm H7)

I don't know if it is a pipeline issue, specifically for the case of biotech companies that are founded out of academic labs, for example. I think there are relatively equal numbers of grad students in the hard sciences now that are female. It is definitely field dependent in some of the quantitative sciences. It's still skewed more heavily towards men. It is my understanding that in recent decades, it's become much more equitable where $52 \%$ of biological chemistry PhDs are female. It's just that then, when you go on to post-docs and you go onto academic positions, it becomes disparate again. (Founder and CSO, Firm B9)

In the late 70 s, early 80 s, $40 \%$ of the computer science graduates were women, now its $17 \%$. I would say for a young woman wanting to be technical and code, when I came out of college, I was the only girl in the group of 50 engineers, but I never felt odd that I was a girl. No one ever said you couldn't write code because you're a girl. They might've said you shouldn't be working because you're a girl but not you can't write code. That I think has gotten worse. It is now the young men under 30 who write code. That whole stereotyping I think has gotten worse. (President and CEO, Firm H8)

There's just not that many women applicants. I have to push really hard to keep positions open long enough that we do get those women applicants, especially on the engineering side. I see it in the applicant pool. That's the other place where it is very apparent. (Founder and CEO, Firm $\mathrm{H} 2)$

We are trying to hire women. We only interviewed two women developers. It's not because we didn't take interviews. We just don't see resumes. We didn't hire them, because they sucked. We hired women on the marketing team, but the first hires were all guys because they were great. When we found women that were awesome, great. I don't think of gender too much. Maybe I should. Think the problem is a lot earlier on. More women should get into the field. I think it we made it more cool to be in tech, and to be a founder, more women would get in to it. (CoFounder, Firm H7)

It's definitely skewed to male ratio, and definitely at the more senior levels. Big companies have to make a real effort. It starts with girls in grade school and getting them interested. I think there is an interest. 
Now, I just think you need to make it a viable option for women, and a friendly one. I think you'll find more women are in an environment where they want a more nurturing, you know, fun and friendly, and not that its shying away from competition, but it's not we are going to drink all night, do this kind of stuff. I think women mature faster, and they are looking for a more mature organization. This may mean that the desire to be in startups is not as great. But I think there is definitely a need. (COO, Firm H9)

Another potential cause for the lower numbers of women in STEM that was often provided was the reality of women having to choose between being a mother and a business leader. Many of the women described the pressures of raising children and the feeling that it would be challenging, if not impossible, to successfully carry out both roles at the same time. Other women said that they were able to start a company when their children were older, hinting at the challenges of having both young children and a young company simultaneously.

I have made sacrifices. My brother and I fight about this all the time, I don't think you can have it all. As much as Sheryl (Sandberg) was saying you can. You do have to make sacrifices and choices. Some people are lucky to have it all because they have all of the resources and support around them. It's not realistic to think that you can. You have to be ready to make choices. I definitely want to have a family one day, but I think it would be really hard to think I could try to have one right now, to think I would be successful in this company and be successful at home. So, it's balance, and figuring out what's right for you. (Founder and CEO, Firm H6)

I feel this pressure right now: kids. I mean to start a family. If I were to do that, I couldn't even imagine if I were to do that right now. A lot of my friends are going through that right now and it's awesome to see but then when I think about myself, I could not do what I'm doing, in the position that I'm at and manage that. I don't think I could do that at this stage. So I think that family is a big part of that decision making process. (Co-Founder and CEO, Firm H1)

The age in which you are eligible to be a CEO, unless you are a child genius, is right around the age that maybe you have small children or kids or are thinking about starting a family. They need their mother, that's 
just the way kids are. I think that makes it hard to want to be a CEO or want to have a position of power and responsibility, moreover, where people are going to need you to maybe sacrifice some of those other things that are important to you. This isn't necessarily an appealing lifestyle to a lot of women. (Co-Founder and CEO, Firm B7)

The other often mentioned idea of why there are fewer women as business leaders is that the STEM sectors are overwhelmingly male, with an inertia that makes it difficult to get established professionally as a woman. The concept of different cultures within genders was mentioned throughout the interviews, as women compete differently than men, and also seek recognition in different forms than men do. Having a different culture and feeling like you don't fit in could be deterrents for many women trying to get established in a career.

It's just a question of numbers. When the numbers are 95 to 5, that's what happens. I don't think people are doing it on purpose, not shying away from it or confused about it, that's just the way it is, because the numbers are so imbalanced. (CEO, Firm B3)

I think that anytime you're a woman entering an overly male dominated industry, there's an energy barrier to jumping headfirst into that. It's a little uncomfortable. I think it takes a certain personality type to be ok with that and want to do it anyway. There's inertia against that when it is so overwhelmingly male dominated. (Founder and CSO, Firm B9) Interestingly, despite experiencing many gender-specific challenges and wondering about the lower numbers of women in leadership positions within their sectors, many of the women stated that they had been unaware for a long time of their minority status. Several women interviewees described growing up not realizing that women were not typically leaders, or believing that they were part of the boys' club and not feeling excluded. Many women described coming to the realization that they were part of a minority group and being surprised: 
I don't operate with a bias, I don't think about the bias. Growing up with three brothers, I always thought I was in the boys club. I just recently found out I'm not. It was a weird thing, this earlier version of it the bias wasn't as overt, and I thought less of it. Now, combined with the sort of billion-dollar huge rift, it's quite overt. Even though women are speaking up more, it strikes me that the boys club is more pronounced. And now, years and years after not thinking I couldn't be in the club, there is a little bit of a different view there which is a surprise. (CO-Founder and CEO, Firm H4)

My entire life, I've always been the woman minority. In middle school I used to go to math group in Europe and on our whole country team and I was always the only girl. In computer engineering, I think there were 5\% girls in my major, so I've always been the only girl. In consulting I didn't feel the only minority. I just don't see it. If people treat me different because I'm a woman, I would think, oh, they treat me different because I'm not a good enough developer. As a software developer there are very few women. I felt a lot of times, maybe it's because I'm foreign, or I have an accent, but I never really thought people were treating me different because I am a woman. (Co-Founder, Firm H7)

After reading the Babson study last summer, that's when I realized that I was a minority. I didn't realize, just thought I was normal. I don't think I'm alone in this. I think a lot of people are like me, thinking, "What? I don't get it." And then maybe they are shocked like I am, and come to the realization of, “Oh, I didn't realize I am a minority." I didn't know it. I don't know if that's a good thing or a bad thing, but I didn't know. Maybe I knew it but just ignored it. (President and CEO, Firm H3)

In discussing the disparity in the numbers of women in the C-suite in hi-tech and biotech, the women interviewees also discussed ways to close the gender gap and encourage more women to pursue leadership careers. Solutions included more mentoring of young women, changing the way women network professionally, and implementing the Rooney Rule during the hiring of company executives. Thirty percent of the interviewees commented on how the representation of women among leaders in hi-tech and biotech could be increased. Fifty percent identified mentoring young women as a solution, as mentors help to guide the careers of their mentees by showing through their 
own example what is possible and thereby helping their mentees to achieve their potential. Networking differently was mentioned by $60 \%$ of interviewees, since being unable to enter male dominated peer groups was the most frequently cited reason that women are not more equally represented in the upper echelons of businesses. Use of the Rooney Rule was mentioned as a solution as it would allow for interviews of qualified applicants that might not otherwise be considered. The Rooney Rule, which was first implemented in 2003 by the National Football League, requires that minority candidates be interviewed for upper echelon positions, but it does not stipulate a quota or preference for minority candidates in the actual hiring. Applied to positions of leadership, the Rooney Rule would allow for more women to be considered for positions, without demanding any affirmative action in the hiring decision. In other words, it would simply produce a more diverse pool of applicants to be considered for a position. The Rooney Rule has had success in the hiring of African American coaches in the NFL, which previously hired only white males for coaching positions. Women interviewed had the following comments on possible solutions to the gender gap in positions of leadership in STEM:

I think that women that are leaders need to be much more focused on seeing if they can mentor more women in this environment. I don't mean you bring someone into your specific organization as much as you're available for people to talk to, to provide insight to. I think that we are missing that. I know that I've had some outreach with people that are doing that and I've definitely helped a few, but there is not an organized way to do this, and I think that would be extremely helpful. The ones that could use your help are at a college, university level; when you're graduating, to say, let me be your mentor for the first year, let me help you. Let me check in with you on a monthly basis. I think that would be really interesting to do. (COO, Firm H9) 
Women tend to join women's groups for networking purposes, and I think that is the wrong approach. We get along fine with other women. It's the venture groups that are all men that we aren't getting into. I would say, less emphasis on the women's group, and more emphasis on groups that will help find us funds and getting involved in those. (CEO and President, Firm B4)

There is more of an opportunity for men to network. Certainly when I go to the various organizations there are women, but again, that is a minority. So, you can certainly begin to network with them, but I think we are reaching the wrong group. (COO, Firm H9)

I think the answer lies in getting more women on boards of companies. It happens to be one area where it's still fairly male. I think it's a way to really begin to drive that. I will tell you that I've always had 2-3 women on my own board and I think it is a really healthy thing for VCs to understand that when you're out getting an independent, it's not just diversity from an industry or operational perspective, but from a gender perspective as well. I think that is a really helpful thing. (Co-Founder and President, Firm B5)

We need more women in venture to get more women entrepreneurs funded and more women considered for these higher-level jobs and more things will change. I think it's all about consideration, not about achievement, as was seen with the Rooney Rule. After (the NFL) implemented it, three years later, there was a super bowl, with two African American coaches facing off on one another. It wasn't about performance; the African American coaches were just as good as the white coaches, and it was about access to the job. I think the same is true for women and jobs in Silicon Valley. (CEO and President, Firm H3)

\section{The importance of a company's geographic location.}

The location of a company relative to universities, venture capital, a talented labor

pool, and industry accelerators and incubators was another factor in the success of the women's business ventures, and questions 5, 6, and 7 examined the factor. The questions focused on education, funding, and the culture of Silicon Valley, a known hi-tech and biotech hub. Of the women interviewed, 16 had companies in the Silicon Valley area, and the remaining had firms in Arizona, Maryland, Boston, and New York. A total of 
$50 \%$ of all interviewees mentioned the importance of geography in some way during their interview (70\% of hi-tech and 30\% of biotech). Of the 4 companies not in the Silicon Valley industry hub, $75 \%$ mentioned the importance of their location. As previously discussed, geography played an important role in the presence of accelerators and incubators, resources that $40 \%$ of interviewees had taken advantage of.

Geography, and being located within a hub, in particular, was often brought up as it related to funding. The choice of whether to locate a company in an industry hub was often described as being the choice to have rich funding resources or none at all. A total of $25 \%$ of women interviewed (40\% in biotech and 10\% in hi-tech) discussed geography as it related to funding, as discussed previously on page 64 . One interview participant outside of the Silicon Valley hub was in the process of moving her company to the Bay Area in order to access the Bay Area funding opportunities. In their responses to questions 5-7, the interviewees described the implications of their choice to establish their firms inside or outside industry hubs, especially with respect to finding funding.

(On debating where to move to found her company) We were trying to do something that was pretty unique. It was a mix of hardware, consumer, and biotech, and I thought that the investor climate in the Bay Area would be more receptive of that than in Boston. Those were the two cities; I was thinking Boston or the Bay Area. Boston is great but in terms of the investor climate I think it's a little more conservative. I don't think the investors are as risk-taking or willing to take a bet. So, I though the investor climate was good. (Co-Founder and CEO, Firm H1)

An often-cited geographical factor was proximity to a university and the resources that it provides. A total of $25 \%$ of the women interviewed ( $40 \%$ of biotech respondents and $10 \%$ of hi-tech respondents) discussed how their proximity to a university benefited their business. For example, an entrepreneur who sets up their company near their own 
university is better able to maintain and leverage the network of students and faculty they created at the university, and this network can be advantageous during the start up and long afterward. Biotech respondents mentioned the benefits of being close to sources of innovation, as most of the biotech industry looks to universities to provide a research and analytic pipeline into new products. There was also a discussion of the changing innovation landscape, and how learning environments are shifting from being academic, university-based to being non-institutional or DIY, community-based bio labs, where anyone can go to learn about biology and biotechnology and apply what they learn as they see fit.

It was fortuitous that I got into school at (a prestigious private East Coast University). I got into a couple schools but I figured (this particular University) was going to be the pinnacle of innovation and intelligence, and I knew I was trying to meet smart people. We thought about moving the company to the Valley from Boston, and decided to stay for a couple of reasons. One reason is that we have a hardware product, and we feel like the ecosystem was definitely richer here than it was in CA. I think that living here, having access my alma mater community has been hugely beneficial. (Co-Founder and CEO, Firm H5)

I think it's going to be more interesting as biotech becomes less tied to academia. Biologists have started spaces meant for their community. No matter what your background, you can learn biology for whatever you wanted to do. These spaces are cropping up all over the country. Currently (venture capitalists) are buying their pipeline out of academia. Now, regular people are starting their own labs outside of academia. People are starting companies without any academic ties because you don't need a $\mathrm{PhD}$ to do five years of research. You can just fund it yourself. There are 12-year-old kids who are doing these equivalent of $\mathrm{PhD}$ courses, because they are taking classes with their grandparents after school. There are artists who are picking up trash off the street and sequencing the DNA and making a map based on what those people should look like based on their DNA. (Co-Founder, Firm B8) 
The talent pool was also discussed as a function of geography. Being located in a recognized sector hub puts a company in proximity to higher numbers of employees that work in the field. Of the women interviewed, $20 \%$ mentioned geography as it relates to talent, or $30 \%$ of women in biotech and $10 \%$ of women in hi-tech. Typically, women that were located in a recognized hub mentioned access to qualified people, at a higher premium of pay, whereas women located outside of a hub cited challenges of having a dearth of talent in their respective areas.

Talent is a challenge. We could always use more people but we can't afford more people. We have wonderful people, as we have a positive supply. At a certain point, though, I am going to have a need for positions that I won't have the talent for. That's a geography issue. Geography keeps coming up in this conversation. If you aren't in a hub, that is a challenge. I didn't experience that when I was in Chicago for most of my career. We have wonderful innovation out here but we don't represent the market. The university has great technology, but technology is different than sources to launch. (Co-Founder and President, Firm B5)

I think we are fortunate to have access to a lot of smart people. The resources in the area are great and biotech is a pretty small world, so people have worked together before. You find one person and they say, "You should really talk to this person." We've pretty quickly gotten to the best people, I think. When we run into an issue, I have all of these different minds working on the problem with me, we set up calls where everybody's on the line and we figure out how to work through stuff. (Founder and CSO, Firm B9)

One of the most commonly mentioned geographical factors in the discussions was the decision to locate a business within a hub. Many women discussed being in areas either rich in resources or void of them, and they generally agreed on the necessity of being located in a hub in order to be successful. As mentioned, $80 \%$ of the women interviewed had located their companies in Silicon Valley. Of the companies that were not located in the industry hub of Silicon Valley, two were located in industry hubs of 
Boston and New York, which have comparable access to industry-related resources, and one business was in the process of moving to California in order to be closer to the resources of one of the state's industry hubs. Women interviewees had the following to say about being located within a hub or outside of one:

(If we weren't in our current geography) I think it would've been so much harder. All of the people that are involved in the company are here. A lot of the key people we found through the Silicon Valley network. It's a hub. I think there are some cultural differences between the East Coast and West Coast. The real biotech hubs are San Diego, San Francisco, and Boston. We could've gone to Boston, but I think that the West Coast tends to favor youth and look kindly on youth. So for me personally, it has been a good fit for me to be out here. Just the formality of East Coast biotech tends to favor established veterans with track records who have done successful companies before or hire people out of upper levels of management in the industry. For me, I was a kid straight out of grad school with a dream. That's Silicon Valley. (Founder and CSO, Firm B9)

When I spoke to mentors at my alma mater, professors there, they said you either need to come back to Boston or go out to the Bay Area if you want to be in biotech. I was drawn to the Bay Area. Because of my background in engineering, I felt that at that time and now, there is more of a confluence of engineering, biology and medicine and sequencing: a lot of different opportunities. (Executive in Residence, Firm B10)

It also just made sense for us. As we've been so lean for so long, I think moving to CA would have been a catch 22. Your access to resources in infinitely higher, but your overhead is also infinitely higher. So that's sort of the tradeoff. There's probably a couple times a quarter where I'll think, "We should be in CA, this is stupid." But we would've died. There's no way we would have survived. The price competition for salaries and everything else that's out there. (Co-Founder and CEO, Firm H5)

The section above helps to demonstrate qualitatively the benefits of being located within hi-tech and biotechnology clusters when stating and growing female-led companies, but also the drawbacks. In an effort to gain a greater understanding of possible geographical relationships between female-led companies and attributes seen as 
foundational towards building a successful company, the next subsection shall discuss the quantitative portion of the study.

\section{Quantitative Portion: Data Analysis}

This section focuses on the quantitative portion of the study, namely, the exploratory data analysis that assessed the geographic distribution and spatial relationships within each of business numbers, university $R \& D$, and venture capital expenditures in biotech and hi-tech throughout the state of California, using data aggregated to the county level. As discussed in the data analysis methodology section, data were thematically mapped to review geographic distribution, followed by hot spot analysis to discern if geographic clustering behavior was present. The hot spot analysis returned results in a new feature class for each variable, which was mapped to determine if the null hypothesis that the data variable under study exhibits no hot spot spatial cluster patterns was accepted or rejected for each variable. If no hot spots were highlighted on a resultant map, this indicated that the null hypothesis was not rejected, that the data is randomly geographically distributed throughout the state, while a hot spot on the map indicates a rejection of the null hypothesis for the variable under study, showing similarity in some neighboring values and a non random geographic distribution at the county level throughout the state.

This data analysis is exploratory in nature. More detailed analysis beyond the scope of this thesis should more carefully consider distributional assumptions and examine associations between different variables, potentially at different spatial scales. Data were mapped by county throughout the state of California, with two regions 
repeatedly emerging as identified hot spots in the results, the San Francisco Bay Area and Southern California. The San Francisco Bay Area Region (Bay Area) is defined as the following nine counties: Alameda, Contra Costa, Marin, Napa, San Francisco, San Mateo, Santa Clara, Solano, and Sonoma. While population was not taken into account in this initial exploratory analysis of the data, it is worth noting that the Bay Area is home to 7 million people (Bay Area Census).

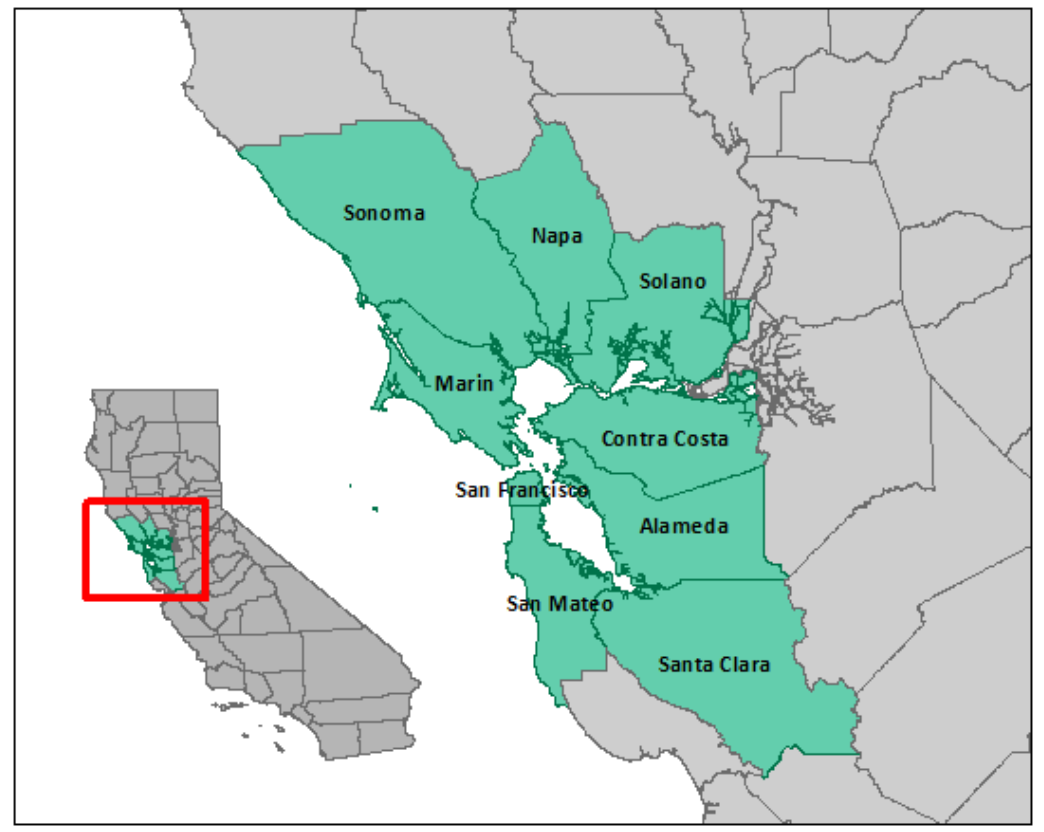

Figure 4. San Francisco Bay Area (Bay Area) Counties (Map Base Source: ArcMap 10.2.1, 2016)

The Southern California region is defined as the geographic region that comprises California's southernmost 10 counties: Imperial, Los Angeles, Orange, Riverside, San Bernardino, San Diego, Santa Barbara, and Ventura. Though not taken into account in the analysis, it is interesting to note that with 22 million people, this Southern California region houses $60 \%$ of California's population (Southern California, 2016). The rest of 
this section focuses on data analysis, through both thematic mapping and exploratory hot spot analysis of variables such as number of businesses (including percentage womenled), university R\&D expenditures, and venture capital expenditures (including percentages and expenditures going toward women-led businesses) in the fields of hi-tech and biotech.

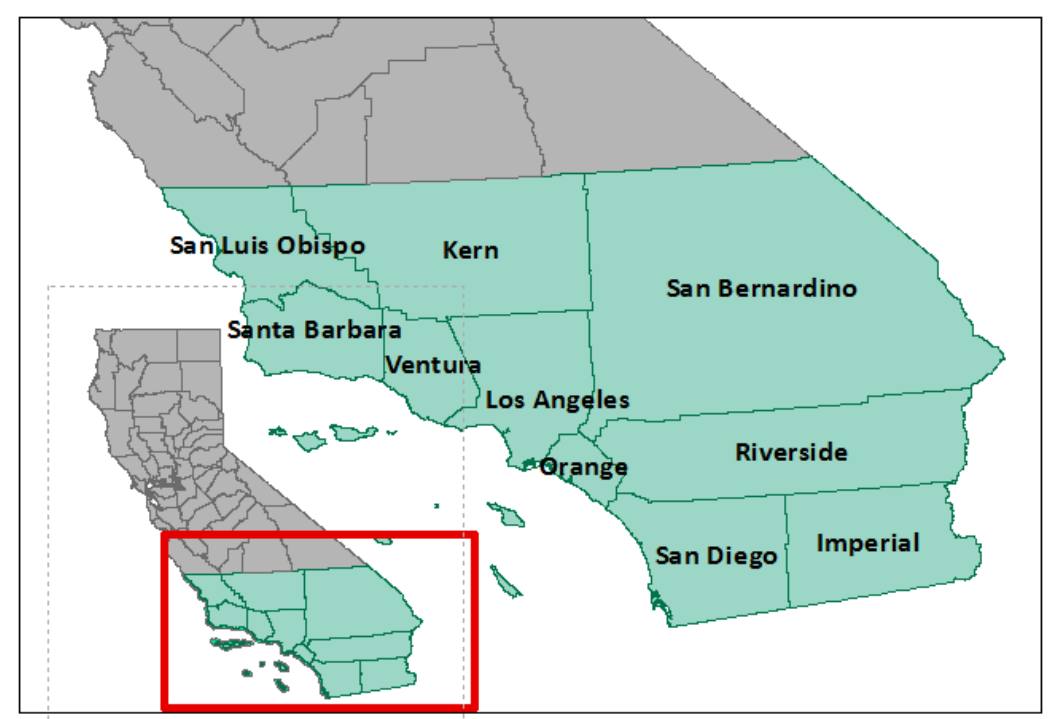

Figure 5. Southern California Region Counties (Map Base Source: ArcMap 10.2.1, 2016)

\section{Hi-Tech and Biotech Data.}

\section{Hi-Tech Businesses Throughout California.}

A total of 23,622 hi-tech companies were identified throughout California in February 2015. As can be observed in figure 6, these businesses are distributed throughout the state, with higher numbers of businesses observed in Southern California and the Bay Area regions. Geographically, hi-tech businesses are more widely distributed throughout the state than biotech businesses, with only one county having no 
hi-tech businesses. The highest numbers of hi-tech businesses per county were located in Los Angeles and Orange County, with 4,493 and 3,149 companies, respectively. It is surprising to see higher numbers of hi-tech businesses in the Southern California region, with 13,375 hi-tech businesses being located there, compared to 6,440 hi-tech businesses in the Bay Area, given the Bay Area's status as a world leader in hi-tech. One thing to note on the analysis is that the map is based on the number of companies by county, and is not a reflection of company size and revenue, which would likely yield very different results. Also to note is that the company counts are inclusive of sole proprietorships, which results in higher company numbers. The analysis also does not take into account population density, which again could impact exploratory analysis results. Cluster analysis, shown in figure 7, reflected the same observation made in the thematic map, that Southern California is a hotspot of the number of hi-tech counties. This provides evidence that biotech businesses are not randomly distributed across the state and exhibit spatial cluster patterns. 


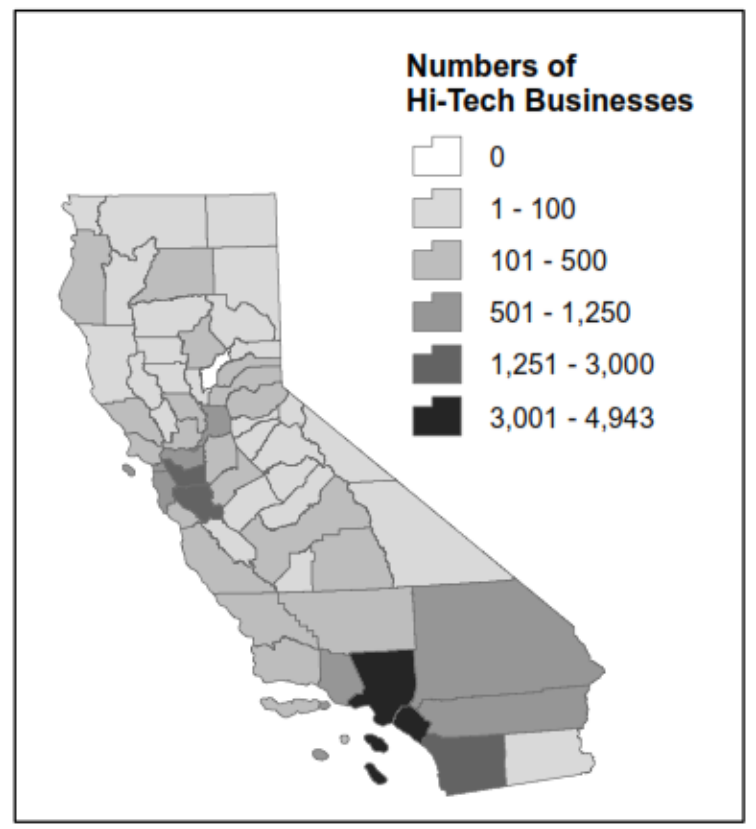

Figure 6. Number of Hi-Tech Businesses per California County

(Source: Reference USA, 2016) (Map Base Source: ArcMap 10.2.1, 2016)

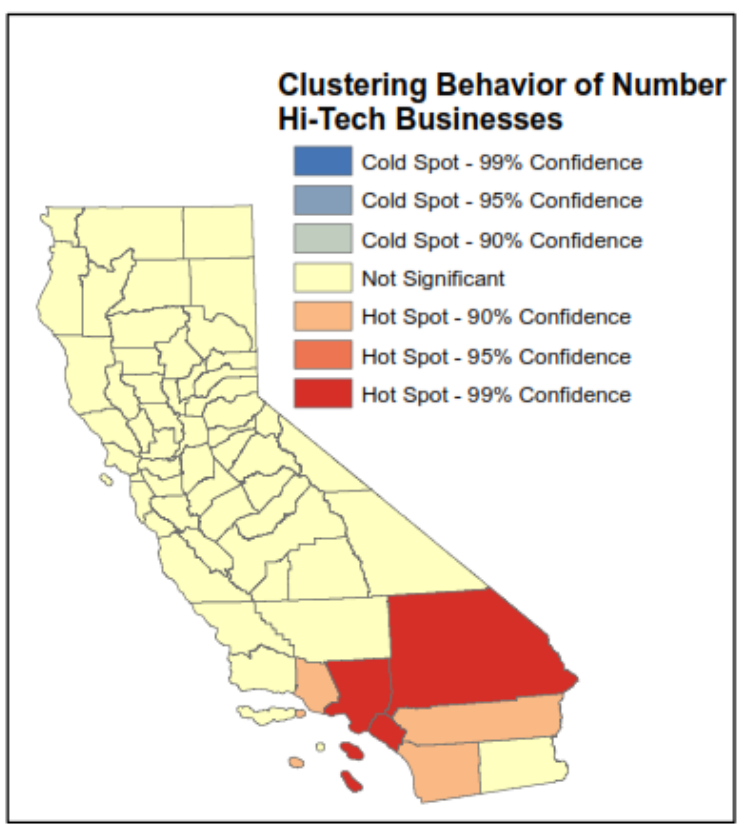

Figure 7. Cluster Behavior of Number of Hi-Tech Businesses per California County (Source: Reference USA, 2016) (Map Base Source: ArcMap 10.2.1, 2016) 
In reviewing the results described above, it became apparent that further exploration of the Getis-Ord Gi* tool was needed. While the Getis-Ord Gi* hot spot analysis tool is a very popular spatial analysis tool, it does have the caveat that it relies on the values of the attributes being normally distributed. Because of the true nature of the data, the attributes being measured have true zeros, such as the number of hi-tech businesses per county, and the scaling and skewness of the data can affect the interpretation of the confidence levels. Many of the variables that underwent exploratory analysis in this study had many true zeros as values, representing zero amounts within many counties. Out of all of the attributes that were mapped and put through the GetisOrd Gi* tool, the number of hi-tech businesses per county had the fewest true zeros, with only Yuba County having no hi-tech businesses within its boundary. To illustrate the sensitivity of the Getis-Ord Gi* tool to the skewness of the data, the values of the data

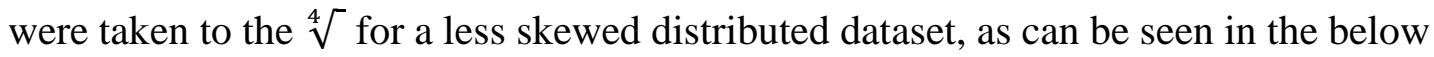
figures, with the numbers of hi-tech business data being seen with its original distribution

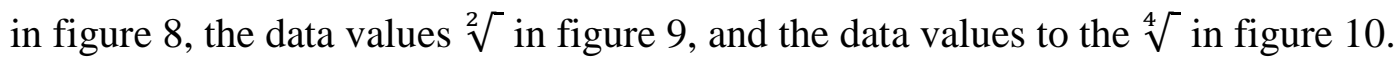




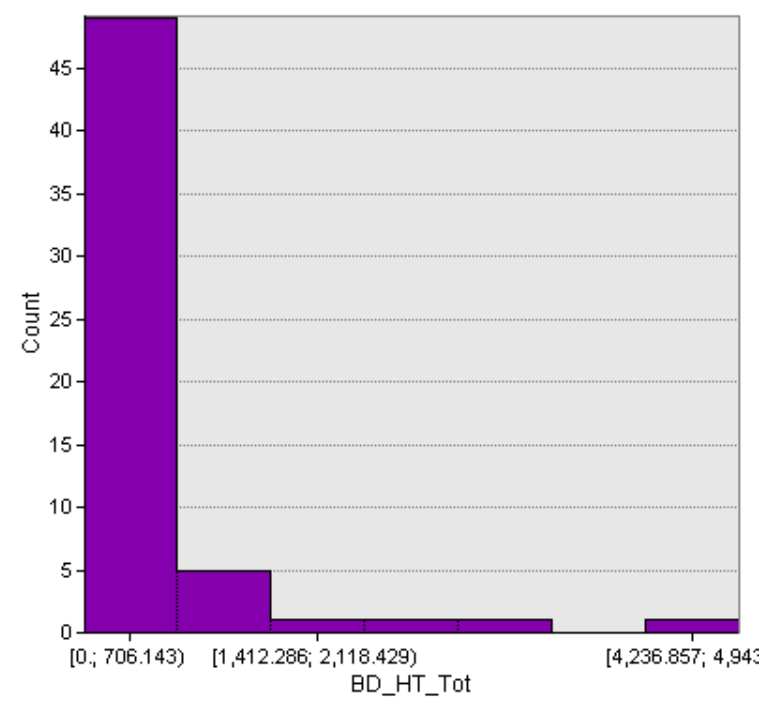

Figure 8. Original Data Histogram for Numbers of Hi-Tech Businesses per County

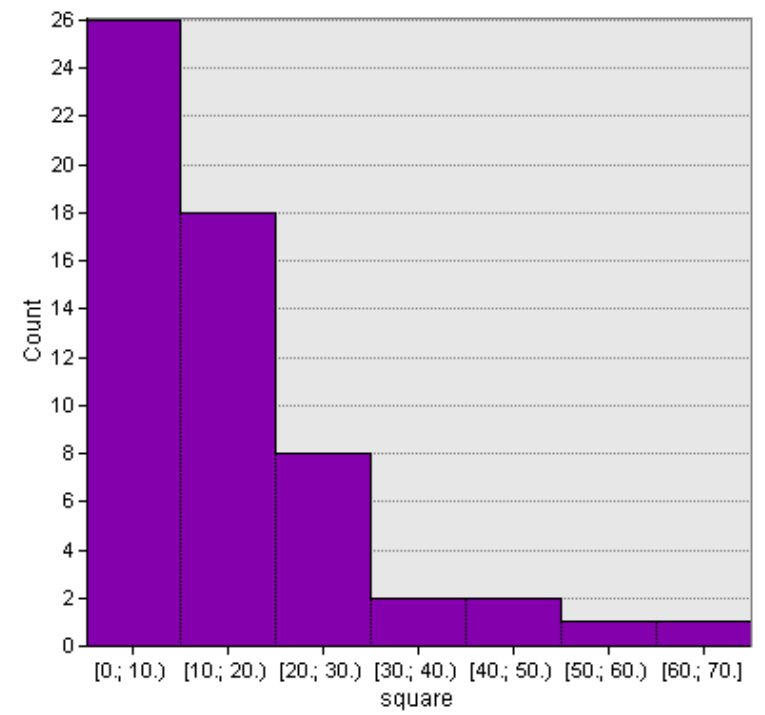

Figure 9. Data Histogram for Numbers of Hi-Tech Businesses per County to the $\sqrt[2]{ }$ 


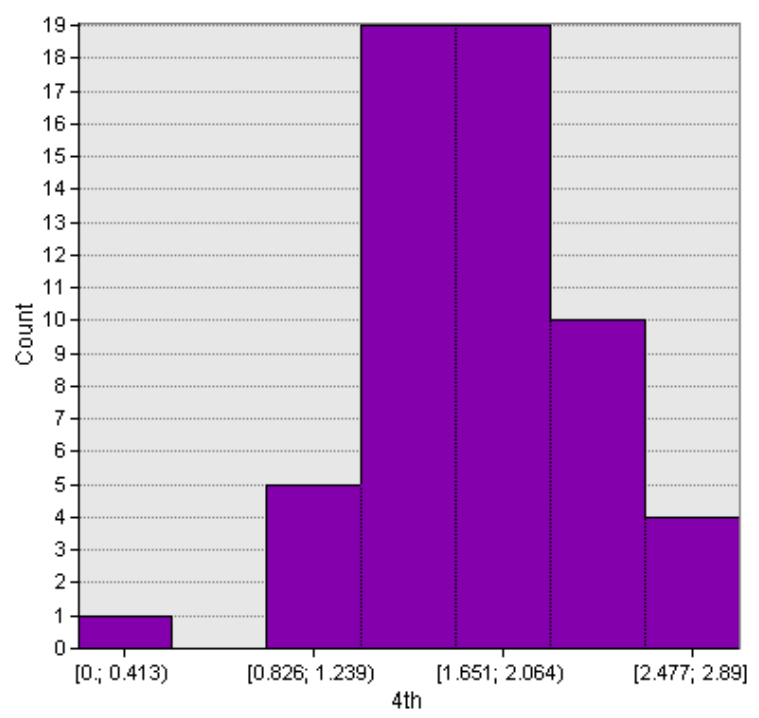

Figure 10. Data Histogram for Numbers of Hi-Tech Businesses per County to the $\sqrt[4]{ }$

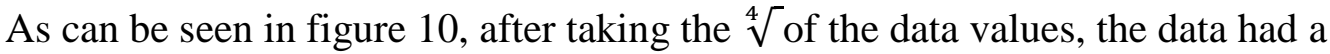
less skewed distribution with the counties maintaining their same relative order, when compared to the original data, as in figure 8 , or the data squared, as seen in figure 9 . This less skewed data can be seen in the data in Figure 10, as well as the mapped data, in figure 11. The resulting hot spot analysis displayed different results than the analysis of the original data distribution, with both the Bay Area region and the Southern California regions showing up as hot spots on the fourth root scale, and with cold spots showing up in Northern California on this fourth root scale, as seen in figure 12. While it is possible to get to a more normal distribution for the undergoing exploratory analysis in this study through taking the $\sqrt[4]{ }$, this example was done for illustrative purposes only and not on all of the variables analyzed, since the fourth root will not reduce the proportion of zeros that are present in the variables. For future work, there are alternative geo-statistical methods, 
which, while more complicated, can handle the skewed nature of the data with many zeros and would be considered as an approach on further analysis of the data.

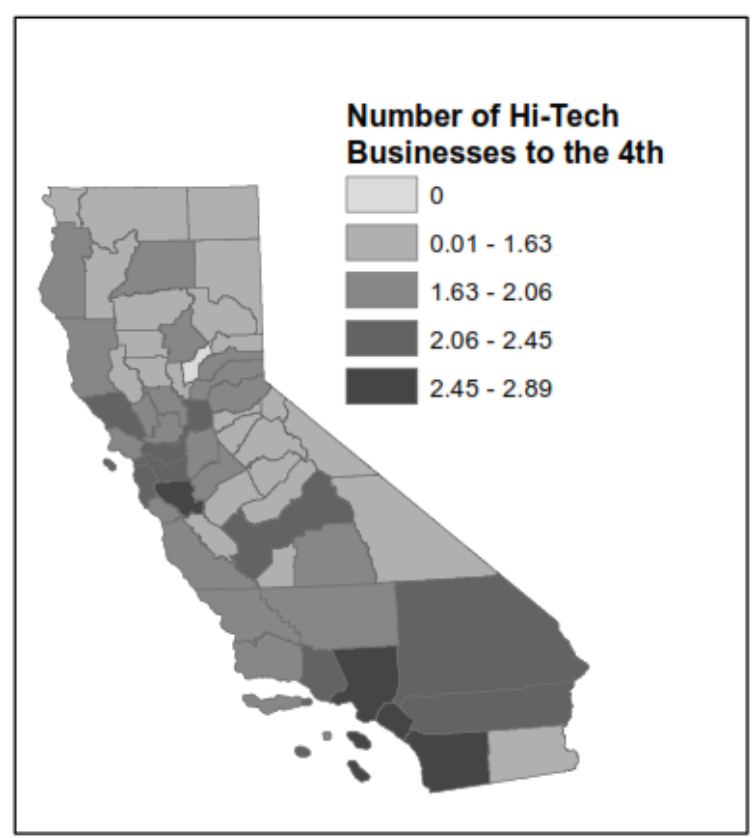

Figure 11. Number of Hi-Tech Businesses after $4^{\text {th }}$ root transformation per California County (Source: Reference USA, 2016) (Map Base Source: ArcMap 10.2.1, 2016) 


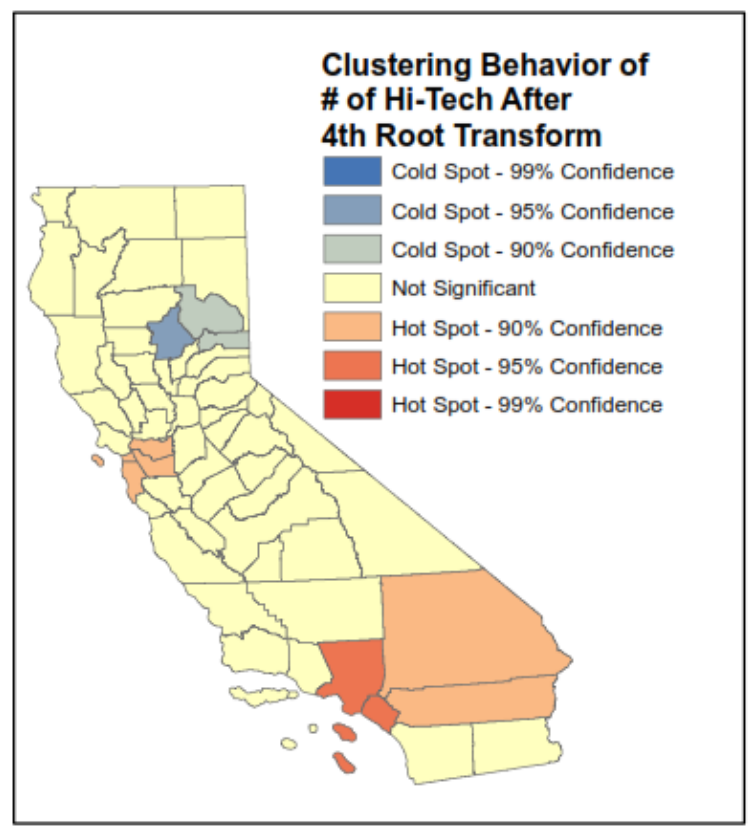

Figure 12. Cluster Behavior of Number of Hi-Tech Businesses after $4^{\text {th }}$ root transformation per California County (Source: Reference USA, 2016) (Map Base Source: ArcMap 10.2.1, 2016)

\section{Hi-Tech (women-led businesses).}

Out of the 23,622 hi-tech companies in the state, $15 \%$, or 3,545 companies, were women led as of February 2015. As seen in figure 13, the percentage of women-led businesses is highest at 54\% in Amador County, located within the Sierra Nevadas, with the majority of counties having an even distribution of women-led businesses throughout the state of between 11-20\%. The median percentage of women-led businesses in hi-tech is $13.8 \%$ per county, with an interesting geographic pattern of higher percentages of over 50\% women led hi-tech businesses near, but not within the Bay Area. As figure 14 demonstrates, hot spots were not returned from the hot spot analysis tool, providing insufficient evidence of clustering versus a random distribution of women-led hi-tech businesses throughout the state at the county level. 


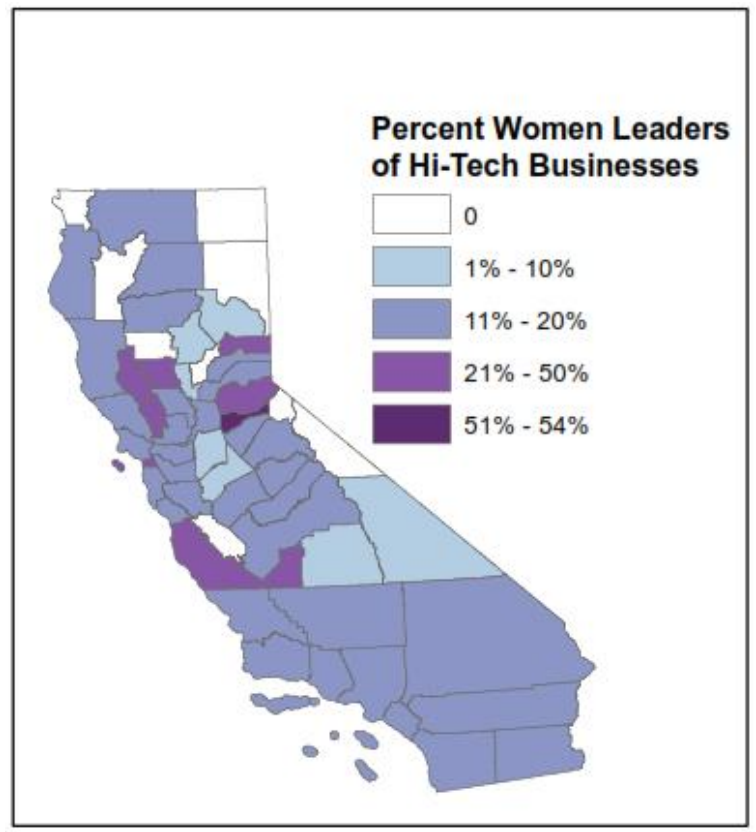

Figure 13. Percent of Women Business Leaders in Hi-Tech Businesses per California County (Source: Reference USA, 2016) (Map Base Source: ArcMap 10.2.1, 2016)

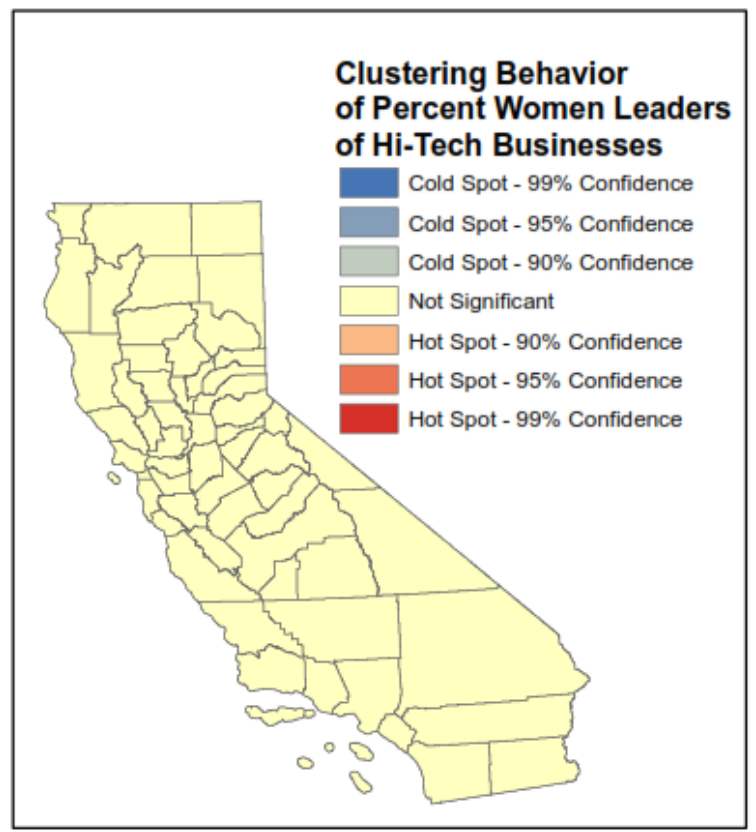

Figure 14. Cluster Behavior of Percent of Hi-Tech Women Business Leaders of Hi-Tech Businesses per California County (Source: Reference USA, 2016) (Map Base Source:

ArcMap 10.2.1, 2016) 


\section{Biotech Businesses Throughout California.}

A total of 110 biotech companies were located throughout California as of February 2015. As was done with hi-tech business data, biotech business data were checked to make sure no duplication occurred in company numbers due to multiple business locations, and when a company was recorded in the database more than once only the headquarter location was used. The geographic distribution of the data shows higher numbers of biotech businesses in Southern California and Bay Area regions, with 62 and 40 biotech businesses, respectively. As seen in figure 15, higher numbers of biotech numbers are expected in Southern California due to San Diego's prevalence as a biotech industry sector hub. As figure 16 demonstrates, exploratory hot spot analysis indicated clustering behavior, with Southern California counties having neighboring features with high values, providing evidence against the null hypothesis that biotech businesses are randomly distributed throughout the state, and showing higher neighboring numbers of biotech businesses in Southern California, supporting this regions status as a biotech hub. 


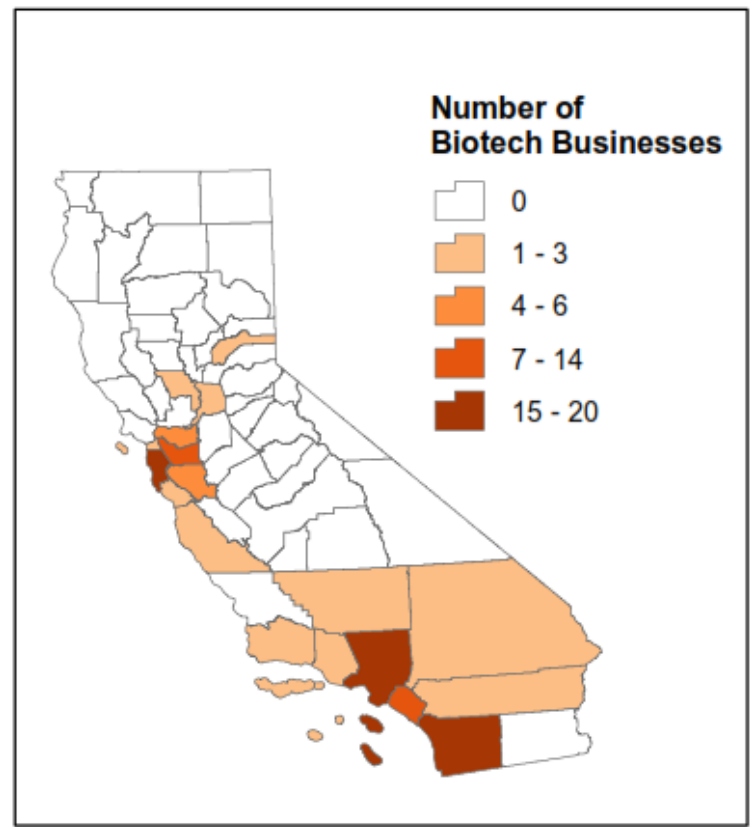

Figure 15. Number of Biotech Businesses per California County (Source: Reference USA, 2016) (Map Base Source: ArcMap 10.2.1, 2016)

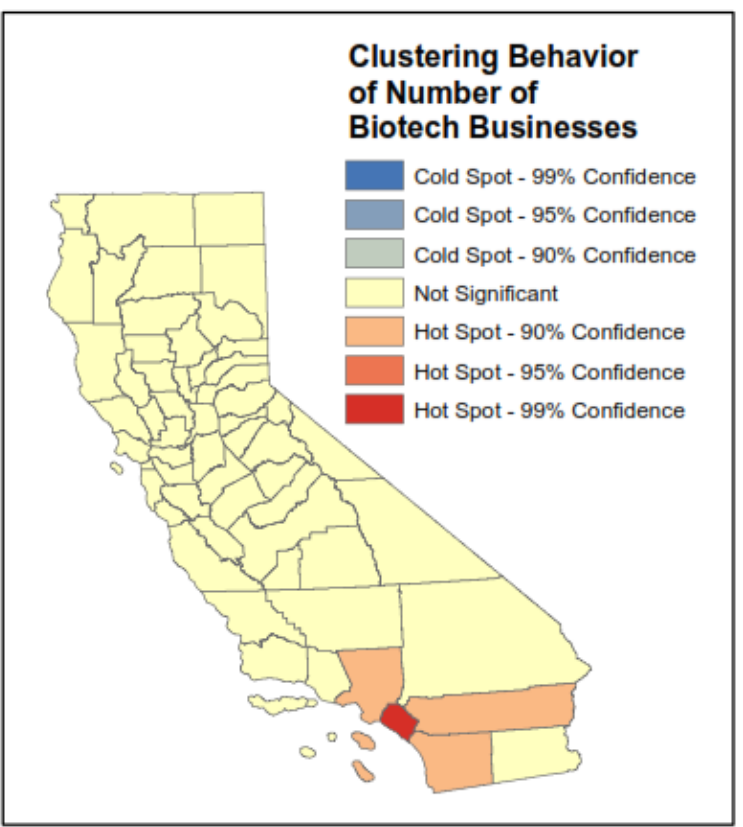

Figure 16. Cluster Behavior of Number of Biotech Businesses per California County (Source: Reference USA, 2016) (Map Base Source: ArcMap 10.2.1, 2016) 


\section{Biotech (Women-led businesses).}

Out of the 110 biotech companies throughout California in February 2015, 20\%, or 22 of the companies were women-led. Geographically it is interesting to note that while the total number of biotech businesses is highest in Southern California, the percentages of women-led biotech businesses were higher in the Bay Area. As figure 17 shows, the median percentage of women-led biotech businesses throughout the state is $10 \%$, with the percentage of women led businesses ranging from 0-100\%. It should be mentioned that the small sample size, 110 biotech businesses throughout the state, could skew the resulting data. For example, having only 1 biotech company in Nevada County means that since the one biotech company there is ran by a woman, the percentage becomes 100\%. As demonstrated in figure 18, clustering behavior of women led businesses shows hot spots, or high $\mathrm{G}_{i}{ }^{*}$ values in the Bay Area, providing some evidence against the null hypothesis of random distribution of women led hi-tech companies throughout the state. However, we note that the exploratory hot spot analysis may be highly sensitive to the large proportion of counties with zeros. San Benito County is also shown as a hot spot even though it has no women led businesses due to the high percentage values of its neighboring counties. The hot spot analysis is presented as an initial analysis, but more sophisticated analyses should be undertaken in future work beyond this thesis. Results should be interpreted as preliminary, motivating future studies. While the finding of higher percentages of women led companies in the Bay Area is of interest, this study does not yet isolate contributing factors. 


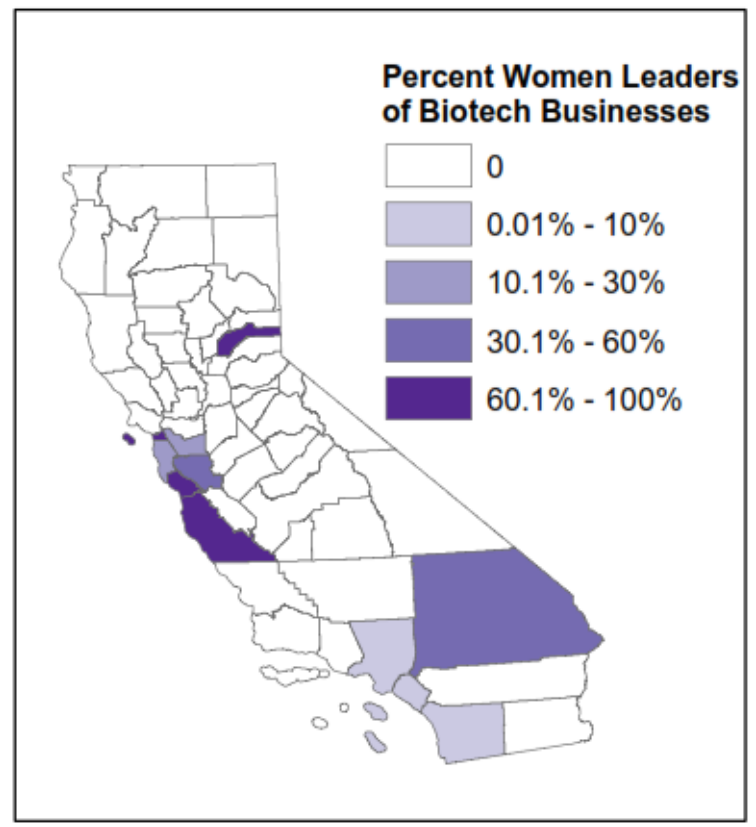

Figure 17. Percent of Women Business Leaders of Biotech Businesses per California County (Source: Reference USA, 2016) (Map Base Source: ArcMap 10.2.1, 2016)

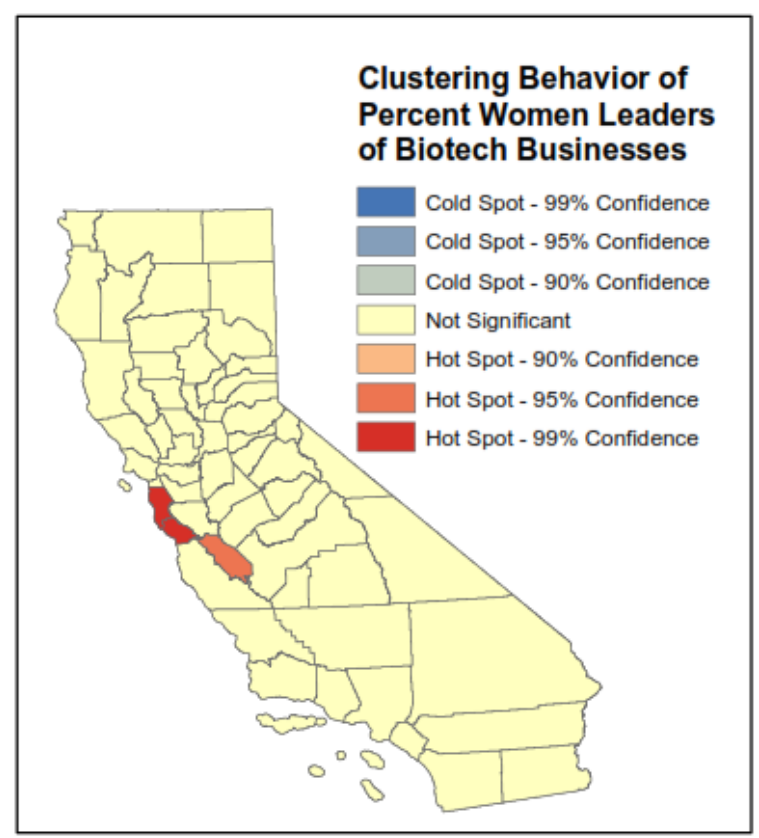

Figure 18. Cluster Behavior of Percent of Women Business Leaders of Biotech Businesses per California County (Source: Reference USA, 2016) (Map Base Source: ArcMap 10.2.1, 2016) 


\section{University data.}

\section{Numbers of Universities Offering Biotech Majors.}

In 2012, there were a total of 49 universities in California offering biotech majors, according to the National Science Foundation, National Center for Science and Engineering Statistics, Integrated Science and Engineering Resources Data System (WebCASPAR) database. As displayed in figure 19, two distinct groups of higher numbers of universities are identified in the Southern and Northern California regions. The highest numbers of universities providing hi-tech majors are in Los Angeles and San Diego counties, at 17 and 9 universities, respectively. Higher numbers of universities providing biotech majors are located in Southern California, with 33 universities in the region, compared to 8 universities with biotech majors in the Bay Area. One thing to note on the data is that 2012 is the most recent year for which university data were available for at the time of this study, and the number of universities offering biotech majors may have changed in interim years. As seen in figure 20, clustering behavior is observed in Southern California, providing evidence against the null hypothesis of random distribution of universities with Biotech majors, and supports the idea of San Diego's status as a biotech hub due to the cluster of universities with biotech majors provided there. Ventura is shown as a hot spot in spite of the fact that there are no universities offering biotech majors in surrounding counties. However, Ventura County is in close proximity to Los Angeles County, which has the highest number of universities offering biotech majors in the state. 


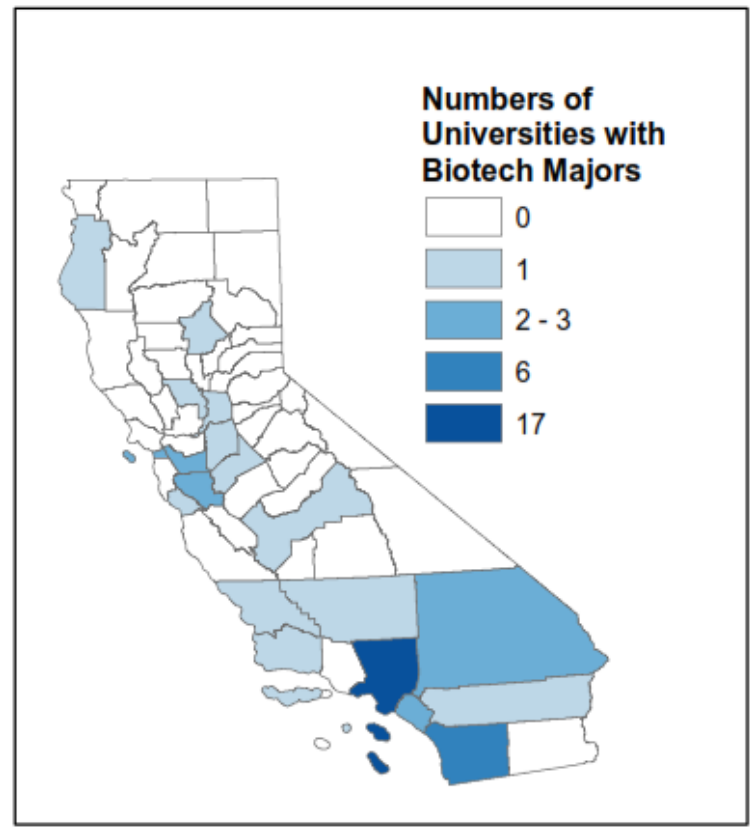

Figure 19. Number of Universities with Biotech Majors per California County (Source: National Center for Science and Engineering Statistics, Integrated Sciences and Engineering Resources Data System, 2016) (Map Base Source: ArcMap 10.2.1, 2016)

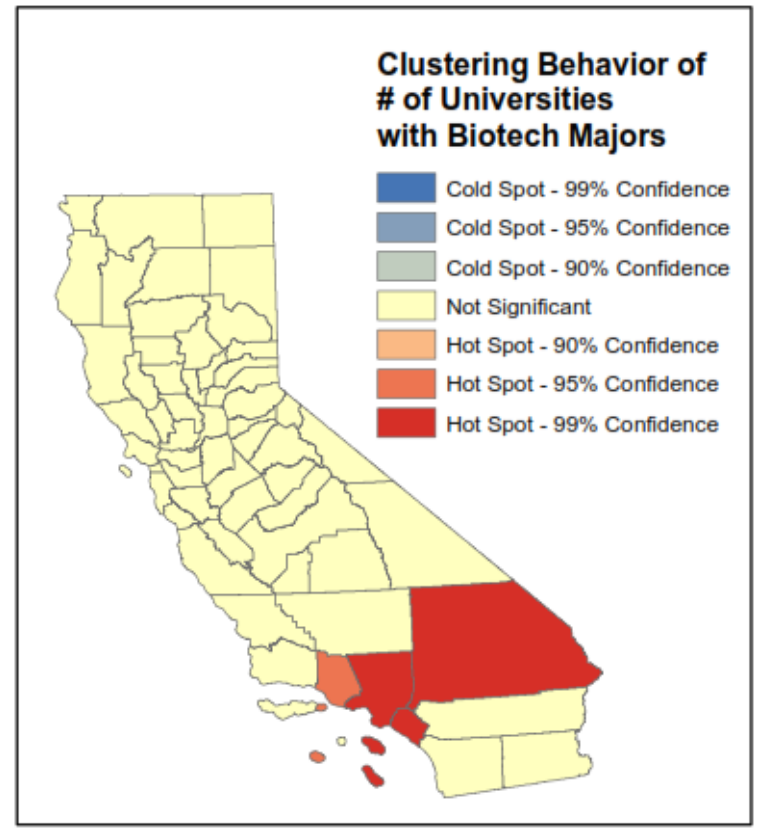

Figure 20. Clustering Behavior of Number of Biotech Majors per California County (Source: National Center for Science and Engineering Statistics, Integrated Sciences and Engineering Resources Data System, 2016) (Map Base Source: ArcMap 10.2.1, 2016) 


\section{University R\&D Expenditures in Biotech.}

The total amount of university expenditures for R\&D in biotech in 2012 was $\$ 1,107,081,024$, among 49 universities. Geographically, university expenditures in biotech R\&D vary throughout the state, with the majority of counties falling into the $\$ 131,000$ - \$26,030,000 range. The median amount of biotech $R \& D$ expenditures for counties throughout the state is $\$ 19,087,603$. As demonstrated in figure 21 , Southern California invested $\$ 784,233,016$ into biotech $R \& D$ expenditures. The county with the highest amount of $R \& D$ expenditures in 2012 is San Diego at $\$ 460,350,016$, which is to be expected given its status as an industry hub. Yolo county is also interesting to note, as the University of California Davis spent $\$ 168,799,000$ in biotech R\&D, dwarfing the expenditure amount of $\$ 125,787,000$ spent in the entirety of the Bay Area. Figure 22 displays clustering behavior throughout the lower region of Southern California, bordering San Diego, providing evidence against the null hypothesis of random geographic distribution of university $R \& D$ expenditures in biotech, and further supporting San Diego's status as a biotech hub. Imperial County is shown as a hot spot even though there were no Imperial County university biotech R\&D expenditures, since Imperial County had neighbors with high R\&D expenditures in biotech. Such results are due to the neighboring weighted structure of the $\mathrm{G}_{i}{ }^{*}$ statistic. 


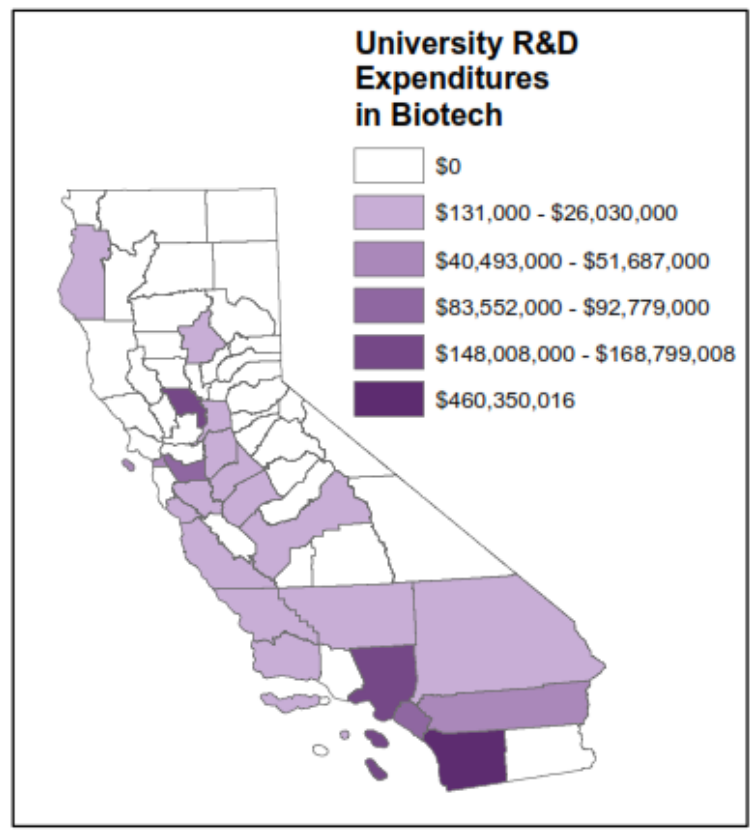

Figure 21. University R\&D Expenditures in Biotech per California County (Source: National Center for Science and Engineering Statistics, Integrated Sciences and Engineering Resources Data System, 2016) (Map Base Source: ArcMap 10.2.1, 2016)

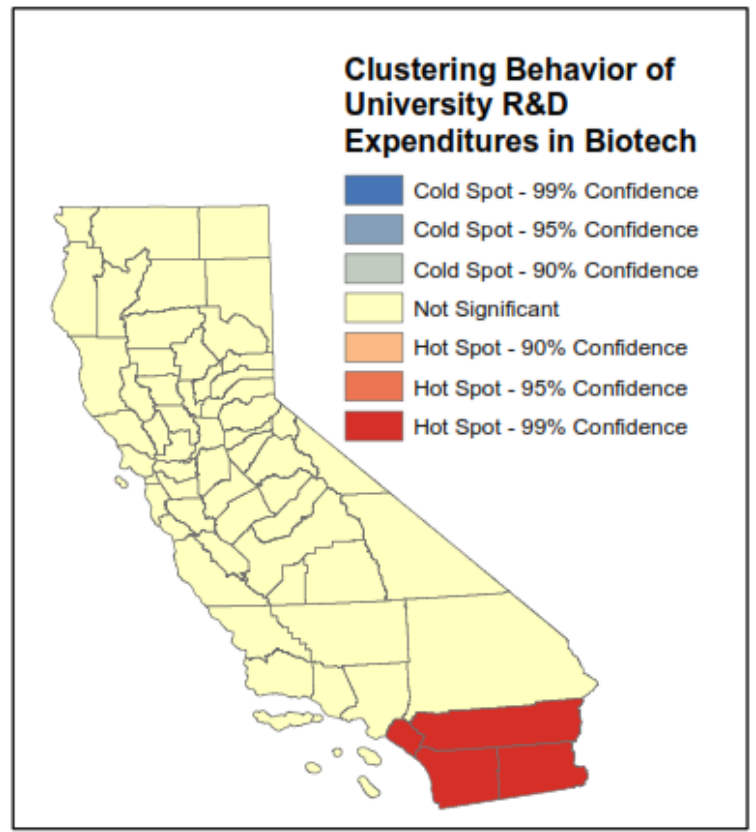

Figure 22. Clustering Behavior of University R\&D Expenditures in Biotech per California County (Source: National Center for Science and Engineering Statistics, Integrated Sciences and Engineering Resources Data System, 2016) (Map Base Source: ArcMap 10.2.1, 2016) 


\section{Numbers of Universities with Hi-tech Majors.}

A total of 39 universities that provided hi-tech majors in 2012 are located throughout California. Geographically, universities with hi-tech majors are distributed throughout the state, with higher numbers in both the Southern California and Bay Area regions. Interestingly, figure 23 shows that the Southern California region houses higher numbers of universities offering hi-tech majors than the Bay Area, with 20 universities in Southern California and 8 universities in the Bay Area. The highest number of universities offering hi-tech majors in 2012 was in Los Angeles County, with 9 universities. Cluster analysis confirms this trend in figure 24, showing a geographic cluster of universities providing hi-tech majors in Southern California. The presence of the hot spot provides evidence against the null hypothesis of random geographic distribution of universities offering hi-tech majors, and with surprising results. Given the Bay Area's status as a hi-tech hub, one would assume cluster behavior to be found there. One thing to note on the data is that the university numbers are measured for only 4 year institutions and do not include those with certificate programs, which could alter the results. As mentioned elsewhere, university size and research facilities are not yet taken into account, and results may be different after factoring those in. Another thing to note was that the data is reflective of the number of universities providing hi-tech majors in 2012, and that values may have changed in interim years. 


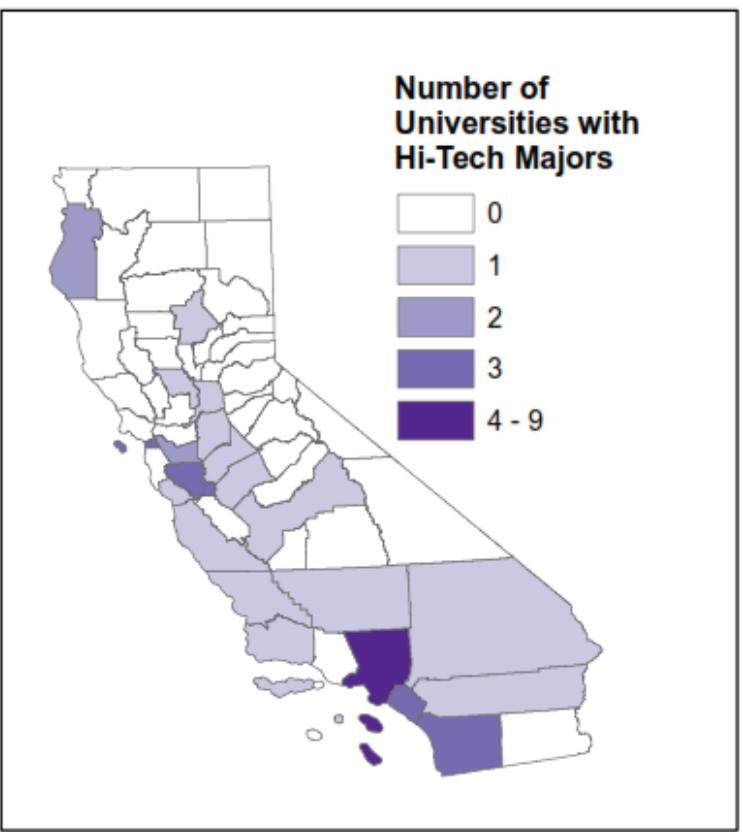

Figure 23. Number of Universities with Hi-Tech Majors per California County (Source: National Center for Science and Engineering Statistics, Integrated Sciences and Engineering Resources Data System, 2016) (Map Base Source: ArcMap 10.2.1, 2016)

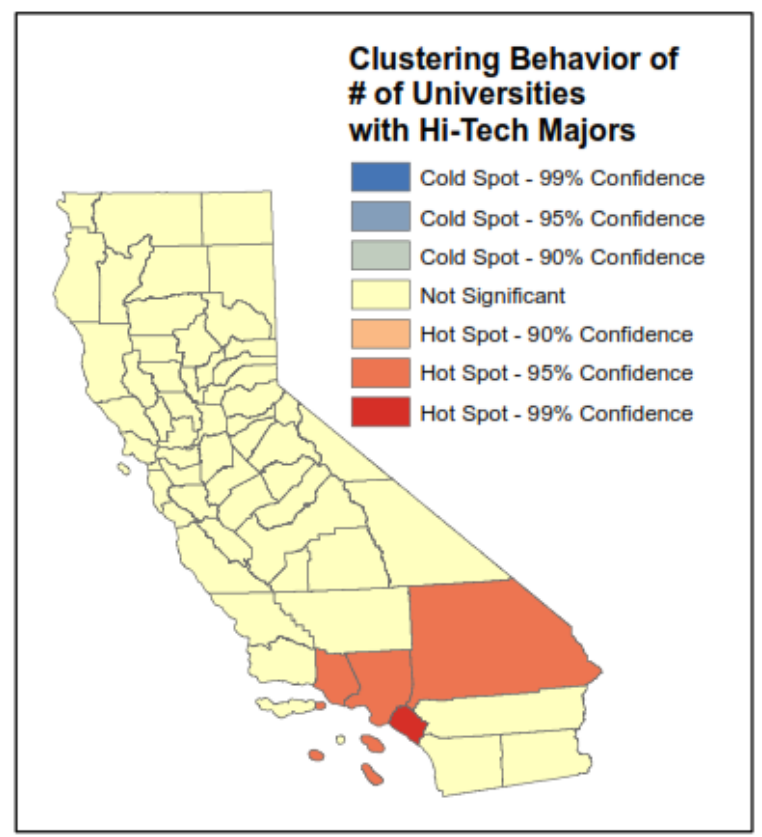

Figure 24. Clustering Behavior of Number of Hi-Tech Majors per California County (Source: National Center for Science and Engineering Statistics, Integrated Sciences and Engineering Resources Data System, 2016) (Map Base Source: ArcMap 10.2.1, 2016) 


\section{University R\&D expenditures in hi-tech.}

The total amount of university R\&D spent throughout California in 2012 was $\$ 672,853,000$. Geographically, the Southern California and Bay Area regions with surrounding counties have higher university R\&D expenditures in hi-tech. Interestingly, figure 25 demonstrates that Southern California exhibits higher values for R\&D expenditures in hi-tech than does the Bay Area, with $\$ 439,658,000$ and $\$ 185,927,000$ in expenditures, respectively. The median amount of university R\&D expenditures in hitech was $\$ 11,600,913$ per county. Los Angeles and San Diego counties have the highest expenditure amounts of $\$ 183,237,000$ and $\$ 144,614,000$, respectively. Clustering by $\mathrm{G}_{i}{ }^{*}$ analysis, as shown in figure 26 , indicates Orange County as a hot spot since it is nestled between the two aforementioned counties with the County highest hi-tech expenditure values, namely Los Angeles County and San Diego. This neighborhood based

preliminary hot spot analysis provides evidence against the null hypothesis that university R\&D expenditures in hi-tech exhibit no spatial clustering, although with surprising results of the hot spot occurring in the Southern California region given the Bay Area's hi-tech hub status. A more sophisticated analysis may find different results, and this motivates the need for continued study past the current thesis. As mentioned in the number of universities offering hi-tech majors results section, the dataset only reflects R\&D expenditures made at 4 year institutions and does not include universities with certificate programs, which also could alter the results. 


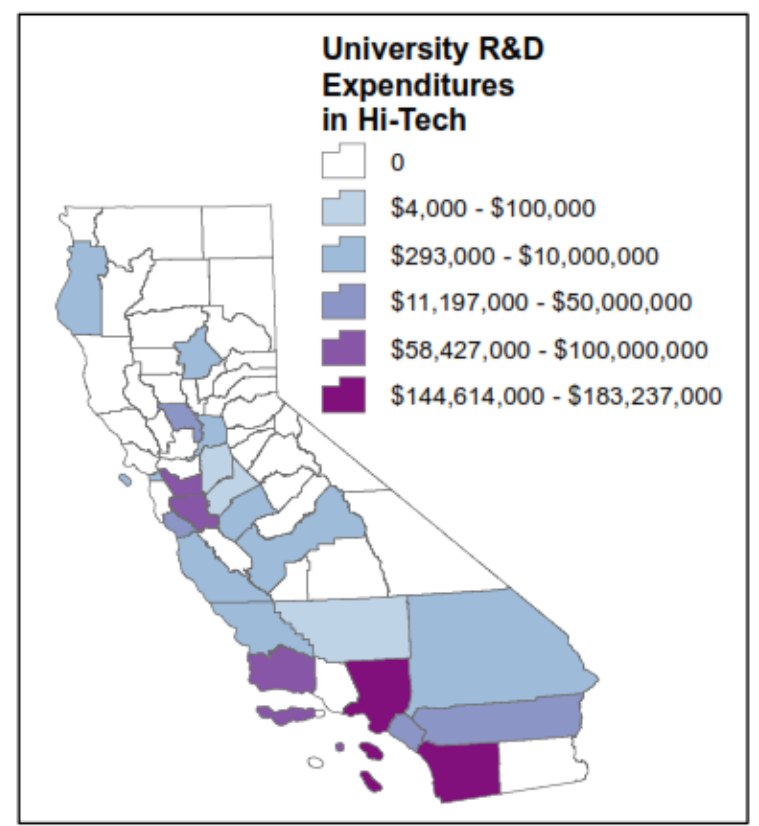

Figure 25. University R\&D Expenditures in Hi-Tech per California County (Source: National Center for Science and Engineering Statistics, Integrated Sciences and Engineering Resources Data System, 2016) (Map Base Source: ArcMap 10.2.1, 2016)

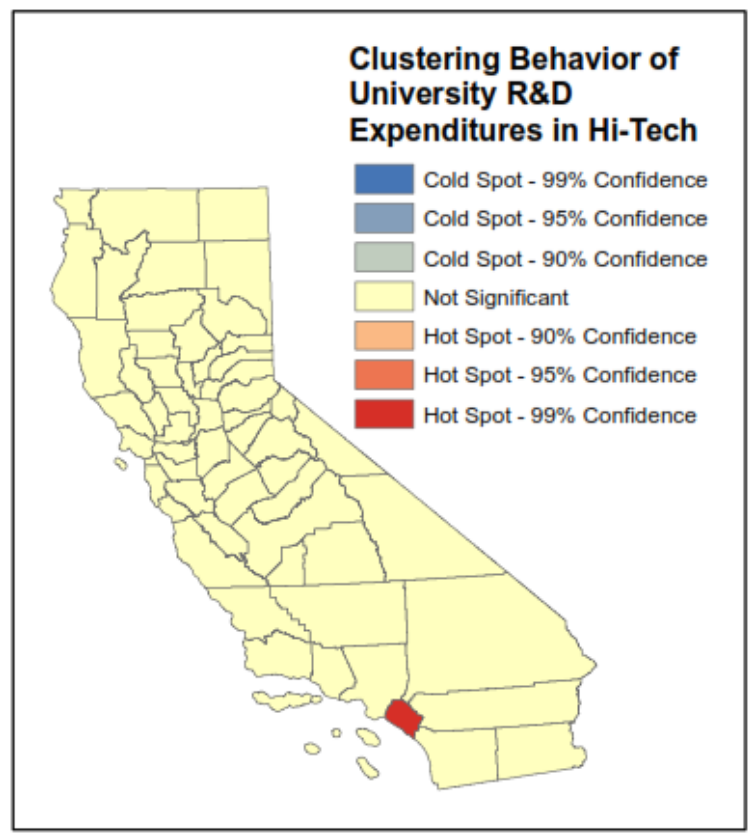

Figure 26. Clustering Behavior of University R\&D Expenditures in Hi-Tech per California County (Source: National Center for Science and Engineering Statistics, Integrated Sciences and Engineering Resources Data System, 2016) (Map Base Source: ArcMap 10.2.1, 2016) 


\section{Venture capital data.}

\section{Number of biotech companies awarded venture capital deals.}

A total of 126 venture capital deals were made towards the biotech industry throughout California in 2014. As seen in figure 27, higher funding amounts of venture capital expenditures are located in both the Southern California and Bay Area regions, with a few other counties throughout the state having 1-5 companies funded. Southern California had a total of 40 companies funded, while the Bay Area had 82. That result was interesting, as were the additional counties that received venture capital deals, Yolo and Sacramento, which neighbor the Bay Area. The counties with the highest numbers of businesses that received funding are San Mateo and San Diego, with 46 and 34 companies receiving funding, respectively. Looking at the exploratory $\mathrm{G}_{i}{ }^{*}$ cluster analysis in figure 28 shows cluster behavior to be located in the Bay Area. This provides evidence against the null hypothesis that the number of biotech businesses receiving funding is geographically random at the county level, with surprising indicator of a hotspot in the Bay Area. As the biotech hub is known to occur in San Diego, one would expect to see higher numbers of biotech businesses to be awarded funding in the Southern California region. Santa Cruz County is shown as a hot spot by the $\mathrm{G}_{i}{ }^{*}$ exploratory analysis due to being a geographic neighbor of counties that have a high number of biotech businesses being funded by venture capital, even though it did not have any hitech companies itself. The unexpected results of seeing a cluster in the Bay Area could be due to the majority of venture capitalists being located in the Bay Area, possibly 
preferring to invest in companies in geographic proximity, as stated in the literature review. Future analyses may use alternative methods to account for the high proportion of zeros.

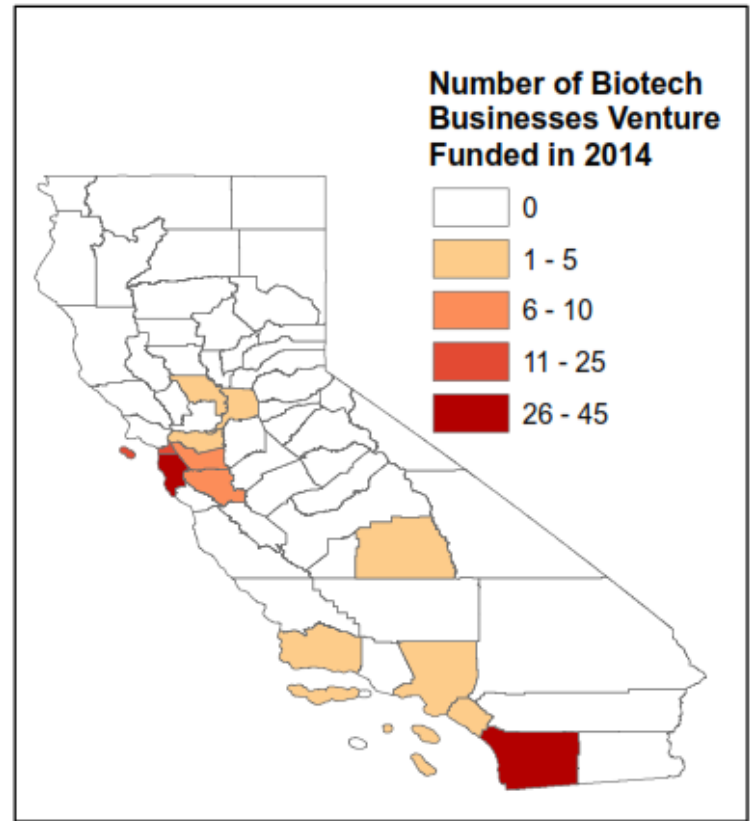

Figure 27. Number of Biotech Businesses Venture Funded in 2014 per California County (Source: PricewaterhouseCoopers/National Venture Capital Association, 2015) 


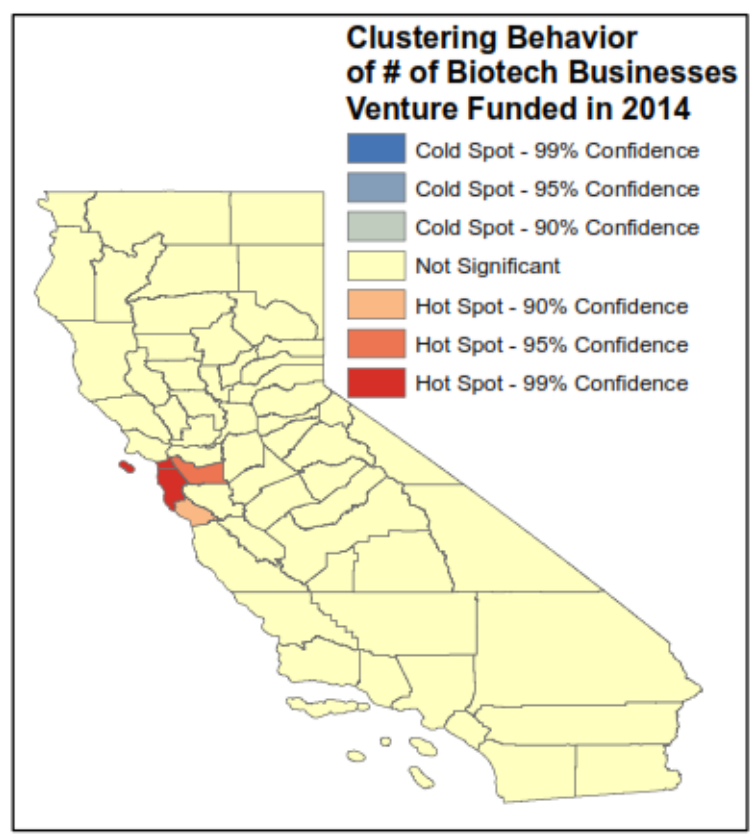

Figure 28. Cluster Behavior of Number of Biotech Businesses Venture Funded in 2014 per California County (Source: PricewaterhouseCoopers/National Venture Capital Association, 2015)

\section{Percentages of women led biotech companies awarded venture capital funding.}

Out of 126 venture capital deals that were made within the California biotech industry in 2014,17 of those deals, or $13.5 \%$ of venture capital deals in biotech, were awarded to women-led companies. 12 counties throughout California had companies that secured a venture capital deal, out of those 12,5 counties had at least one woman-led company secure venture capital funding, as shown in figure 29. The mean percentage of women-led companies to all of the counties that had venture capital deals awarded was $6.8 \%$, with a range of $0-25 \%$ women-led companies securing funding. One thing to note is the small sample size of the data. Los Angeles County, for example, had the highest rate of women securing funding with $25 \%$ of the women-led companies getting venture backed funding. This county had a total of 4 companies that secured venture capital 
funding, with one of those company leaders being a woman, bringing the county percentage to $25 \%$. Women led businesses secured deals in both the Bay Area and Southern California regions, with geographic clustering observed in the Bay Area and in Orange County. Orange County was indicated as a hot spot by $\mathrm{G}_{i}{ }^{*}$ method in spite of having no women led biotech companies due to neighborhood weighting and the proximity of high business numbers in neighboring communities. As demonstrated in figure 30, c lustering behavior provides evidence against the null hypothesis of random geographic distribution of percentages of women led companies receiving venture capital funding at the county level, but the small data sample size and the uncertainty on influencing factors make insights difficult to interpret.

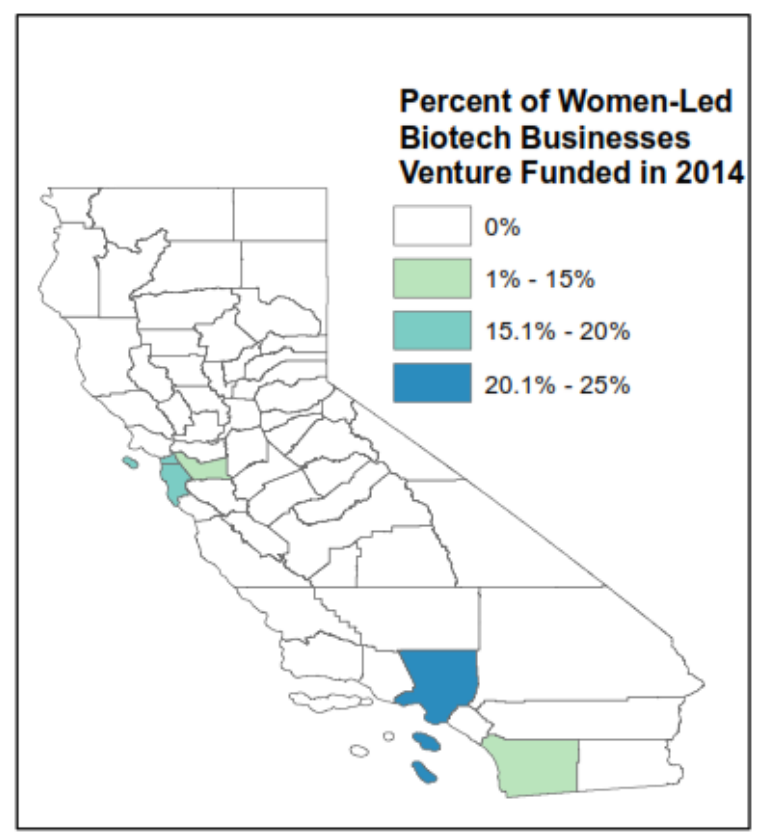

Figure 29. Percent of Women-Led Biotech Businesses Venture Funded in 2014 by California County (Source: PricewaterhouseCoopers/National Venture Capital Association, 2015) 


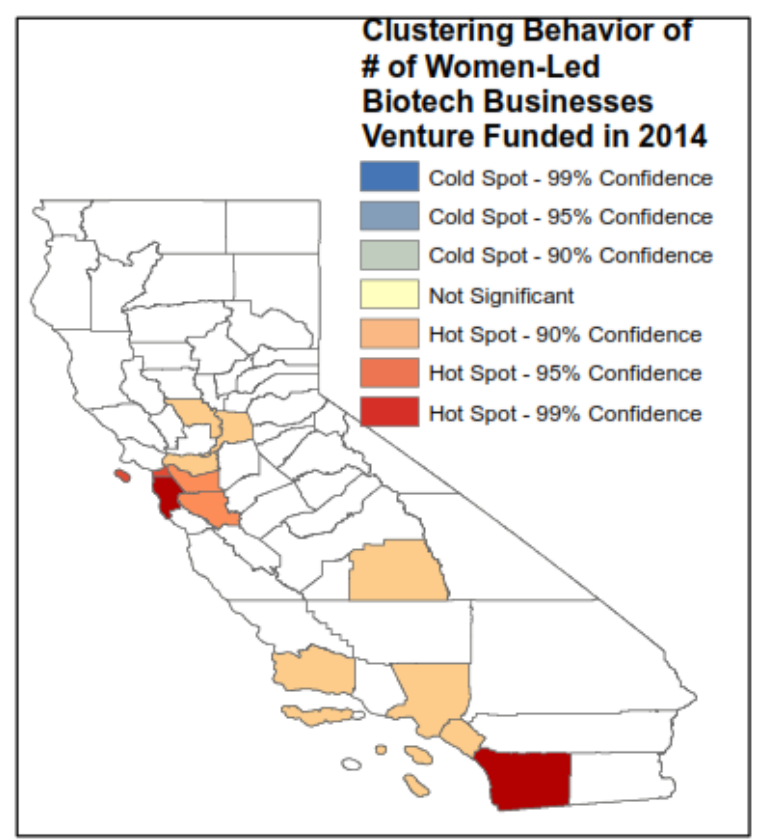

Figure 30. Cluster Behavior of Percent of Women-Led Biotech Businesses Venture Funded in 2014 per California County (Source: PricewaterhouseCoopers/National Venture Capital Association, 2015)

\section{Number of hi-tech companies awarded venture capital deals.}

A total of 909 venture capital deals were made toward the hi-tech industry throughout California in 2014. As shown in figure 31, the Bay Area and Southern California regions can be observed as two clusters in the number of venture capital deals being awarded in and near the Bay Area and along the coast of Southern California. The Southern California region had 157 hi-tech companies funded while the Bay Area had 746 hi-tech companies awarded funding. Interestingly, counties that neighbored the Bay Area region also had higher numbers of hi-tech businesses awarded venture capital funding. The two counties with the highest number of companies receiving funding were San Francisco and San Mateo counties, with 312 and 275 companies being awarded funding, respectively. Figure 21 displays geographic clustering of the number of hi-tech 
companies receiving venture capital funding is observed in the Bay Area, providing evidence against the null hypothesis that the number of venture capital deals awarded to hi-tech companies is geographically randomly distributed throughout the state at the county level. The indication of a hot spot of hi-tech companies in the Bay Area further supports the notion of the Bay Area being a hi-tech hub, as well as the idea that a higher number of companies get funding due to proximity to venture capitalists, as discussed in the literature review.

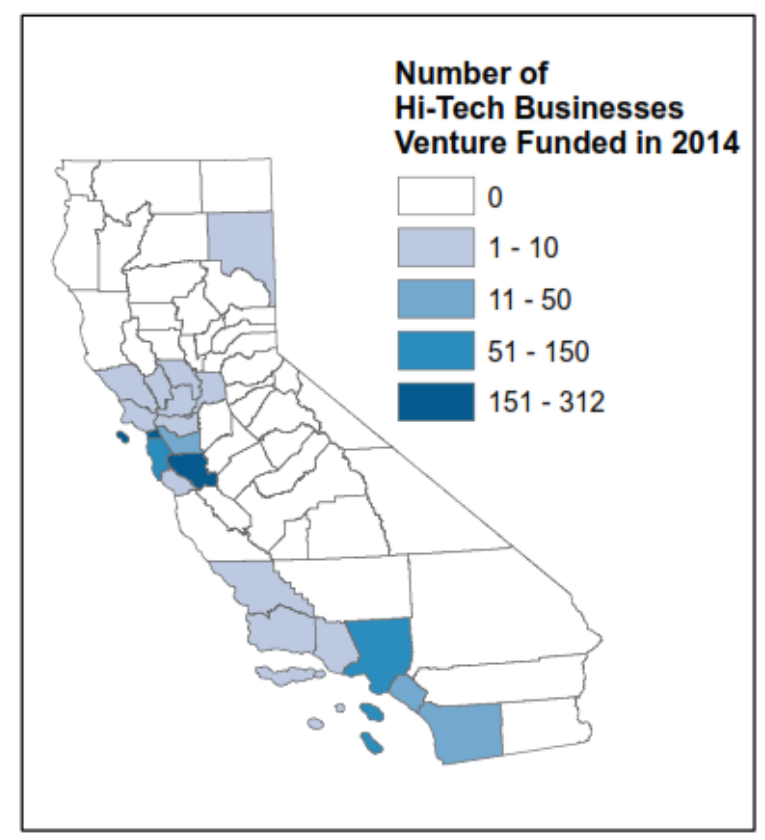

Figure 31. Number of Hi-Tech Businesses Venture Funded in 2014 per California County (Source: PricewaterhouseCoopers/National Venture Capital Association, 2015) 


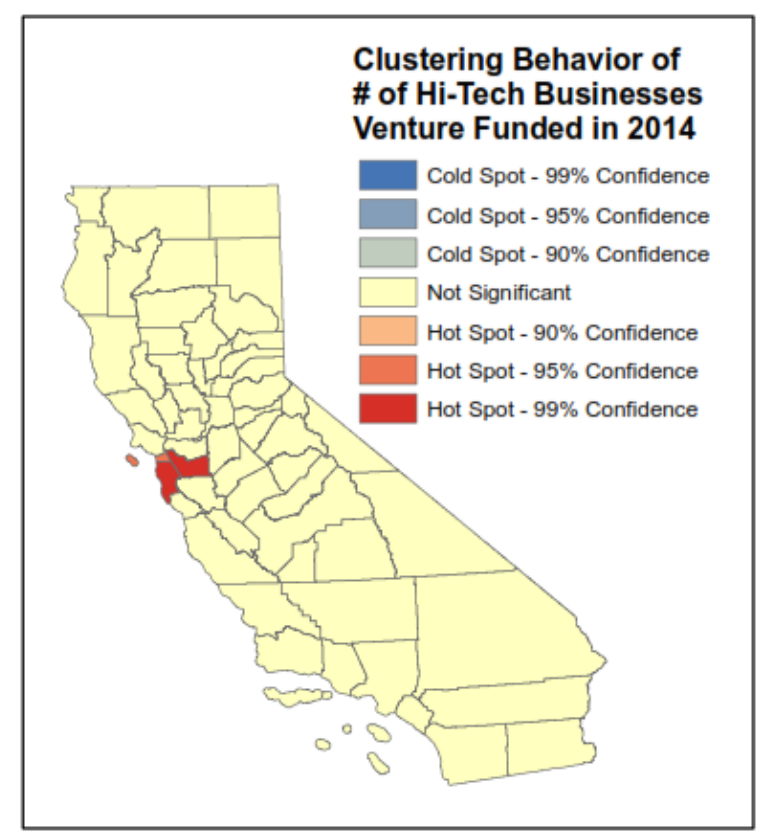

Figure 32. Cluster Behavior of Number of Hi-Tech Businesses Venture Funded in 2014 per California County (Source: PricewaterhouseCoopers/National Venture Capital Association, 2015)

\section{Percentages of women led hi-tech companies awarded venture capital funding.}

Out of the 909 deals that were made within the hi-tech industry throughout California in 2014,50 of those deals, or $5.5 \%$, were awarded to women-led companies. As shown in figure 33, the number of counties that contained women-led companies was much smaller than the total number of counties that received venture capital, with only 5 counties seeing a woman secure a venture capital deal, out of the total of 19 counties that received hi-tech sector venture funding. The mean value for the percentage of women receiving funding throughout all counties that saw funding activity in the hi-tech sector in 2014 was $1.7 \%$, with values ranging from $0-7.8 \%$. The two counties that saw the highest percentages of women led firms receiving funding were San Francisco and Los Angeles counties, with $7.27 \%$ and $7.79 \%$, respectively. An interesting finding was the similarity 
to the maps of the percentage of hi-tech women led businesses being awarded venture capital funding to the percentage of women led biotech businesses being awarded venture capital funding throughout the state. Other than the sample sizes of the datasets of total numbers of businesses funded and the percentages of women receiving the funding and San Mateo County in the Bay Area, the maps would be identical. However, we recognize that we do not yet take business size and other related factors into account. Figure 34 displays c lustering behavior shows a similar pattern for the number of biotech businesses, with a hot spot in both the Bay Area and Orange County, which is again indicated as a hot spot in the $\mathrm{G}_{i}^{*}$ analysis due to being in proximity to neighbors with higher values of women led companies receiving venture capital funding. While the rejection of the null hypothesis that percentages of women led companies receiving venture capital funding are geographically randomly distributed is of interest, it is difficult to determine causality of the results, motivating further study of interrelationships between factors beyond the current thesis. 


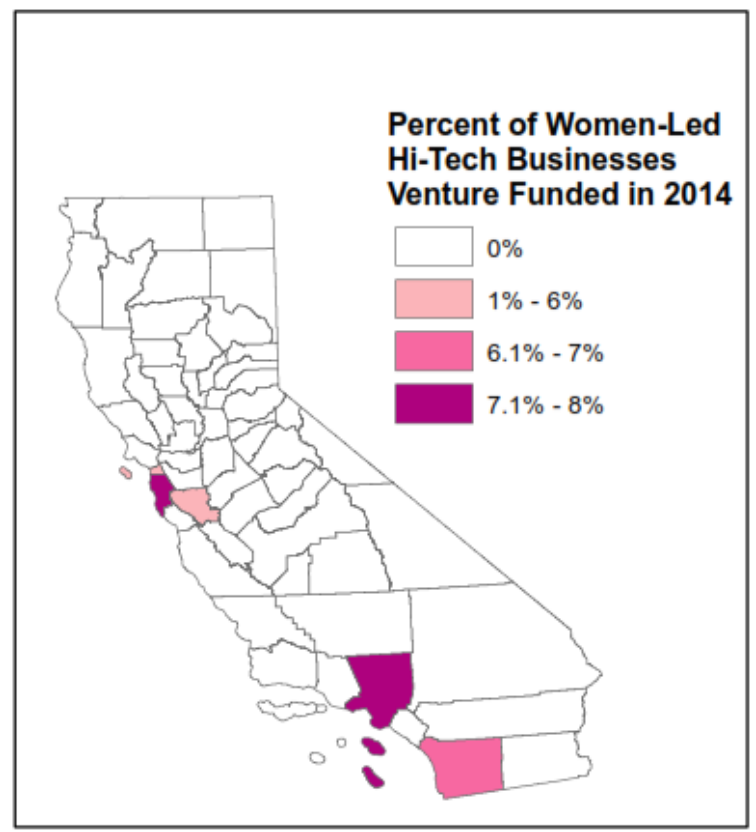

Figure 33. Percent of Women-Led Hi-Tech Businesses Venture Funded in 2014 by California County (Source: PricewaterhouseCoopers/National Venture Capital Association, 2015)

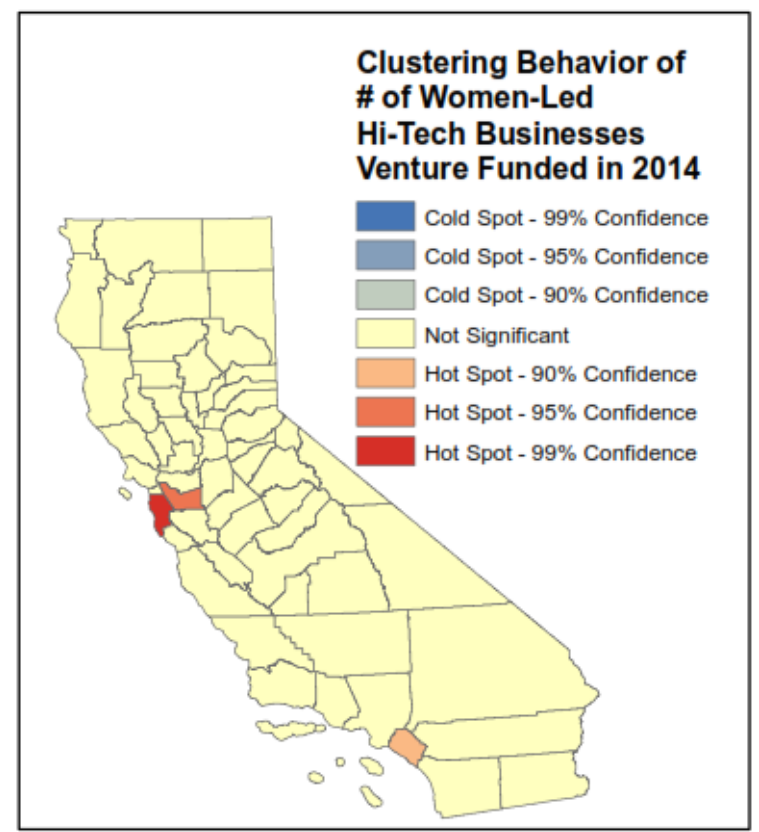

Figure 34. Cluster Behavior of Percent of Women-Led Hi-Tech Businesses Venture Funded in 2014 per California County (Source: PricewaterhouseCoopers/National Venture Capital Association, 2015) 


\section{Venture Capital Expenditures in the Biotech Sector in 2014.}

The total amount of venture capital expenditures in the biotech sector throughout California was $\$ 29,931,803,032$ amongst the 126 deals struck in 2014. Venture capital expenditures are seen throughout the state, with the highest expenditure amounts going towards companies in two counties that do not fall within either the Southern California or Bay Area regions. An interesting finding, shown in figure 35, was that the Bay Area gets higher amounts of expenditures at $\$ 10,919,940,240$ than did the Southern California region at $\$ 103,162,703$. This is surprising given the Southern California's reputation as a biotech industry hub, and gives additional support to the notion of venture capitalists investing in companies with geographic proximity to themselves. The two counties with the highest amounts of venture capital, Yolo (largest employer is UC Davis) and Tulare, had companies that received $\$ 1,185,900,000$ and $\$ 6,000,000,000$ in expenditures respectively. As displayed in figure 36, no geographic clusters were determined by the hot spot analysis tool, not rejecting the null hypothesis of random distribution of venture capital biotech expenditures across the state, and shows no spatial clustering of statistical significance. We note however that this exploratory result may be sensitive to the very high proportion of zeros and skewness of the original data. 


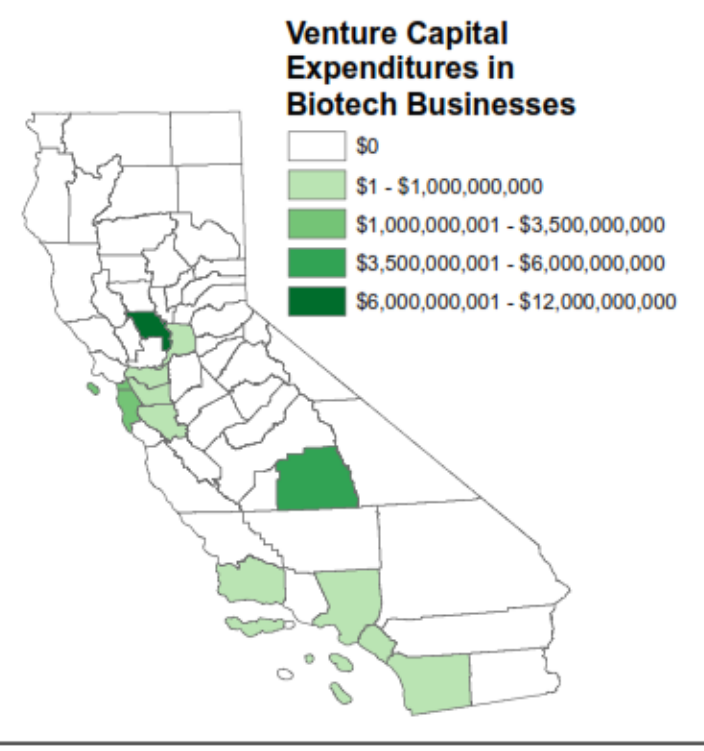

Figure 35. Venture Capital Expenditures in Biotech Businesses in 2014 by California County (Source: PricewaterhouseCoopers/National Venture Capital Association, 2015)

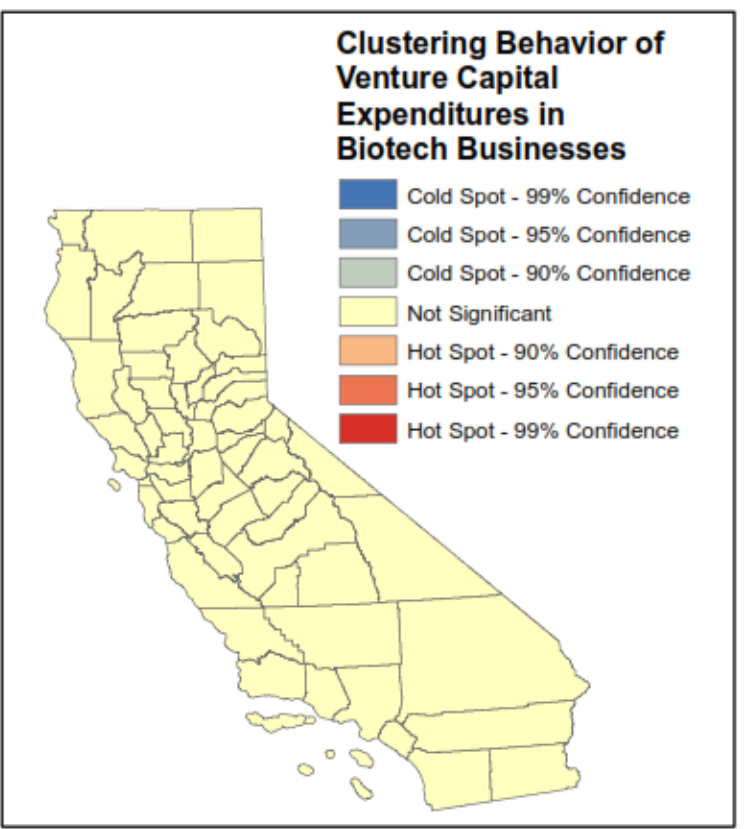

Figure 36. Cluster Behavior of Venture Capital Expenditures in Biotech Businesses in 2014 by California County (Source: PricewaterhouseCoopers/National Venture Capital Association, 2015) 


\section{Percentage of venture capital expenditures awarded to women-led biotech}

businesses.

Out of the $\$ 29,931,803,032$ of venture capital funding that was awarded to the 126 biotech businesses throughout California in 2014, \$921,546,100 of that, or $3.1 \%$, went to women-led companies. As seen in figure 37, women-led biotech companies obtained venture capital expenditures in 5 out of the 12 counties with companies that received venture capital funding in 2014. Los Angeles saw the highest percentage of expenditures going towards women-led businesses at $25 \%$. Hot spots of venture expenditures going towards women-led businesses are indicated in both the Bay Area region and in Orange County, with Orange County being indicated as a hot spot due to its position between two counties with high amount of venture capital expenditures going to woman led biotech businesses. Figure 38 shows clustering behavior of higher percentages of venture capital going towards women-led biotech businesses provided evidence against the null hypothesis that expenditures exhibit no spatial clustering throughout the state, though it is hard to determine reasons behind the geographic cluster. These initial exploratory results may be very sensitive to the high proportion of counties with zero percentages and skewness of the data. 


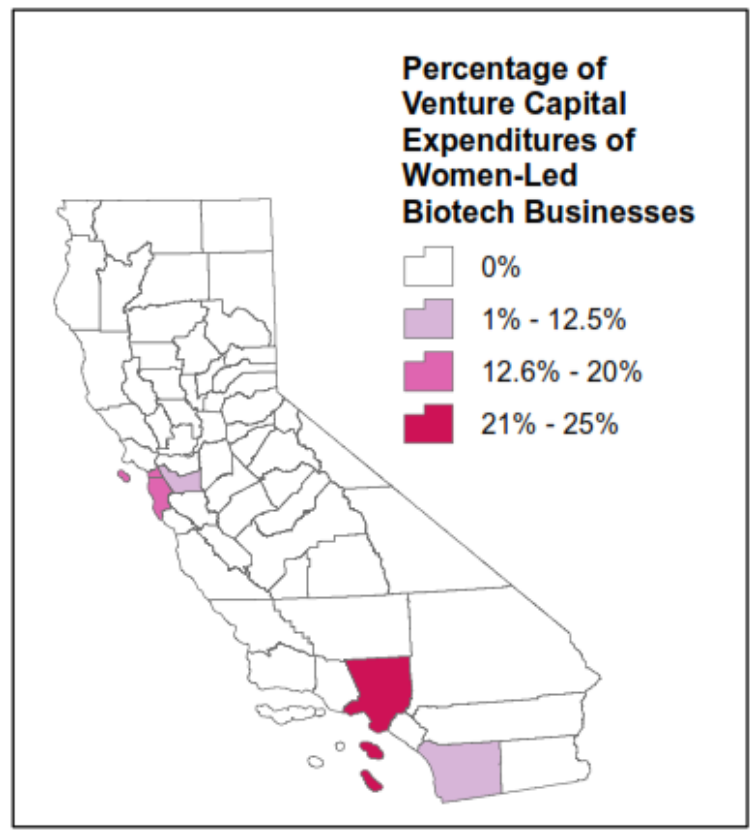

Figure 37. Percentage of Venture Capital Expenditures of Women-Led Biotech Businesses in Biotech in 2014 by California County (Source:

PricewaterhouseCoopers/National Venture Capital Association, 2015)

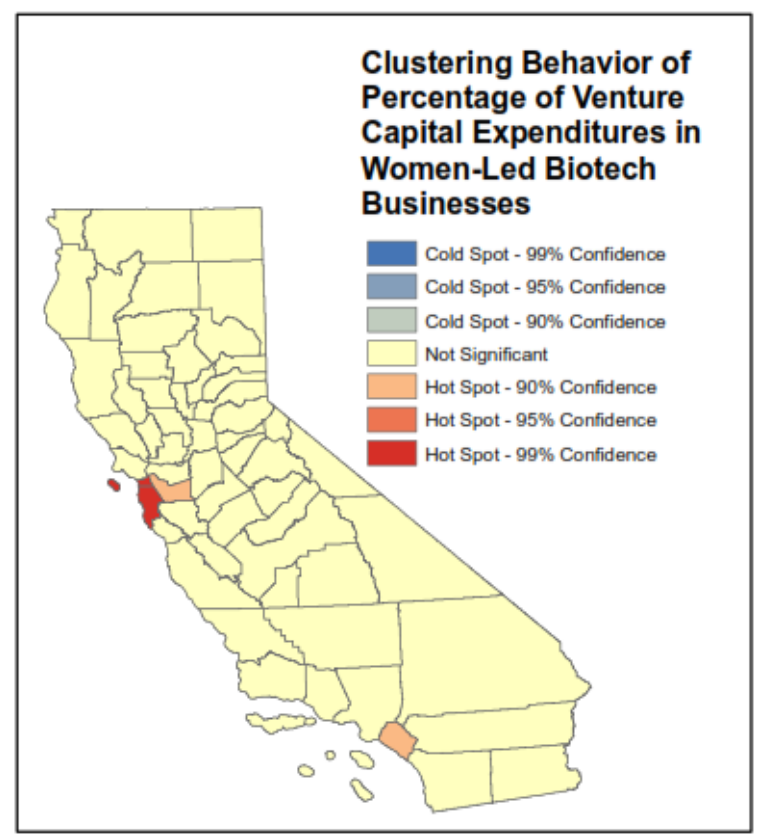

Figure 38. Cluster Behavior of Venture Capital Expenditures to Women-Led Biotech Businesses in Biotech in 2014 by California County (Source:

PricewaterhouseCoopers/National Venture Capital Association, 2015) 


\section{Venture capital expenditures in the hi-tech sector in 2014.}

The total amount of venture capital expenditures going towards the 909 deals made within the hi-tech sector throughout California in 2014 was $\$ 17,263,043,992$. As shown in figure 39, higher amounts of venture capital expenditures were awarded in the Bay Area and nearby counties, and along the coast of the Southern California region. The Bay Area had higher venture capital expenditures than did Southern California, with $\$ 15,235,483,664$ and $\$ 1,995,460,128$ in expenditures, respectively. The two counties with the highest amounts of venture capital expenditures are San Francisco at $\$ 7,830,370,000$, and Santa Clara at $\$ 5,414,510,000$. Exploratory hot spot clustering behavior, shown in figure 40, is observed in the Bay Area region, due to high values of venture capital expenditures being awarded to hi-tech companies in neighboring counties within this region. The geographic clustering provides evidence against the null hypothesis that venture capital expenditures are randomly distributed throughout the state, and supports the idea that higher venture capital expenditures occur within the hitech industry hub of the Bay Area. Results may be sensitive to the skewness of the original data and high proportion of zeros. 


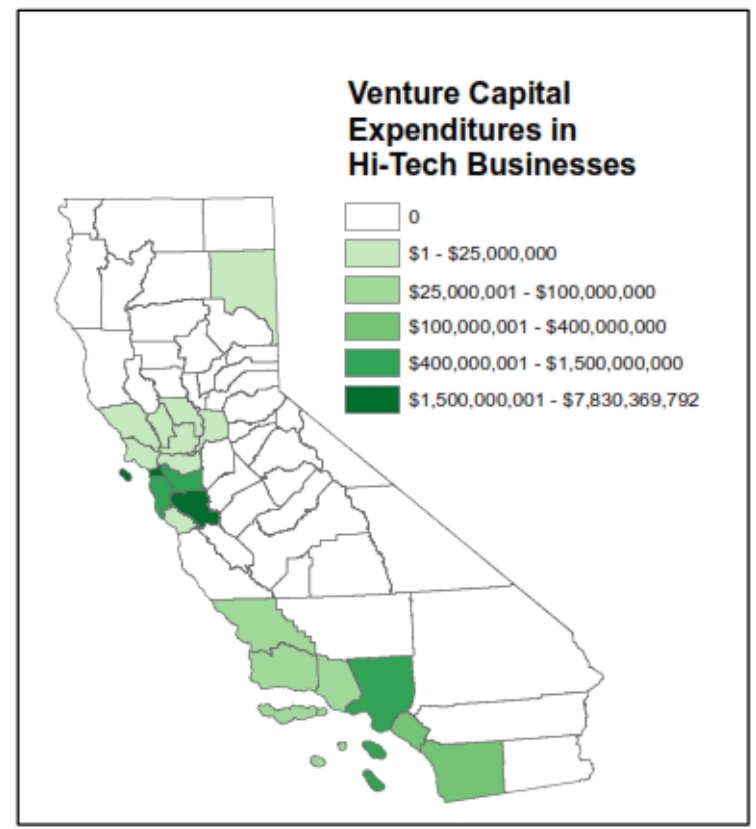

Figure 39. Venture Capital Expenditures in Hi-Tech Businesses in 2014 by California County (Source: PricewaterhouseCoopers/National Venture Capital Association, 2015)

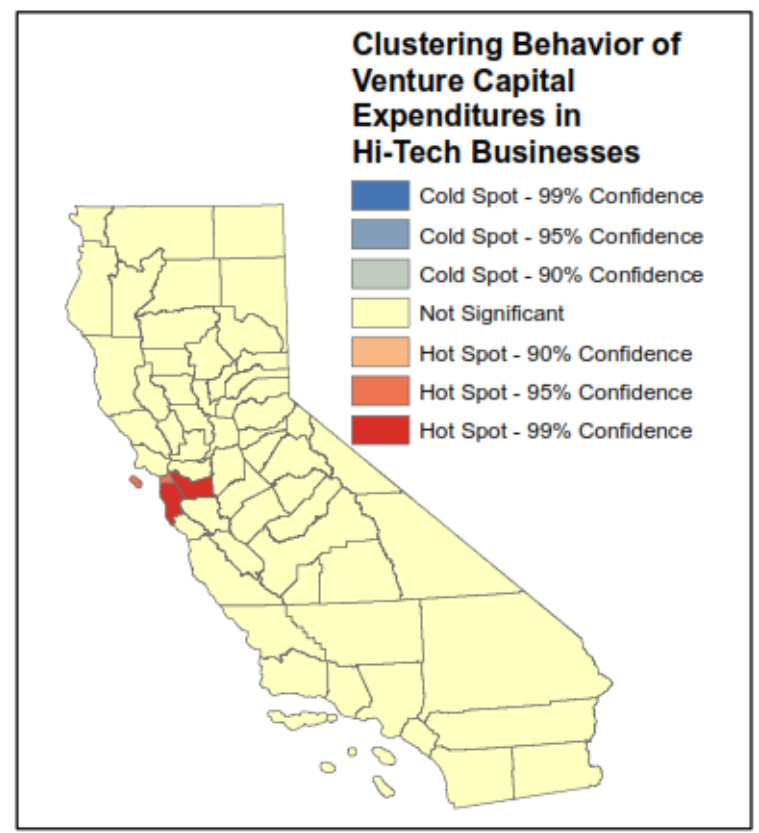

Figure 40. Cluster Behavior of Venture Capital Expenditures in Hi-Tech Businesses in 2014 by California County (Source: PricewaterhouseCoopers/National Venture Capital Association, 2015) 


\section{Percentage of venture capital expenditures awarded to women-led biotech}

businesses.

Out of the $\$ 17,263,043,992$ of venture capital funding that was awarded to the 909 hi-tech businesses in California in 2014, $\$ 988,202,484$, or $5.7 \%$, went to financing women led companies. Women-led biotech companies obtained venture capital expenditures in 5 counties, out of the 19 counties with companies that received venture capital funding in 2014. Figure 41 demonstrates that Los Angeles and San Francisco counties had the highest percentages of expenditures going towards women led businesses at $7.8 \%$ and $7.3 \%$, respectively. Hot spot clustering of higher venture capital expenditure percentages towards women-led businesses are indicated in the Bay Area region, and in Orange County, which, even though it had no expenditures awarded towards women, is nestled between two counties with higher percentages of expenditures towards women-led businesses. Interestingly, figure 42 shows these exploratory hot spot results for the percentage of expenditures going towards women-led businesses in hi-tech, in addition to providing evidence against the null hypothesis of random geographic distribution, was similar to that of expenditures in the biotech industry, although reasons behind that are hard to determine, and sensitivity of results to the high proportion of zeros must be investigated. 


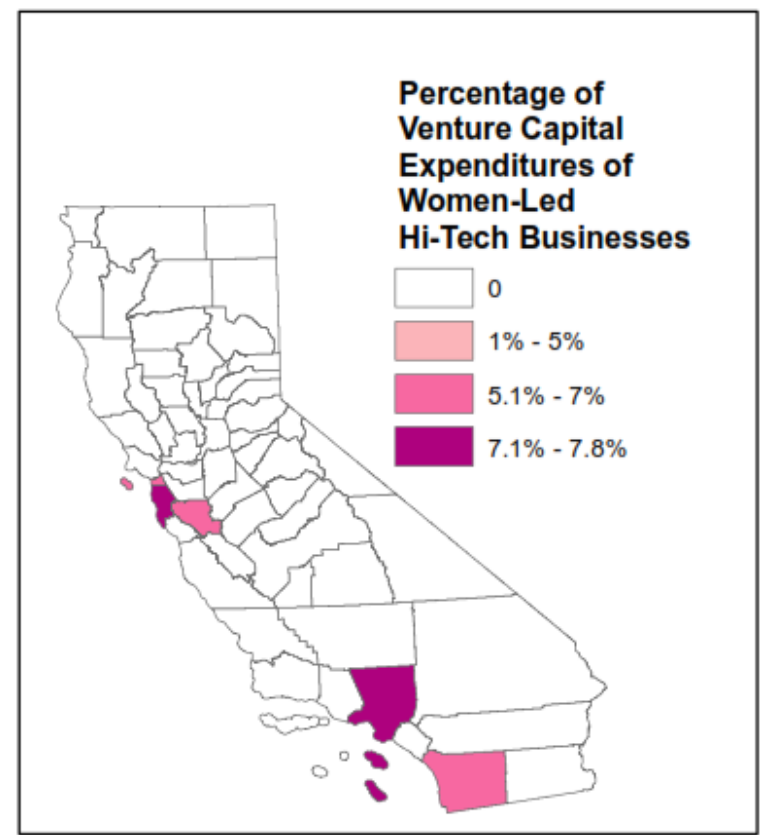

Figure 41. Percentage of Venture Capital Expenditures of Women-Led Hi-Tech Businesses in Biotech in 2014 by California County (Source:

PricewaterhouseCoopers/National Venture Capital Association, 2015)

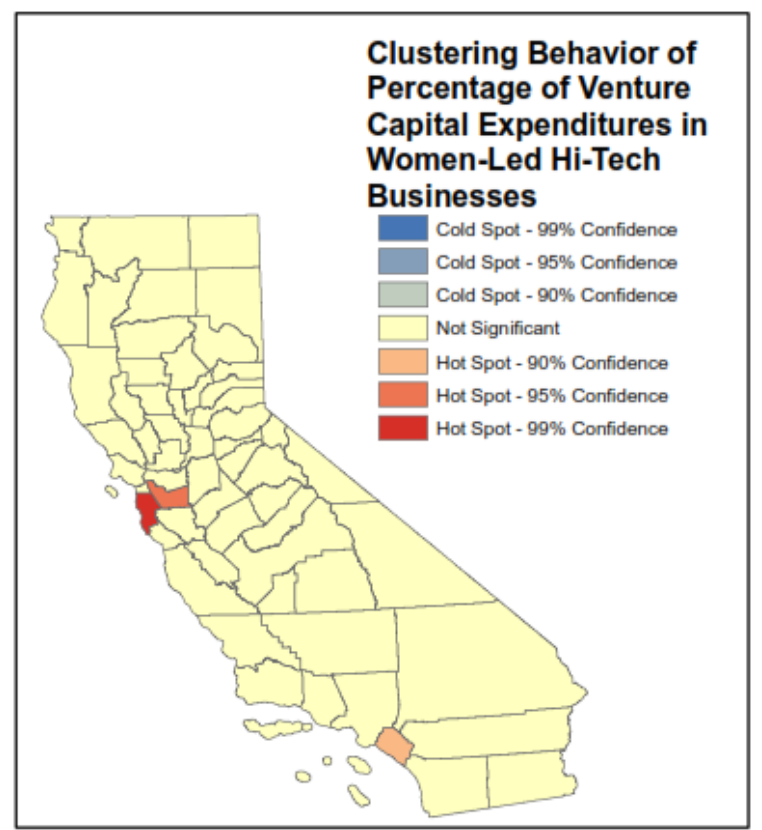

Figure 42. Cluster Behavior of Venture Capital Expenditures to Women-Led Hi-Tech Businesses in Biotech in 2014 by California County (Source:

PricewaterhouseCoopers/National Venture Capital Association, 2015) 
In sum, this section reviewed the major quantitative exploratory analysis for the study, which motivate the need for further focused analyses using more sophisticated methods to account for high proportions of zeros and skewness of the data. Alternative quantitative measures also should be explored at a variety of spatial scales, in addition to investigating covariation amongst variables. The next section, the Discussion, shall analyze the significance of these findings.

\section{Discussion}

This chapter covers the implications of the study findings and focuses on how the qualitative and quantitative findings support the current literature on the impact of business industry formation factors on women entrepreneurs in the hi-tech and biotech sectors. Specifically, five study findings will be interpreted. This includes (1) the percentage of businesses that participated in an incubator or accelerator within geographic business clusters, (2) potential reasons for the low numbers of women business leaders in hi-tech and biotech, (3) the percentages of companies that were spun out of a university, (4) how biotech as a sector was more open to women than hi-tech, and (5) the lower percentages of women receiving venture capital funding as compared to men.

\section{Business Participation in an Accelerator or Incubator}

While it did not come as a surprise that higher numbers of hi-tech or biotech businesses were geographically concentrated in certain areas, the real estate that each business occupied and the formative programs those businesses were involved with were not so obvious. Qualitative results from the study showed that $35 \%$ of companies 
interviewed participated in an accelerator or incubator program, both of which are designed to encourage faster growth of small companies. As previously stated, while similar in function, accelerators and incubators differ in formality and cost, and take on companies of different sizes and at different stages of development. Fifty percent of the biotech companies interviewed were currently located within or had participated in an incubator, meaning they held an office or lab-space real estate agreement with the incubator that provided access to a shared office and lab equipment that would otherwise be very costly. Twenty percent of hi-tech businesses included in the study participated in an accelerator program, which, unlike incubators, consists of a more formal trade between the business and the program. All firms interviewed exchanged a portion of company equity to participate in the program designed to quickly get businesses to further growth levels in a short period of time under the advisement of a team of industry experts. Both incubators and accelerators could be sponsored by a university, major corporation, government entity, venture capital firm, or other funding source, and are typically found in areas with a high number of industry-related businesses, further encouraging the concept of a geographic industry hub.

While the high percentage of businesses interviewed that had been involved with accelerators and incubators was surprising, it was difficult to determine if this pattern applies to both the biotech and hi-tech industries or if this was specific to women led businesses. As discussed in the literature review, author Mayer (2008) has shown that women-run businesses tend to be smaller and less profitable than their male-led equivalents, making the higher overhead costs associated with real estate and employee 
compensation within industry hubs more challenging. Given the smaller size and revenues of women-led businesses, being in geographic proximity to an industry hub and gaining access to its resources through an incubator or accelerator program become all the more advantageous.

While the quantitative data indicate an overall exploratory pattern of geographic concentration of both hi-tech and biotech businesses in their known hubs (see Figures 8 and 10), the data also indicate different patterns of geographic concentrations for the women-led companies included in the study that deviate from the known hi-tech and biotech hubs of the bay area and southern California regions, respectively. Specifically, for biotech businesses, a hot spot can be found in the Southern California region (see Figure 10), though the percentage of women-led companies within the region is small, and higher percentages of women-led companies are located along the outskirts of the hub (see Figure 11). Similarly, hot spots of hi-tech companies were indicated in both the Bay Area and Southern California regions (see Figure 8), with lower percentages of women-led businesses observed in those regions, and higher percentages of women-led businesses located outside the Bay Area hub. These exploratory results for both biotech and hi-tech businesses included in the study provide some support of the work done by Mayer (2008), which found that women-led businesses, being smaller in size and profits than men-led businesses, were less often located within an industry hub, as they were able to pay less in rents and employee compensation in areas outside of the hub. We do note, however, that the quantitative hot spot analysis are exploratory, and that more sophisticated analyses are needed due to high proportions of zeros and skewness in the 
measures for many variables. Also the sizes and productivity of the companies should be considered in future work. Though there are currently no data about the percentage of businesses that have been involved with an incubator or accelerator, this would be an interesting topic for future studies.

\section{Reasons for Low Percentages of Women Business Leaders in Hi-Tech and Biotech}

The study also focused on the potential contributing reasons of underrepresentation of women leaders in both the biotech and hi-tech industries of STEM. Several reasons for women's generally lower participation within these fields have been

cited, such as industry stereotypes, women's minority status, lack of female role models, discrimination, gender differences in cognitive development and scientific performance, and low enrollment in corresponding college majors. The low proportion of women enrolled in computer science programs specifically has been termed by researchers as the “incredible shrinking pipeline," as lower numbers of women with educational backgrounds in the field result in lower numbers of qualified women as candidates for employment. The lower numbers of women entrepreneurs in these fields have been attributed to women owning businesses in female-typed sectors where they have previous work experience (such as service sectors, teaching, retail, or social assistance) and to the additional difficulties that women face in balancing both family and business priorities.

The women interviewed supported the ideas about the contributing factors for lower women's participation in the STEM fields of hi-tech and biotech that were discussed in the literature review. The overwhelming majority of interviewees indicated that they had not envisioned a leadership role for themselves and that they had founded 
their businesses because of a personal cause they were passionate about. As was reported by the Bayer Corporation (2010), interviewees stressed that they had been frequently discouraged by professors from pursuing hi-tech majors in college and by the overall difficulty of breaking through the inertia in fields dominated by men. With respect to the lower representation of women business leaders in STEM, the majority of interviewees cited pattern recognition and differential treatment from venture capitalists and others, discomfort in competing in a male dominated culture, and an inability to have a work-life balance, specifically one that allowed them to be both a mother and a business leader. Although seen as successful, all interviewees noted that they still had ongoing personal struggles with these professional and life roles.

Exploratory quantitative findings from this study also supported the idea that women are under-represented as business leaders, in terms of both the lower numbers of women business leaders in hi-tech and biotech, and the number and size of venture capital deals secured by women within these industries. Study data found that in February 2015, only $20 \%$ of the biotech businesses in California were women-led, and that they received only $13.5 \%$ of venture capital deals and only $3.1 \%$ of the total venture capital expenditures in 2014. Similarly, study data found that only $15 \%$ of the state's hitech businesses were women-led in February 2015, and that they received only 5.5\% of the venture capital deals, for a total of $5.7 \%$ of expenditures, in 2014. While it is difficult to map out many of the contributing factors mentioned above, a topic of interest for future studies would be looking at the geographic relationship between women enrolled in related academic majors to the number of women-led companies within those fields. 


\section{Businesses Spun Out of University}

Regarding the importance of academe, $50 \%$ of all companies interviewed were started in connection with the founder's alma mater university. As mentioned previously, the interviewees were an educated group of women, all of them having at least a bachelor's degree and 65\% having an advanced degree. Eighty-five percent of the interviewees acknowledged the positive role that the university had on their career. Importantly, the connections that the interviewees made while acquiring a university degree were paramount to starting a successful company. Almost all of the companies included in this study were founded with the help of the interviewee's faculty advisor, or through a university-offered course or program aimed at entrepreneurship. In the case of the former, when the company was set up with assistance from the interviewee's faculty advisor, the advisor would typically sit on the company's board and continue to advise the company after the company was founded. This provided the company the advantage of a connection to the university and resources such as grant funding, a talented labor pool of students, and an open knowledge base of current research findings. In the latter case, when the company was founded through a university-offered course or program, the interviewees had access to the talent pool of skilled students and to faculty advice, and easier access to funds for their resultant ventures.

The high percentages of companies founded through the university supports the current literature and notions of university knowledge spillovers that contribute to industry hub formation (Mayer, 2007; Saxenian, 1996). The literature states that knowledge spillovers from universities follow from the links that are made when 
university administrators assist in the formation of new businesses and when a specialized and talented labor pool is provided to nearby businesses, and from the funding of research by university R\&D that translates into new products. When business owners have connections within a university, the connections can lead to an exchange of ideas and information that is mutually beneficial to both parties. For example, business owners can be a source of information on current market trends to the university, of employment for recent graduates, and of contract funds for research, whereas the university can provide skilled employees, courses and community development, new research findings and innovations, access to university facilities, and contracted research and development.

Quantitative factors assessed in this study pertained to the numbers of universities per county and the amounts of R\&D expenditures for both the biotech and hi-tech sectors. An exploratory analysis based on the methodology of ESRI's hot spot analysis tool indicated geographic clusters of university R\&D for both hi-tech and biotech industries located in the Southern California region. The analysis tool was sensitive to the true skewed nature of the data, meaning there was not a normal, bell curved shaped distribution of data due to the large amount of counties with zero values (see Figures 13 and 15), and results should therefore be viewed with caution. Further analyses are needed with more sophisticated methods to account for the skewed nature of the data. While the Bay Area did not come up in hot spot analysis showing geographic clusters of university $R \& D$ expenditures, the tools' sensitivity to the skewed nature of the data 
should again be emphasized, with the hope of using alternative geostatistical tools that can handle such data in the future.

\section{Biotech Sector More Open to Women than Hi-Tech}

This study, as was demonstrated by both the qualitative and quantitative data, found biotech to be a more open technology field for women. The literature review attributed the higher percentages of women in the biotech industry (compared to other technology industries) to higher percentages of women having educational backgrounds in biology (Priluck, 2010). Interviews in this study confirm those findings, and note additional differences between the hi-tech and biotech industries. The quantitative data also supports the notion of higher numbers of women leaders, and higher numbers of venture capital deals being secured by women in biotech versus hi-tech.

The literature review noted a disparity between the participation of women in hitech and biotech, with women representing $46 \%$ of all positions in biological and life sciences, and only 26\% in professional computing professions (Priluck, 2010; Catalyst, 2013). That same pattern was also revealed in the literature review regarding womenfounded businesses, with $12 \%$ of biotech founders being female, compared to $1 \%$ of hitech firms (McQuaid, Smith-Doerr, and Monti, 2010). The trend of higher percentages of women in biotech is believed to be due to higher percentages of women having an educational background in biology and life sciences, compared to computer science. The low percentage of women in computer science programs is known as the incredible shrinking pipeline, as women are resultantly not adequately represented in the employment talent base. The low proportion of women in technology is detrimental not 
only to the hi-tech industry because of the lack of diversity, but also to women since they miss out of the economic earning potentials of the hi-tech field, which has higher wages and a smaller gender wage gap than in other fields, namely, a $14 \%$ wage gap in the hitech sector, versus a $21 \%$ wage gap in non hi-tech sectors.

The differences between the hi-tech and biotech business leaders that were interviewed for this study substantiate the above. These biotech business leaders were usually more educated, with $90 \%$ of them holding an advanced degree, compared to $40 \%$ of hi-tech interviewees. Biotech interviewees were also more apt to say that their education had been beneficial to their career, with $100 \%$ of respondents believing their education had been beneficial to their success, compared to $70 \%$ of hi-tech interviewees. Additionally, $60 \%$ of biotech respondents founded their firm alongside their alma mater, as opposed to $40 \%$ of hi-tech respondents. Women-led biotech companies were also more likely to participate in an incubator or accelerator, with $50 \%$ being connected to one of these programs at some point, compared to $20 \%$ of hi-tech companies amongst the interviewed. There were also differences between the two sectors related to funding experiences. Women-led biotech interviewees discussed bootstrapping as a financing mechanism $10 \%$ of the time, whereas hi-tech interviewees mentioned it $50 \%$ of the time. Additionally, 50\% of biotech respondents mentioned positive, company-advancing interactions with venture capitalists, compared to $20 \%$ of hi-tech respondents. Finally, biotech respondents were more apt to acknowledge the benefits of being geographically proximate to university resources ( $40 \%$ of biotech compared to $10 \%$ of hi-tech), and being close to a specialized talent pool (30\% of biotech and $10 \%$ of hi-tech interviewees.) 
The quantitative data also supported the idea of the biotech industry being more open to women than the hi-tech industry. The study revealed that in February 2015, 20\% of the biotech businesses were women-led, compared to $15 \%$ of hi-tech businesses. The study findings also revealed that venture capital deals in 2014 told a somewhat similar story, with $13.5 \%$ of deals going towards women-led biotech companies, compared to $5.5 \%$ of deals going towards women-led hi-tech companies. Finally, the study determined that venture capital expenditures were relatively close in terms of percentages of expenditures to women-led companies, with $3.1 \%$ and $5.7 \%$ of expenditures going to women-led biotech and hi-tech businesses, respectively. While it was not within the scope of this study, it would useful for future studies on this topic to gather and assess data on the number of degrees held by women in hi-tech and biotech, both bachelor and advanced degrees, and to investigate to what extent these women went on to have successful careers as senior leaders in the hi-tech and biotech industries.

\section{Low Percentages of Women Receiving Venture Capital}

As stated in the literature review, women receive less venture capital funding than their male counterparts, specifically less than $10 \%$ in the last 40 years and $4.1 \%$ during the 1990s (Brush, Carter, et al, 2004). In addition to monetary funds, receiving lower levels of venture capital support deprives women of a leading factor in new enterprise formation, as venture capitalists act as ambassadors of the companies they support through social networks, contacts, and guidance. Venture capital, and the guidance provided by those that supply it, is very important to businesses, especially in cashhungry industries such as hi-tech and biotech. Existing literature cites lower 
representations of women both amongst venture capitalists and amongst entrepreneurs applying for funding as the reason for lower attainment of venture capital by women (Gatewood et al., 2003). Another reason for the lower amounts of venture capital funding given to women that is cited by the literature is differences between men's and women's social networks, as there is little opportunity for the introduction of womenoriented social networks to the predominately male social networks of venture capitalists (Loscoccoo \& Robinson, 1991).

All the women interviewed had previous experiences in obtaining venture capital, and mentioned in detail their challenges and difficulties in securing funding. The women interviewed also discussed alternate options of financing, namely bootstrapping, using their own funds, or getting loans from friends and family, and the difficulties of making business decisions with funds as a limiting resource. Positive aspects of venture capital were discussed and supported the notion of venture capitalists being advantageous to entrepreneurs trying to build up a business through connections, industry expertise, and guidance. While interviewees stressed that getting funding was difficult regardless of gender, they also expressed their opinions on potential reasons why women secure less funding than men. The women most often cited pattern recognition and a tribal way of investing —or "like investing in like" —on the part of the venture capitalists as reasons for lower numbers of women getting funding. The interviewees also cited the low proportion of women in venture capital as a discouraging factor, as well as different social networks of men and women, differences in competition and pitching methods between men and women, and fear among investors of gender-based legal retaliation if a deal went sour. 
The women interviewed were quick to mention the importance of geography, specifically, a company's proximity to venture capital. Women who had companies in Silicon Valley were more apt to describe the benefits of proximity to venture capital firms, whereas women located well outside of the known hubs, namely those located in Maryland and Arizona, cited additional challenges in obtaining funding, even to the point of relocating the company to be closer to funding resources.

Study findings revealed that in 2014, women-led firms received $13.5 \%$ and $5.5 \%$ of all venture capital funding going towards the biotech and hi-tech sectors, respectively. These findings from the study support the literature, and fall in line with the figure of 5\% of venture capital funding going towards women-led hi-tech companies that is cited in previous studies (Brush, Carter, et al, 2004). For future studies, it would be interesting to explore the relationship between percentages of women getting venture capital funding and the percentages of women business leaders within sectors.

\section{Conclusion}

\section{Chapter Introduction}

This chapter provides the conclusion to the study. The chapter begins with a summary of the empirical findings, which explore geographic distribution and clustering behavior of factors believed to encourage the formation of hi-tech and biotech business hubs. The chapter then moves to reviewing how the factors that encourage business aggregation in hubs impact women entrepreneurs in the hi-tech and biotech sectors. Finally, the chapter closes with implications of the study and ideas for future research. 


\section{Summary of Findings}

The literature review revealed that businesses in both biotech and hi-tech are potentially lucrative and known to cluster geographically, providing economic benefits to the regions they occupy. Geographic clusters are also beneficial for businesses that reside within them, as they put the business in proximity to factors that further propel their growth, such as access to venture capital, a skilled labor pool, and university resources. While this self-reinforcing cycle of business clustering provides benefits both to the regions they occupy and to the businesses within them, both of these sectors are known to be predominantly male dominated, with an under-representation of women. This under-representation of women in hi-tech and biotech can be seen in the workforce as a whole and in upper-echelon positions, such as business leaders. This is problematic for the female workforce, which is left out of the earnings potential of these industries, and for the industry sectors themselves, which are set to grow exponentially but do not have their projected needs met by the current supply of domestic skilled labor.

Specifically, previous literature has focused on either the business cluster formation or on the causality of under-representation of women in the workforce as well as the lower numbers of women entrepreneurs in STEM fields. Typically, previous studies focused on exploration of factors that contribute to business cluster formation, women's participation in STEM fields, or the representation of women as entrepreneurs. Little research has been done to combine these factors, to explore how factors that contribute to business clusters impact women business leaders, how women succeeded in professions held more frequently by men, and as business leaders and entrepreneurs in 
predominantly male oriented industries. Thus, this study aimed to look at the impact of factors believed to contribute to successful business cluster formation on women business leaders within the fields of hi-tech and biotech, with an emphasis on the state of California.

This section provides a brief review of the key findings of the qualitative and quantitative components of the study, including the results of exploratory geospatial analysis and the research findings of 20 interviews with women business leaders in hitech and biotech.

\section{Quantitative Study Components}

Overall, factors believed to be behind the self-reinforcing cycle of business cluster formation were seen to be subject to geographic concentration and clustering, in terms of the number of industry sector businesses, venture capital expenditures, and university presence. Geographic clustering, having resulting in hot spots of activity, was indicated in the number of hi-tech businesses, biotech businesses and universities, in R\&D expenditures, and in the number of venture capital deals awarded in both the hi-tech and biotech industry sector hubs. Exploratory clustering results motivated the need for more sophisticated analyses in future studies. The distribution of women-led businesses in hitech and biotech was very different from overall business distribution in these sectors, with the number of women-led businesses being lower and the geographic distribution of women-led businesses often not in the highest percentages within the industry hub. This was especially true for biotech and hi-tech clusters found in the Bay Area and Southern California regions. We note, however, that the size and revenue of the company were not 
taken into account. The tendency for women-led businesses to be located just outside of industry hubs could be a matter of higher overhead costs, such as rent and salaries associated with those hubs. The study found that women, especially those in the biotech field, start businesses through connections made at university or in university courses aimed at entrepreneurship. These tie-ins to universities allowed the women access to hub resources.

Biotech businesses seemed relatively more open to women's participation, as can be seen in the quantitative data (as it relates to the number of women-led businesses and venture capital deals) and in the qualitative data (in the higher number of women interviewees with advanced degrees, the higher percentages of women starting their business alongside their alma mater, the higher percentages in accelerators, the higher number of businesses, and the higher numbers accessing venture capital funding).

\section{Qualitative Study Components}

The women interviewed were business founders and C-level executives in the biotech and hi-tech sectors. Both sectors are known to be predominantly male dominated, with only $20 \%$ and $15 \%$ women business ownership in those fields in the state of California as of February 2015. The interviews aimed to investigate how factors thought to influence the formation of business clusters, namely venture capital access, university resources, and access to a skilled labor pool, impacted women's business ventures in biotech and hi-tech sectors. Interview questions focused on leadership histories, factors that contributed to leadership aspirations, challenges encountered by and the perseverance of the women, the influence of university and education, experiences with 
funding, potential reasons for lower numbers of women business leaders in STEM, and possible ways of encouraging further participation of women. Underlying the conversations were the perspectives and insights of the women interviewees about the importance of geography to success of their businesses.

The women described their leadership backgrounds and their experiences in positions typically held by men in these male-dominated fields. While many women claimed they did not realize they were in the minority until later in life, the majority of all women interviewed noted the inertial challenges that follow from the present domination of men in STEM fields and the difficulties of getting established in those industries as a minority gender. The interviewees stressed that inertia starts at a young age, with lower numbers of women enrolled in related majors at university, where they are often times dissuaded from the major by professors (particularly in hi-tech). Women interviewees were then faced with lower numbers of women in their profession in entry-level positions and management positions, which some argued could further discourage participation in the industry due to a lack of female mentors or role models. The study found that the women who pursued the path of business leadership confronted additional issues of trying to raise money in the male-dominated field of venture capital. The venture capital field, being male dominated, is not favorable to women since venture capitalists are not within their social networks and have a preconceived notion of what a successful entrepreneur looks like, which is similar to themselves and results in gender discrimination. These barriers came on top of the added challenge of finding an adequate work-life balance. Despite the strides women in general have made in the workplace, 
these women were still more often than not the primary childcare givers and had a difficult time balancing the needs of small children and the demands of a growing business.

Nevertheless, the women interviewed found ways to succeed as business leaders, through a combination of either experiential or innate factors. Experientially, the women interviewed uncovered ways to gain further traction as business leaders through pursuing higher education, creating businesses alongside universities, participating in business accelerators and incubators, and exploring options to further reduce the gender gap in these sectors going forward. These women business leaders also cited advantages as business leaders in predominately male dominated industries, such as being able to more easily recruit women employees to their organizations (enabling them to access the benefits of a more diverse workforce), more memorability and name recognition, and the ability to utilize direct attempts to target the gender gap through funding and conference presentation opportunities.

Several similarities in innate driving factors were found amongst the women interviewees, some of which included personality characteristics such as tenacity, focus, resilience, and a determination to succeed in their business ventures. The majority of women interviewed mentioned a desire to have a positive impact upon the world, whether through the mission of their company, philanthropy, or through mentoring young women and further reducing the gender gap in STEM. One theme that was present in many of the interviews was the need to change the conversation about women business leaders in STEM into a more positive one, into a conversation that focuses not on gender disparities 
and discrimination, but rather frames things in a more positive light, highlighting the progress women are making, their successes, and the impacts they are having in the world. The current negative tone of the conversation is further discouragement to those working to succeed within these sectors and to the women debating pursuing their dreams of business leadership. Instead of focusing on the current problems due to pattern recognition, the focus should become how to most effectively change the pattern.

\section{Future Research}

This study has implications for future research of women business leaders in both the hi-tech and biotech sectors. Women business leaders in both the hi-tech and biotech sectors are under-represented, in terms of the number of their businesses and the amount of venture capital their businesses receive. Future studies could use more sophisticated methods in bivariate geo-statistical analysis to further explore the relationship between the number of women-led businesses in the sectors, venture capital expenditures, and university R\&D expenditures. This study could also be expanded to additional geographical hubs and industries for further analysis. This analysis would be of interest in reflecting on how to encourage further participation of women in fields of hi-tech and biotech, particularly as business leaders in these sectors. 


\section{BIBLIOGRAPHY}

Adams, R. B. and Ferreira, D. (2009). Women in the boardroom and their impact on governance and performance. Journal of Financial Economics 94(2), 291-309.

Ahl, H. (2006). Why research on women entrepreneurs needs new directions. Entrepreneurship: Theory and Practice 30(5), 595-621.

Aldrich, H. (1989). Networking among women entrepreneurs. In O. Hagan, C. Rivchun and D. Sexton (Eds.), Women-Owned Businesses. New York: Praeger Publishers.

Almeida, P. and Kogut, B. (1997). The exploration of technological diversity and the geographic localization of innovation. Small Business Economics 9(1), 21-31.

Alsos, G. A., Isaksen, E. J. and Ljunggren, E. (2006). New venture financing and subsequent business growth in men-and women-led businesses. Entrepreneurship Theory and Practice 30(5), 667-686.

American Express OPEN. (2014). State of Women-Owned Business Report. Retrieved from http://www.womenable.com/content/userfiles/2014_State_of_Womenowned_Businesses_public.pdf

Arthur, W. B. (Ed.). (1994). Increasing Returns and Path Dependence in the Economy. University of Michigan Press.

Audretsch, D. B., and Feldman, M. P. (2004). Knowledge spillovers and the geography of innovation. Handbook of Regional and Urban Economics 4, 2713-2739.

Audretsch, D. B. and Stephan, P. (1996). Company-scientist locational links: The case of biotechnology. American Economic Review 86(4), 641-652.

Bay Area Census (2010). Retrieved from http://www.bayareacensus.ca.gov/bayarea.htm

Bayer Corporation. (2010, March). Executive summary. Bayer Facts of Science Education XIV: Female and Minority Chemists and Chemical Engineers Speak About Diversity and Underrepresentation in STEM. 15-21.

Beaverstock, J. (1996). Sub-contracting the accountant!: Professional labor markets, migration and organizational networks in the global accountancy industry. Environment and Planning A 28, 303-326.

Beaverstock, J. and Smith, J. (1996). Lending jobs to global cities: Skilled international labor migration, investment banking and the city of London. Urban Studies 33(8), 1378-1394. 
Becker-Blease, J. R. and Sohl, J. E. (2007). Do women-owned businesses have equal access to angel capital?. Journal of Business Venturing 22(4), 503-521.

Bell, L. A. (2005). Women-led firms and the gender gap in top executive jobs. Business $1689,1-41$.

Biernacki, P., \& Waldorf, D. (1981), Snowball sampling: Problems and techniques of chain referral sampling. Sociological Methods \& Research, 10(2), 141-163.

Bollinger, J. (2013, May 24). The tech gender gap: Title analysis. Retrieved from http://www.fastcompany.com/3008216/tracking/minding-gap-how-yourcompany-can-woo-female-coders

Branson, D., (2006). No Seat at the Table: How Corporate Governance keeps Women out of America's boardrooms. New York: New York University Press.

Bruder, J. (2010). We need more female Venture Capitalists. Retrieved from http://www.forbes.com/2010/06/30/venture-capital-women-finance-forbeswoman-net-worth-business.html

Brush, C.G., (1992). Research on women business owners: Past trends, a new perspective and future directions. Entrepreneurship, Theory and Practice 14(1), 7-26.

Brush, C., Carter N., Gatewood E., Greene P., Hart M. (2001). Women business owners and equity capital: The myths dispelled. Retrieved from http://www.dianaproject.org/Data/publications/publicationsfordow/themythsdispe lled/myths_dispelled.pdf

Brush, C., Carter, N., Gatewood, E., Greene, P. and Hart, M. (2004). Gatekeepers of venture growth: A Diana project report on the role and participation of women in the venture capital industry. Retrieved from

http://www.dianaproject.org/Data/publications/publicationsfordow/gatekeepersof ventu/gatekeepers_of_venture_growth.pdf

Brush, C., Carter, N., Gatewood, E., Greene, P. and Hart, M. (2009). Women business owners and equity capital: The myths dispelled. Babson College Center for Entrepreneurship Research Paper 2009-11.

Caldas de Castro, C. M. and Singer, B. H. (2006). Controlling the false discovery rate: A new application to account for multiple and dependent test in local statistics of spatial association. Geographical Analysis 38, 180-208. 
Canning, J., Haque, M., and Wang, Y. (2012). Women at the wheel: Do female executives drive start-up success?. Retrieved from http://www.goldenseeds.com/content/PDFs/WomenPE_report_final.pdf

Catalyst. (2004). Connecting Corporate Performance and Gender Disparity. Retrieved from http://www.catalyst.org/system/files/The_Bottom_Line_Connecting_ Corporate_Performance_and_Gender_Diversity.pdf

Catalyst. (2007). The Bottom Line: Corporate Performance And Women's Representation on Boards. Retrieved from http://www.catalyst.org/knowledge/bottom-line-corporate-performance-andwomens-representation-boards

Catalyst. (2013). Census of Women Board Directors of the Fortune 1000. Retrieved from http://www.catalyst.org/knowledge/2013-catalyst-census-fortune-500-womenboard-directors

Ceci, S. J. and Williams, M. W. (2010). Sex differences in math-intensive fields. Current Directions in Psychological Science 19, 275-279.

Collins, B. W. (2007). Tackling unconscious bias in hiring practices: The plight of the Rooney rule. NYUL Rev., 82, 870.

Corporate Women Directors International (CWDI) (2007). Women board directors of the Fortune Global 200. Retrieved from www.globewomen.com/cwdi/ CWDI.html

Dosi, G. (1982). Technological paradigms and technological trajectories: A suggested interpretation of the determinants and directions of technological change. Research Policy 11, 147-162.

Ensmenger, N. L. (2012). The Computer Boys Take Over: Computers, Programmers, and the Politics of Technical Expertise. Cambridge, Massachusetts: MIT Press.

Environmental Systems Research Institute. (2016, April 30). Cluster and Outlier Analysis (Anselin Local Moran's I). Retrieved from http://pro.arcgis.com/en/pro-app/toolreference/spatial-statistics/cluster-and-outlier-analysis-anselin-local-moran-s.htm

Environmental Systems Research Institute. (2016, April 30). Data Classification Methods. Environmental Research Institute. Retrieved from http://pro.arcgis.com/en/pro-app/help/mapping/symbols-and-styles/dataclassification-methods.htm

Environmental Systems Research Institute. (2016, April 30). Hot Spot Analysis (GetisOrd $\left.G i^{*}\right)$. Retrieved from http://desktop.arcgis.com/en/arcmap/10.3/tools/spatialstatistics-toolbox/hot-spot-analysis.htm 
Environmental Systems Research Institute. (2016, April 30). How Hot Spot Analysis (Getis-Ord $\mathrm{Gi}^{*}$ ) works. Retrieved from http://desktop.arcgis.com/en/arcmap/10.3/tools/spatial-statistics-toolbox/h-howhot-spot-analysis-getis-ord-gi-spatial-stati.htm

Faulconbridge, J., Beaverstock, J. and Hall, S. (2009). The "war for talent": The gatekeeper role of executive search firms in elite labour markets. Geoforum 40(5) 800-808.

Findlay A. M., Li, F., Jowett, A., Skeldon, R. (1996). Skilled international migration and the global city: A study of expatriates in Hong Kong. Transactions of the Institute of British Geographers 21(1), 49-61.

Forbes. (2011). Global diversity and inclusion: Fostering innovation through a diverse workforce. Retrieved from http://images.forbes.com/forbesinsights/StudyPDFs/Innovation_Through_Diversit y.pdf

Freear, J., Sohl, \& Wetzel, W. (1995), “Angels: Personal Investors in the Venture Capital Market," Entrepreneurship and Regional Development, (7), pp. 85-94.

Gatewood, E. J., Carter, N. M., Brush, C. G., Greene, P. G. and Hart, M. M. (2003). Women entrepreneurs, their ventures, and the venture capital industry: An annotated bibliography. Stockholm: ESBRI (Entrepreneurship and Small Business Research Institute). Retrieved from http://www.hbs.edu/faculty/Pages/ item.aspx?num=14747

Gatewood, E. J., Brush, C. G., Carter, N. M., Greene, P. G. and Hunt, M. M. (2009). Diana: A symbol of women entrepreneurs' hunt for knowledge, money, and the rewards of entrepreneurship. Small Business Economics 32, 129-144.

Getis, A. and Ord, J. K. (2008). The analysis of spatial association by use of distance statistics. Perspectives on Spatial Data Analysis Advances in Spatial Science, 127-145. doi:10.1007/978-3-642-01976-0_10

Goldman Sachs. (2013, April 25). Women's work: Driving the economy. Equity Research: Fortnightly Thoughts, 53. Retrieved from http://www.goldmansachs.com/our-thinking/investing-in-women/researcharticles/womens-work.pdf

Greene, P. G., Hart, M. M., Gatewood, E. J., Brush, C. G. and Carter, N. M. (2003). Women entrepreneurs: Moving front and center: An overview of research and theory. Coleman White Paper Series 3, 1-47. 
Harpern, D. F., Benbow, C. P., Geray, D. C., Gur, R., Hyde, J. S. and Grensbacher, M. A. (2007). The science of sex difference in science and mathematics. Psychological Science in the Public Interest, 8, 1-51. Retrieved from http://134.173.180.115/berger/pdf/Halpern2007.SciSexDif.Pub.pdf

Harrison, R. T. and Mason, C. M. (2007). Does gender matter?: Women business angels and the supply of entrepreneurial finance. Entrepreneurship: Theory and Practice $31(3), 445-472$.

Hewlett, S. A., Buck Luce, C., Servon, L. J., Sherbin, L., Shiller, P., Sosnovich, E. and Sumberg, K. (2008). The Athena factor: Reversing the brain drain in science, engineering, and technology. Retrieved from http://documents.library.nsf.gov/edocs/HD6060-.A84-2008-PDF-Athena-factorReversing-the-brain-drain-in-science,-engineering,-and-technology.pdf

Jaffe, A. B., Trajtenberg, M. and Fogarty, M. S. (2000). Knowledge spillovers and patent citations: Evidence from a survey of inventors. American Economic Review 90, 215-218.

Kelley, D. J., Singer, S. and Herrington, M. (2012). The global entrepreneurship monitor. 2011 Global Report, GEM 2011, 7.

Kenney, M. (2000). Understanding Silicon Valley: The Anatomy of an entrepreneurial region." Stanford Business Books. Retrieved from http://www.sup.org/books/title/?id=654

Löfsten, H. and Lindelöf, P. (2002). Science parks and the growth of new technologybased firms - academic-industry links, innovation and markets. Research Policy 31(6), 859-876.

Loscocco, K. and Robinson, J. (1991). Barriers to women's small-business success in the United States. Gender and Society 5(4), 511-532.

Malecki, E. (1997). Entrepreneurs, networks, and economic development: a review of recent research. Advances in Entrepreneurship, Firm Emergence and Growth, 3, 57-188.

Mayer, H. (2007). What is the role of the university in creating a high-technology region?. Journal of Urban Technology 14(3), 33-58.

Mayer, H. (2008). Segmentation and segregation patterns of women-owned high-tech firms in four metropolitan regions in the United States. Regional Studies, 13571383. 
McQuaid, J., Smith-Doerr, L. and Monti, D. J. (2010). Expanding entrepreneurship: Female and foreign-born founders of New England biotechnology firms. American Behavioral Scientist 53(7), 1045-1063.

Miller, C. C. (2012). In Google's inner circle, a falling number of women. The New York Times. Retrieved from http://www.nytimes.com/2012/08/23/technology/ingoogles-inner-circle-a-falling-number-of-women.html?_r=0

Miller, W. F., Hancook, M. and Rowen, H. (2000). The Silicon Valley edge: A habitat for innovation and entrepreneurship. Stanford: Stanford University Press.

Monck, C. S. P., Porter, R. B., Quintas, P., Storey, D. J. and Wynarczyk, P. (1988). Science Parks and the Growth of High Technology Firms. London: Croom Helm.

Morrison, A. M., White, R. P. and Van Velsor, E. (1987). Breaking the Glass Ceiling. Boston: Addison-Wesley Publishing Company.

Murack, J. (2015, September 20). Regression Analysis using ArcMap. Retrieved from https://libraries.mit.edu/files/gis/spatial_auto_presentation_iap2013.pptx

National Science Foundation. (2004). Broadening participation in America's science and engineering workforce: The 1994-2003 decennial and 2004 biennial reports to congress by Committee on Equal Opportunities in Science and Engineering. Retrieved from http://www.nsf.gov/od/ceose/reports/ceose2004report.pdf

National Science Foundation. (2009). Women, Minorities, and Persons with Disabilities in Science and Engineering. Retrieved from http://www.nsf.gov/statistics/wmpd/

National Science Foundation. (2010). Women, Minorities, and Persons with Disabilities in $S \& E$. Retrieved from http://www.nsf.gov/statistics/women/

National Women's Business Council. (2012). Intellectual Property and Women Entrepreneurs. Retrieved from https://www.nwbc.gov/sites/default/files/IP\%20\&\%20Women\%20Entrepreneurs. pdf

National Women's Business Council. (2014). Building Bridges: Leveraging Research and Relationships to Impact the Business Climate for Women (2014 Annual Report). Retrieved from: http://nawbo.org/pdfs/NWBC\%20FY14\%20Annual\%20Report.pdf

Ord, J. K. and Getis, A. (2010). Local Spatial Autocorrelation Statistics: Distributional Issues and an Application. Geographical Analysis, 27(4), 286-306. doi:10.1111/j.1538-4632.1995.tb00912.x 
Østergaard, C. R., Timmermans, B. and Kristinsson, K. (2011). Does a different view create something new?: The effect of employee diversity on innovation. Research Policy 40, 500-509.

Porter, M. E. (1998). Clusters and the new economics of competition. Harvard business review 76(6), 77-90.

Post-Kammer, P. and Smith, P. L. (1985). Sex differences in career self-efficacy, consideration, and interests of eighth and ninth graders. Journal of Counseling Psychology 32, 551-559.

Powell, W. W., Koput, K. W., Bowie, J. I. and Smith-Doerr, L. (2002). The spatial clustering of science and capital: Accounting for biotech firm-venture capital relationships. Regional Studies 36(3), 291-305.

Prevenzer, M. (1997). The dynamics of industrial clustering in biotechnology. Small Business Economics 9(3), 255-271.

Priluck, J. (2010). The Biotech Advantage: Why Women Start Biotech Firms at Higher Rates Than They Start Other Kinds of High-Tech Firms. Slate. Retrieved from http://www.slate.com/articles/business/small_business/2010/10/the_biotech_adva ntage.html

Quintana-Garca, C. and Benavides-Velasco, C. A. (2008). Innovative competence, exploration and exploitation: The influence of technological diversification. Research Policy 37, 492-507.

Randall, C., Price, B.\& Reichgelt, H. (2003). Women in computing programs: Does the incredible shrinking pipeline apply to all computing programs? SIGCSE Bull $35(4), 55-59$.

Richardson, K. (2015). Attracting and retaining foreign highly skilled staff in times of global crisis: A case study of Vancouver, British Columbia's biotechnology sector. Population, Space and Place. Retrieved from http://onlinelibrary.wiley.com/doi/10.1002/psp.1912/abstract

Robb, A. M. and Coleman, S. (2010). Financing strategies of new technology-based firms: A comparison of women-and men-owned firms. Journal of Technology Management and Innovation 5(1), 30-50.

Robb, D. (2003, January 6). IT Gender Gap Widening. EarthWeb. Retrieved from http://www.datamation.com/career/article.php/1564501/IT-Gender-GapWidening.htm 
Rosenblatt, R. A. (1995, March 16). “Glass Ceiling” Still Too Hard to Crack, U.S. Panel Finds. Los Angeles Times, A1, A18

Sawada, M. (2016, April 30). Global Spatial Autocorrelation Indices - Moran's I, Geary's $C$ and the General Cross-Product Statistic. Retrieved from http://www.lpc.uottawa.ca/publications/moransi/moran.htm

Saxenian, A. (1996). Regional Advantage: Culture and Competition in Silicon Valley and Route 128. Cambridge: Harvard University Press.

Schwartz, E. B. (1976). Entrepreneurship-New female frontier. Journal of Contemporary Business, 5(1). 47-76

Simard, C., Davies Henderson, A., Gilmartin, S. K., Schiebinger, L. and Whitney, T. (2008). Climbing the Technical Ladder: Obstacles and Solutions for Mid-Level Women in Technology. Anita Borg Institute for Women and Technology and the Michael R. Clayman Institute for Gender Research at Stanford University. Retrieved from http://gender.stanford.edu/sites/default/files/Climbing_the_Technical_Ladder.pdf

Stalker P. (2002). Workers without Frontiers: The Impact of Globalization on International Migration. Lynne Rienner: London.

United States Census Bureau. (2010). 2007 Survey of Business Owners (SBO). Retrieved from https://www.census.gov/econ/sbo/getsof.html?07women

United States Chamber of Commerce. (2014). Women-Owned Businesses: Carving a New American Business Landscape. Retrieved from https://www.uschamber.com/sites/default/files/documents/files/CCFWIB_report_ design_final2.pdf

United States Department of Commerce. (2011). Women in STEM: A Gender Gap to Innovation. Retrieved from http://www.esa.doc.gov/sites/default/files/womeninstemagaptoinnovation8311. pdf

Wadhwa, V. and Chideya, F. (2014). Innovating Women; the Changing Face of Technology. New York: Diversion Books.

Wallsten, S. J. (2001). An empirical test of geographic knowledge spillovers using geographic information systems and firm-level data. Regional Science and Urban Economics 31(5), 571-599.

Wikipedia. (2016, March 1). Southern California. Retrieved from https://en.wikipedia.org/wiki/Southern_California\#cite_note-3 
Woodward, D., Figueiredo, O. and Guimarães, P. (2006). Beyond the Silicon Valley: University R\&D and high-technology location. Journal of Urban Economics 60(1), 15-32.

Zook, M. A. (2002). Grounded capital: venture financing and the geography of the Internet industry, 1994-2000. Journal of Economic Geography 2(2), 151-177.

Zucker, L.G., Darby, M. R. and Brewer, M. B. (1998). Intellectual human capital and the birth of U.S. biotechnology enterprises. American Economic Review 88, 290-306. 


\section{APPENDIX}

\begin{tabular}{|c|c|c|c|c|}
\hline \multicolumn{5}{|c|}{ Business Industry NAICS Codes } \\
\hline Industry & HIGH LEVEL & SUB-GROUP & FOCUS GROUP & $\begin{array}{l}\text { NAICS } \\
\text { CODE }\end{array}$ \\
\hline Biotech & Biotech & Biotech & $\begin{array}{l}\text { Medicinal and Botanical } \\
\text { Manufacturing }\end{array}$ & 325411 \\
\hline Biotech & Biotech & Biotech & $\begin{array}{l}\text { In-vitro Diagnostic } \\
\text { Substance } \\
\text { Manufacturing }\end{array}$ & 325413 \\
\hline Biotech & Biotech & Biotech & $\begin{array}{l}\text { Other Biological Product } \\
\text { Manufacturing }\end{array}$ & 325414 \\
\hline Hi-Tech & Manufacturing & Photonics & $\begin{array}{l}\text { Photographic and } \\
\text { Photocopying Equipment }\end{array}$ & 333315 \\
\hline Hi-Tech & Manufacturing & $\begin{array}{l}\text { Computer and } \\
\text { Peripheral Equipment }\end{array}$ & Electronic Computers & 334111 \\
\hline Hi-Tech & Manufacturing & $\begin{array}{l}\text { Computer and } \\
\text { Peripheral Equipment }\end{array}$ & $\begin{array}{l}\text { Computer Storage } \\
\text { Devices }\end{array}$ & 334112 \\
\hline Hi-Tech & Manufacturing & $\begin{array}{l}\text { Communications } \\
\text { Equipment }\end{array}$ & Telephone Apparatus & 334210 \\
\hline Hi-Tech & Manufacturing & $\begin{array}{l}\text { Communications } \\
\text { Equipment }\end{array}$ & $\begin{array}{l}\text { Radio and TV } \\
\text { Broadcasting and } \\
\text { Wireless } \\
\text { Communications } \\
\text { Equipment }\end{array}$ & 334220 \\
\hline Hi-Tech & Manufacturing & $\begin{array}{l}\text { Communications } \\
\text { Equipment }\end{array}$ & $\begin{array}{l}\text { Other Communications } \\
\text { Equipment }\end{array}$ & 334290 \\
\hline Hi-Tech & Manufacturing & $\begin{array}{l}\text { Consumer } \\
\text { Electronics }\end{array}$ & $\begin{array}{l}\text { Audio and Video } \\
\text { Equipment }\end{array}$ & 334310 \\
\hline $\mathrm{Hi}-\mathrm{Tech}$ & Manufacturing & $\begin{array}{l}\text { Electronic } \\
\text { Components }\end{array}$ & Electron Tubes & 334411 \\
\hline Hi-Tech & Manufacturing & $\begin{array}{l}\text { Electronic } \\
\text { Components }\end{array}$ & $\begin{array}{l}\text { Bare Printed Circuit } \\
\text { Boards }\end{array}$ & 334412 \\
\hline Hi-Tech & Manufacturing & Semiconductors & $\begin{array}{l}\text { Semiconductor and } \\
\text { Related Devices }\end{array}$ & 334413 \\
\hline Hi-Tech & Manufacturing & $\begin{array}{l}\text { Electronic } \\
\text { Components }\end{array}$ & $\begin{array}{l}\text { Electronic Coils, } \\
\text { Transformers, and Other } \\
\text { Indicators }\end{array}$ & 334416 \\
\hline Hi-Tech & Manufacturing & $\begin{array}{l}\text { Electronic } \\
\text { Components }\end{array}$ & Electronic Connectors & 334417 \\
\hline Hi-Tech & Manufacturing & $\begin{array}{l}\text { Electro-medical } \\
\text { Equipment }\end{array}$ & $\begin{array}{l}\text { Electro-medical and } \\
\text { Electrotherapeutic } \\
\text { Apparatus }\end{array}$ & 334510 \\
\hline
\end{tabular}




\begin{tabular}{|c|c|c|c|c|}
\hline Hi-Tech & Manufacturing & $\begin{array}{l}\text { Space and Defense } \\
\text { Systems }\end{array}$ & $\begin{array}{l}\text { Search, Detection, } \\
\text { Navigation, Guidance, } \\
\text { Aeronautical, and } \\
\text { Nautical Systems and } \\
\text { Instruments }\end{array}$ & 334511 \\
\hline Hi-Tech & Manufacturing & $\begin{array}{l}\text { Measuring and } \\
\text { Controlling } \\
\text { Instruments }\end{array}$ & $\begin{array}{l}\text { Automatic Environmental } \\
\text { Controls }\end{array}$ & 334512 \\
\hline Hi-Tech & Manufacturing & $\begin{array}{l}\text { Measuring and } \\
\text { Controlling } \\
\text { Instruments }\end{array}$ & $\begin{array}{l}\text { Industrial Process } \\
\text { Control Instruments }\end{array}$ & 334513 \\
\hline Hi-Tech & Manufacturing & $\begin{array}{l}\text { Measuring and } \\
\text { Controlling } \\
\text { Instruments }\end{array}$ & $\begin{array}{l}\text { Totalizing Fluid Meter } \\
\text { and Counting Devices }\end{array}$ & 334514 \\
\hline Hi-Tech & Manufacturing & $\begin{array}{l}\text { Measuring and } \\
\text { Controlling } \\
\text { Instruments }\end{array}$ & $\begin{array}{l}\text { Electricity Measuring and } \\
\text { Testing Equipment }\end{array}$ & 334515 \\
\hline Hi-Tech & Manufacturing & $\begin{array}{l}\text { Measuring and } \\
\text { Controlling } \\
\text { Instruments }\end{array}$ & $\begin{array}{l}\text { Analytical Laboratory } \\
\text { Instruments }\end{array}$ & 334516 \\
\hline Hi-Tech & Manufacturing & $\begin{array}{l}\text { Electro-medical } \\
\text { Equipment }\end{array}$ & Irradiation Apparatus & 334517 \\
\hline Hi-Tech & Manufacturing & $\begin{array}{l}\text { Measuring and } \\
\text { Controlling } \\
\text { Instruments }\end{array}$ & $\begin{array}{l}\text { Other Measuring and } \\
\text { Controlling Instruments }\end{array}$ & 334519 \\
\hline Hi-Tech & Manufacturing & $\begin{array}{l}\text { Communications } \\
\text { Equipment }\end{array}$ & Fiber Optic Cables & 335921 \\
\hline Hi-Tech & Manufacturing & $\begin{array}{l}\text { Electronic } \\
\text { Components }\end{array}$ & Storage Batteries & 335911 \\
\hline Hi-Tech & Manufacturing & $\begin{array}{l}\text { Electronic } \\
\text { Components }\end{array}$ & $\begin{array}{l}\text { Other Miscellaneous } \\
\text { Electrical Equipment and } \\
\text { Components }\end{array}$ & 335999 \\
\hline Hi-Tech & Manufacturing & $\begin{array}{l}\text { Space and Defense } \\
\text { Systems }\end{array}$ & $\begin{array}{l}\text { Guided Missile and } \\
\text { Space Vehicles }\end{array}$ & 336414 \\
\hline Hi-Tech & Manufacturing & $\begin{array}{l}\text { Space and Defense } \\
\text { Systems }\end{array}$ & $\begin{array}{l}\text { Other Guided Missile, } \\
\text { Space Vehicle Parts, and } \\
\text { Auxiliary Equipment }\end{array}$ & 336419 \\
\hline Hi-Tech & $\begin{array}{l}\text { Software } \\
\text { Services }\end{array}$ & Software Publishers & Software Publishers & 511210 \\
\hline Hi-Tech & $\begin{array}{l}\text { Communicatio } \\
\text { ns Services }\end{array}$ & $\begin{array}{l}\text { Internet and } \\
\text { Telecommunication } \\
\text { Services }\end{array}$ & $\begin{array}{l}\text { Wired } \\
\text { Telecommunication } \\
\text { Carriers }\end{array}$ & 517110 \\
\hline Hi-Tech & $\begin{array}{l}\text { Communicatio } \\
\text { ns Services }\end{array}$ & $\begin{array}{l}\text { Internet and } \\
\text { Telecommunication } \\
\text { Services }\end{array}$ & $\begin{array}{l}\text { Wireless } \\
\text { Telecommunication } \\
\text { Carriers }\end{array}$ & 517210 \\
\hline Hi-Tech & $\begin{array}{l}\text { Communicatio } \\
\text { ns Services }\end{array}$ & $\begin{array}{l}\text { Internet and } \\
\text { Telecommunication }\end{array}$ & $\begin{array}{l}\text { Telecommunication } \\
\text { Resellers }\end{array}$ & 517911 \\
\hline
\end{tabular}




\begin{tabular}{|c|c|c|c|c|}
\hline & & Services & & \\
\hline Hi-Tech & $\begin{array}{l}\text { Communicatio } \\
\text { ns Services }\end{array}$ & $\begin{array}{l}\text { Internet and } \\
\text { Telecommunication } \\
\text { Services }\end{array}$ & $\begin{array}{l}\text { All other } \\
\text { Telecommunications }\end{array}$ & 517919 \\
\hline Hi-Tech & $\begin{array}{l}\text { Communicatio } \\
\text { ns Services }\end{array}$ & $\begin{array}{l}\text { Internet and } \\
\text { Telecommunication } \\
\text { Services }\end{array}$ & $\begin{array}{l}\text { Data Processing, } \\
\text { Hosting, and Related } \\
\text { Services }\end{array}$ & 518210 \\
\hline Hi-Tech & $\begin{array}{l}\text { Communicatio } \\
\text { ns Services }\end{array}$ & $\begin{array}{l}\text { Internet and } \\
\text { Telecommunication } \\
\text { Services }\end{array}$ & $\begin{array}{l}\text { Internet Publishing and } \\
\text { Broadcasting, and Web } \\
\text { Search Portals }\end{array}$ & 519310 \\
\hline Hi-Tech & $\begin{array}{l}\text { Engineering } \\
\text { and Tech } \\
\text { Services }\end{array}$ & Engineering Services & Engineering Services & 541330 \\
\hline Hi-Tech & $\begin{array}{l}\text { Engineering } \\
\text { and Tech } \\
\text { Services }\end{array}$ & $\begin{array}{l}\text { R\&D and Testing } \\
\text { Labs }\end{array}$ & Testing Laboratories & 541380 \\
\hline Hi-Tech & $\begin{array}{l}\text { Communicatio } \\
\text { ns Services }\end{array}$ & $\begin{array}{l}\text { Computer Systems } \\
\text { Design and Related } \\
\text { Services }\end{array}$ & $\begin{array}{l}\text { Custom Computer } \\
\text { Programming }\end{array}$ & 541511 \\
\hline Hi-Tech & $\begin{array}{l}\text { Communicatio } \\
\text { ns Services }\end{array}$ & $\begin{array}{l}\text { Computer Systems } \\
\text { Design and Related } \\
\text { Services }\end{array}$ & $\begin{array}{l}\text { Computer Systems } \\
\text { Design }\end{array}$ & 541512 \\
\hline Hi-Tech & $\begin{array}{l}\text { Communicatio } \\
\text { ns Services }\end{array}$ & $\begin{array}{l}\text { Computer Systems } \\
\text { Design and Related } \\
\text { Services }\end{array}$ & $\begin{array}{l}\text { Computer Facilities } \\
\text { Management }\end{array}$ & 541513 \\
\hline Hi-Tech & $\begin{array}{l}\text { Communicatio } \\
\text { ns Services }\end{array}$ & $\begin{array}{l}\text { Computer Systems } \\
\text { Design and Related } \\
\text { Services }\end{array}$ & $\begin{array}{l}\text { Other Computer Related } \\
\text { Services }\end{array}$ & 541519 \\
\hline Hi-Tech & $\begin{array}{l}\text { Engineering } \\
\text { and Tech } \\
\text { Services }\end{array}$ & $\begin{array}{l}\text { R\&D and Testing } \\
\text { Labs }\end{array}$ & $\begin{array}{l}\text { Research and } \\
\text { Development in } \\
\text { Biotechnology }\end{array}$ & 541711 \\
\hline Hi-Tech & $\begin{array}{l}\text { Engineering } \\
\text { and Tech } \\
\text { Services }\end{array}$ & $\begin{array}{l}\text { R\&D and Testing } \\
\text { Labs }\end{array}$ & $\begin{array}{l}\text { Research and } \\
\text { Development in the } \\
\text { Physical, Engineering, } \\
\text { and Life Sciences }\end{array}$ & 541712 \\
\hline Hi-Tech & $\begin{array}{l}\text { Engineering } \\
\text { and Tech } \\
\text { Services }\end{array}$ & Computer Training & Computer Training & 611420 \\
\hline
\end{tabular}




\section{University R\&D Expenditures, Data Definitions}

All University R\&D expenditure data was gathered by the National Science Foundation, National Center for Science and Engineering Statistics, Integrated Science and Engineering Resources Data System (WebCASPAR), https://webcaspar.nsf.gov

\section{R\&D Funding of Academic Studies, By Sector}

\begin{tabular}{|l|l|}
\hline \multicolumn{1}{|c|}{ Biotech } & \multicolumn{1}{c|}{ Hi-tech } \\
\hline Biological Sciences & Computer Science \\
\hline Chemical Engineering & Electrical Engineering \\
\hline & Mechanical Engineering \\
\hline
\end{tabular}

\section{Venture Capital Business Data Definitions}

Venture Capital data was collected for 2014 and was obtained through the PriceWaterHouseCoopers (PWC) MoneyTree Survey database, found at https://www.pwcmoneytree.com.

\section{Biotech}

\section{Biotechnology}

Developers of technology promoting drug development, disease treatment, and a deeper understanding of living organisms. Includes human, animal, and industrial biotechnology products and services. Also included are biosensors, biotechnology equipment, and pharmaceuticals.

\section{Hi-Tech}

\section{Computers and peripherals}

Includes manufacturers and distributors of PCs, mainframes, servers, PDAs, printers, storage devices, monitors, and memory cards. Also included are digital imaging and 
graphics services and equipment such as scanning hardware, graphics video cards and plotters. Integrated turnkey systems and solutions are also included in this category.

\section{Electronics/instrumentation}

Includes electronic parts that are components of larger products and specialized instrumentation, including scientific instruments, lasers, power supplies, electronic testing products and display panels. Also included are business and consumer electronic devices such as photocopiers, calculators, and alarm systems.

\section{IT services}

Providers of computer and internet-related services to businesses and consumers including computer repair, software consulting, computer training, machine leasing/rental, disaster recovery, web design, data input and processing, internet security, e-commerce services, web hosting and systems engineering.

\section{Semiconductors}

Design, develop or manufacture semiconductor chips/microprocessors ore related equipment including diodes and transistors. Also includes companies that test or package integrated circuits.

\section{Software}

Producers of bundled and/or unbundled software applications for business or consumer use including software created for systems, graphics, communications and networking, security, inventory, home use, educational, or recreational. Also included is software developed for specific industries such as banking, manufacturing, transportation, or healthcare. 


\section{Telecommunications}

Companies focused on the transmission of voice and data including long distance providers, local exchange carriers, and wireless communications services and components. Also included are satellite and microwave communications services and equipment. 